This report was prepared as an account of work sponsored by an agency of the United States Government. Neither the United States Government nor any agency thereof, nor any of their employees, makes any warranty, express or implied, or assumes any legal liability or responsibility for the accuracy, completeness, or usefulness of any information, apparatus, product, or process disclosed, or represents that its use would not infringe privately owned rights. Reference herein to any specific commercial product, process, or service by trade name, trademark, manufacturer, or otherwise does not necessarily constitute or imply its endorsement, recommendation, or favoring by the United States Government or any agency thereof. The views and opinions of authors expressed herein do not necessarily state or reflect those of the United States Government or any agency thereof.

\title{
DOE Waste Treatability Group Guidance
}

\author{
T. D. Kirkpatrick
}

Published January 1995

\section{Idaho National Engineering Laboratory Lockheed Idaho Technologies Company Idaho Falls, Idaho 83415}




\section{DISCLAIMER}

Portions of this document may be illegible in electronic image products. Images are produced from the best available original document. 


\begin{abstract}
This guidance presents a method and definitions for aggregating U.S. Department of Energy (DOE) waste into streams and treatability groups based on characteristic parameters that influence waste management technology needs. Adaptable to all DOE waste types (i.e., radioactive waste, hazardous waste, mixed waste, sanitary waste), the guidance establishes categories and definitions that reflect variations within the radiological, matrix (e.g., bulk physical/chemical form), and regulated contaminant characteristics of DOE waste. Beginning at the waste container level, the guidance presents a logical approach to implementing the characteristic parameter categories as part of the basis for defining waste streams and as the sole basis for assigning streams to treatability groups. Implementation of this guidance at each DOE site will facilitate the development of technically defined, site-specific waste stream data sets to support waste management planning and reporting activities. Consistent implementation at all of the sites will enable aggregation of the site-specific waste stream data sets into comparable national data sets to support these activities at a DOE complex-wide level.
\end{abstract}


$\ldots$ 


\section{CONTENTS}

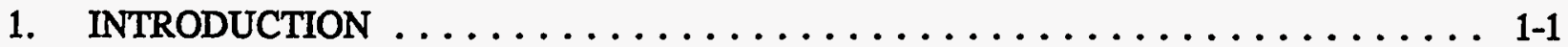

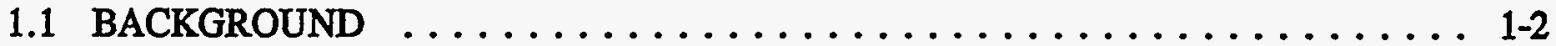

1.2 PURPOSE AND SCOPE $\ldots \ldots \ldots \ldots \ldots \ldots \ldots \ldots \ldots \ldots \ldots \ldots \ldots$

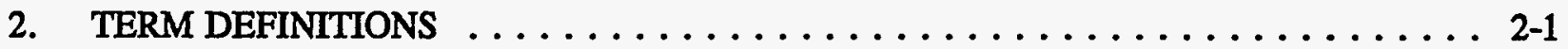

3. METHODOLOGY OVERVIEW ....................... 3-1

3.1 OVERVIEW - TREATABILITY GROUP PARAMETERS $\ldots \ldots \ldots \ldots \ldots$ 3-1

3.2 IMPLEMENTATION GUIDELINES $\ldots \ldots \ldots \ldots \ldots \ldots \ldots \ldots \ldots \ldots$ 3-3

4. RADIOLOGICAL PARAMETER $\ldots \ldots \ldots \ldots \ldots \ldots \ldots \ldots \ldots \ldots$ 4-1

4.1 OVERVIEW OF RADIOLOGICAL CATEGORIES $\ldots \ldots \ldots \ldots \ldots \ldots \ldots$ 4-1

4.2 MIIL TAILINGS RPC COMPONENTS $\ldots \ldots \ldots \ldots \ldots \ldots \ldots \ldots \ldots$ 4-1

4.3 LOW-LEVEL WASTE RPC COMPONENTS $\ldots \ldots \ldots \ldots \ldots \ldots \ldots \ldots$ 4-3

4.4 TRANSURANIC WASTE RPC COMPONENTS $\ldots \ldots \ldots \ldots \ldots \ldots \ldots \ldots$ 4-5

4.5 HIGH-LEVEL WASTE RPC COMPONENTS $\ldots \ldots \ldots \ldots \ldots \ldots \ldots .46$

4.6 COMPLETE RADIOLOGICAL PARAMETER CATEGORIES . . . . . . 4 4-6

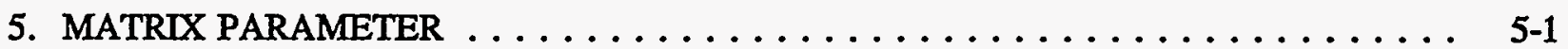

5.1 OVERVIEW OF MATRIX CATEGORIES $\ldots \ldots \ldots \ldots \ldots \ldots \ldots \ldots .5$.

5.2 MATRIX CATEGORY SELECTION GUIDELINES $\ldots \ldots \ldots \ldots \ldots \ldots .5$ 5 2

5.3 DEFINITIONS - LIQUIDS AND ASSOCIATED CATEGORIES $\ldots \ldots \ldots \ldots \ldots$ 5-4

5.4 DEFINITIONS - SOLIDS AND ASSOCIATED CATEGORIES $\ldots \ldots \ldots \ldots .5-7$

5.5 DEFINITIONS - SPECIFIC WASTE FORMS AND ASSOCIATED

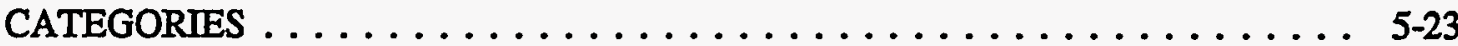

5.6 DEFINITIONS - FINAL WASTE FORMS AND ASSOCIATED CATEGORIES . . . 5-28

5.7 DEFINITION - UNKNOWN/OTHER MATRIX (U9999) CATEGORY . . . . . . . 5-31

6. REGULATED CONTAMINANT PARAMETER ................. 6-1

6.1 OVERVIEW OF REGULATED CONTAMINANT CATEGORIES $\ldots \ldots \ldots \ldots$ 6-1

6.2 RCRA REGULATED WASTE CPC COMPONENTS $\ldots \ldots \ldots \ldots \ldots \ldots \ldots .6 .1$

6.3 TSCA REGULATED WASTE CPC COMPONENTS $\ldots \ldots \ldots \ldots \ldots \ldots \ldots \ldots .6 .6 .7$

6.4 RCRA/TSCA REGULATED WASTE CPC COMPONENTS $\ldots \ldots \ldots \ldots \ldots \ldots$ 6-7

6.5 STATE REGULATED WASTE CPC COMPONENTS . . . . . . . . . . 6 6-7

6.6 RCRA REGULATED WASTE-MEETS LDRS CPC COMPONENTS $\ldots \ldots \ldots \ldots .6$ 6-7

6.7 SUSPECT REGULATED WASTE CPC COMPONENTS $\ldots \ldots \ldots \ldots \ldots .6 .6$

6.8 REGULATED CONTAMINANT PARAMETER CATEGORIES . . . . . . . 6-8

7. APPLICATION EXAMPLES $\ldots \ldots \ldots \ldots \ldots \ldots \ldots \ldots \ldots \ldots \ldots \ldots \ldots \ldots \ldots$ 7-1

APPENDIX A - LOW-LEVEL RADIOLOGICAL PARAMETER CATEGORIES . . . . . . A-1 APPENDIX B - MATRIX PARAMETER CATEGORIES - FOLDOUT CHART $\ldots \ldots \ldots$ B-1 APPENDIX C - EPA CODES BY DESCRIPTIVE COMPONENT ELEMENTS ........ C-1 APPENDIX D - REGULATED CONTAMINANT PARAMETER CATEGORIES $\ldots \ldots \ldots$ D-1 


\section{LIST OF TABLES}

Table 4-1. Low-Level Waste Radiological Parameter Category Variables . . . . . . . . . . . 4-7

Table 6-1. RCRA and RCRA/TSCA Contaminant Category Variables . . . . . . . . . . . 6-9

Table A-1. Low-Level Radiological Parameter Categories . . . . . . . . . . . . . . A-3

Table C-1. Organics (Excluding Dioxins) $\ldots \ldots \ldots \ldots \ldots \ldots \ldots \ldots \ldots \ldots \ldots \ldots \ldots$

Table C-2. Organics - Dioxins . . . . . . . . . . . . . . . . . C-17

Table C-3. Metals - Excluding Mercury . . . . . . . . . . . . . . . . . C-18

Table C-4. Mercury .............................. C-20

Table C-5. Corrosives . . . . . . . . . . . . . . . . . . . . . C-20

Table C-6. Reactives ........................... C-21

Table C-7. Cyanides . . . . . . . . . . . . . . . . . . . . . . C-22

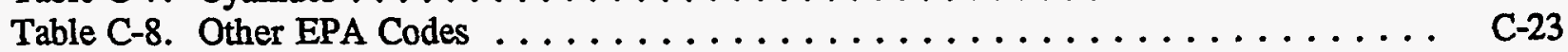

Table D-1. RCRA Hazardous or Mixed Waste CPCs . . . . . . . . . . . . . . D-3

Table D-2. RCRA/TSCA Hazardous or Mixed Waste CPCs . . . . . . . . . . . . D-5

\section{LIST OF FIGURES}

Figure 3-1. Concept Logic . . . . . . . . . . . . . . . . . . . . . 3-2

Figure 4-1. Radiological Parameter Category Components . . . . . . . . . . . . 4-2

Figure 5-1. Matrix Parameter Categories - Initial Categories . . . . . . . . . . . . . 5-3

Figure 5-2. Matrix Parameter Categories - Liquids . . . . . . . . . . . . . . 5-5

Figure 5-3. Matrix Parameter Categories - Solids . . . . . . . . . . . . . . . . . . $5-8$

Figure 5-4. Matrix Parameter Categories - Homogeneous Solids . . . . . . . . . . . . 5-10

Figure 5-5. Matrix Parameter Categories - Debris . . . . . . . . . . . . . . . 5-18

Figure 5-6. Matrix Parameter Categories - Specific Waste Forms . . . . . . . . . . . . . 5-25

Figure 5-7. Matrix Parameter Categories - Final Waste Forms . . . . . . . . . . . . . . . 5-29

Figure 6-1. Regulated Contaminant Parameter Category Components . . . . . . . . . . . . . . 6-2

Figure 7-1. Example 1: Parameter Category Assignments . . . . . . . . . . . . . . 7-2

Figure 7-2. Example 2: Parameter Category Assignments . . . . . . . . . . . . . 7-5

Figure 7-3. Example 3: RPC and CPC Assignments . . . . . . . . . . . . . . . 7-8

Figure 7-4. Example 3: MPC Assignments for Drums D01 Through D12 . . . . . . . . . 7-9

Figure 7-5. Example 3: MPC Assignments for Drums D13 Through D13 . . . . . . . . . 7-9

Figure B-1. Matrix Parameter Categories - Foldout Chart . . . . . . . . . . . . B-3 


\title{
ACKNOWLEDGMENTS
}

Numerous people contributed their time and expertise to develop this guidance. The efforts of these people are gratefully acknowledged. Principal contributors were:

\author{
Rob Black (Scientech) \\ Leon Borduin (Los Alamos National Laboratory) \\ Lydia Chang (DOE Headquarters) \\ Bob Devries (LITCO) \\ Keith Davis (Roy F. Weston) \\ Beth Heath (LITCO) \\ Burdon Musgrave (BCM, Inc.) \\ Wayne Ross (Pacific Northwest Laboratories) \\ Louie Sferrazza (EET Corporation)
}

In addition to the above, the comments and input provided by the many federal government and contractor personnel at the DOE sites are greatly appreciated. 


\section{INTRODUCTION}

This guidance presents a concept for defining and categorizing waste streams based on characteristic parameters that influence waste management technology needs. Implementation of this guidance at each U.S. Department of Energy (DOE) site will facilitate the development of technically defined, site-specific waste stream data sets to support waste management planning and reporting activities. Furthermore, consistent implementation at all of the sites will enable aggregation of the site-specific waste stream data sets into comparable national data sets to support these activities at a DOE complex-wide level.

DOE has numerous sites located throughout the country. These sites generate and manage waste from a variety of production processes and other activities. This includes waste that is radioactive, hazardous, mixed (i.e., radioactive and hazardous), and sanitary (i.e., nonradioactive or hazardous). Historically, most of the waste was generated from activities associated with the production of nuclear materials and weapons for national defense. With the curtailment of defense production, waste continues to be generated at the sites from activities such as the maintenance or closure of facilities, ongoing research and development, and environmental restoration.

Each DOE site is ultimately responsible for managing its waste, from generation through disposal, in compliance with DOE orders and other applicable regulations. Therefore, it is necessary for each site to develop and implement plans for providing the technologies and associated capacities needed to manage its waste. Operating at a broader level over all of the DOE sites, one role of the DOE Headquarters (DOE-HQ) Office of Environmental Restoration and Waste Management (DOE-EM) is to facilitate integration of the site-specific plans into coherent national plans that seek to minimize overall cost through optimizing the use of technologies and facilities. In addition to these waste management planning efforts, both the individual sites and DOE-EM are frequently required to prepare reports presenting waste information.

Whether at the site-specific or national level, preparing valid waste management plans and consistent waste information reports requires developing and maintaining technically defined, site-specific waste stream data sets. Fulfilling the objectives of national planning efforts further requires the ability to compare waste streams across the sites for common technology requirements. The guidance facilitates meeting these requirements by providing a method and set of definitions for:

- Organizing containerized waste into site-specific streams that can support various planning and reporting activities, including assessments to determine the technologies and associated capacities needed to manage the waste

- Aggregating the site-specific waste streams into groups based on similar characteristics that influence waste management technology needs.

The concept presented in this guidance was initially developed as a means of defining and categorizing mixed waste streams based on radiological, bulk physical/chemical form, and regulated contaminant characteristics. Development of the concept was motivated by a need for consistent, technically comparable mixed waste data across the DOE complex to support national assessments of treatment technology and capacity needs. Given this initial motivation, the basis for defining the streams and the subsequent categorizations were referred to as treatability groups. While fundamentally unchanged since initial development, the treatability group concept is also of value in assessing the needs for other facets of waste management. However, for consistency with previous drafts of this guidance, the term treatability groups will continue to be used. In addition, while initially developed for mixed waste, the 
concept as presented in this guidance is equally adaptable to other waste types (e.g., radioactive, hazardous, sanitary) generated and managed throughout the DOE complex.

\subsection{BACKGROUND}

Depending on the specific objectives of a waste management plan or report, the supporting data may be aggregated to various levels of detail. For example, a report may address the total stored inventory of all solid waste at each DOE site. Likewise, a very general plan may address the cumulative capacity needed to treat or dispose of these total stored inventories. At the other extreme, a very specific waste management plan may examine whether a given container of solid waste is acceptable for treatment, storage, or disposal at a given facility. Waste management plans and, often times, reports are typically prepared on a waste stream basis. Given the appropriate basis for defining the streams, plans at this level can identify the various technologies and associated capacities needed to manage a site's waste. The appropriate basis for further aggregating these site-specific waste streams into groups can enable integration of the site-specific plans into national plans that cross site boundaries to identify similar technology needs and candidate facilities for management of the waste.

Development of this guidance was motivated by initial, national planning efforts involving mixed waste management. Following the 1987 byproduct rulemaking, several externally driven, complex-wide reports and studies were prepared on mixed waste characteristics and inventories, and the associated treatment technology and capacity needs. Examples of these efforts were the:

- National Report on Prohibited Wastes and Treatment Options, submitted to the U.S. Environmental Protection Agency (EPA) in January 1990 as required by the Rocky Flats Plant Land Disposal Restrictions Federal Facility Compliance Agreement

- DOE complex-wide Land Disposal Restrictions Case-by-Case Extension Application for Thirds Radioactive Mixed Wastes, submitted to the EPA in November 1991

- Interim Mixed Waste Inventory Report, subnitted to the EPA and the States in April 1993 as required by the October 1992 Federal Facilities Compliance Act.

To support these efforts, characteristic and inventory data on mixed waste streams were collected from the DOE sites, resulting in the development and maintenance of a national data set.

Significant issues that became apparent throughout these efforts were (a) mixed waste streams were not always defined on a basis that supported technically valid assessments of treatment technology needs, (b) the mixed waste streams for some DOE sites were constantly changing, resulting in inconsistencies between the various published reports and studies, and (c) comparisons of streams across the sites to determine common technology needs were not readily achievable. The underlying reason for the first two issues was the lack of a consistently applied, technically based approach to defining the site-specific waste streams; the third issue was due to the lack of a technically based method and set of definitions for aggregating the streams across the sites into treatability groups. As explained below, these underlying reasons are essentially the same.

\subsubsection{WASTE STREAM DEFINITION}

The fact that defining waste streams becomes an issue affecting the technical validity of management plans and the consistency between reports is best understood by examining the general types of waste generated throughout DOE and the manner in which this waste is initially managed following generation. Viewed 
from an initial management perspective after generation, most DOE waste can generally be described as one of the following:

- Relatively large volume, "end of pipe," liquid effluents that are transferred to storage in either tanks or surface impoundments pending final disposition, or that are transferred directly for treatment or disposal. Examples of these are wastewater effluents and high-level waste from spent fuel reprocessing activities.

- Relatively large volume, solid waste that is stored in waste piles pending final disposition. An example of this might be soils from an environmental restoration project.

- Solid or liquid waste that is packaged in containers and transferred to storage pending final disposition, or that is transferred directly for treatment or disposal. Several examples could be cited, since containerized waste has been, and is, generated from numerous processes and activities throughout the DOE complex.

In any of the above cases, the validity of plans assessing the technologies and associated capacities necessary to manage waste streams requires that the basis for defining streams include similarity among characteristic parameters that influence the technology.needs. For waste described by both the first and second bullets, this is usually accomplished by defining streams based on the generation source. Consistent recognition of these source-specific streams between reports is typically not a problem, as long as sufficient comparable information is provided.

Where waste stream definition becomes problematic is for the containerized waste described by the third bullet. A stream of this waste is really just a set of containers grouped together based on some criteria to meet the end use of the data. Most end uses require that the criteria be either based on source or some aspect(s) of the waste characteristics. For example, if the end use is a waste minimization report or study, the criteria are typically based on generation source or activity. The criteria for other efforts may be a specific characteristic attribute (e.g., EPA codes). In some instances, these criteria may result in streams comprised of containers that present the same technology needs. For example, remediation of a solar evaporation basin may produce numerous 55-gallon drums of mixed waste that have the same EPA codes and that are similar in other characteristic attributes (e.g., radiological, bulk physical/chemical form) that influence technology needs.

However, often throughout DOE, containerized waste is generated from intermittent or one-time activities. The varying nature of these activities can result in waste with substantially different characteristics from container to container. Alignment of these containers into streams based only on source, or a single characteristic attribute, may not result in streams for which the individual containers present the same technology needs. Because of this, the technical validity of assessments to determine the technology needs for managing the streams may be questionable. In addition, the various criteria that might be employed to align the waste into streams can result in apparent inconsistencies between reports that present information on the waste.

Consider, for example, a fictitious mixed waste stream that is defined to include one hundred 55-gallon drums of waste from the decommissioning of a process sump. Each of the drums is assigned the same EPA codes and has the same radiological characteristics consistent with the process waste that had been received by the sump. However, the bulk physical/chemical form of the waste differs substantially among the drums, with 60 containing metal-bearing hydroxide precipitate sludge and the remaining 40 containing inorganic debris materials (metal, concrete, etc.). The result of any assessment to determine the treatment technology needs for this stream would likely be misleading or, at least, confusing. This 
problem would be rectified by defining two waste streams, one for the 60 drums of sludge and another for the 40 drums of debris material.

In summary, developing technically valid management plans for containerized waste streams requires that the basis for defining streams include similarities among all of the characteristic parameters that influence technology needs. In addition, consistent identification of waste streams between various reports can be facilitated by including additional parameters in the definition basis that are key to other typical end uses of the data.

\subsubsection{WASTE STREAM COMPARABILITY}

Considering that numerous DOE sites generate and manage waste with a variety of characteristics, application of a consistent basis for stream definition at each site, even if limited strictly to similar technology needs, would likely result in several thousand streams defined across the DOE complex. At the time this guidance was prepared, the national data set on mixed waste alone included 2,012 streams. ${ }^{2}$ While the basis used by some sites for defining their mixed waste streams may extend beyond similar technology-needs, other sites have yet to adequately address this fundamental issue. In any case, these 2,012 streams do not even address other waste types (radioactive, hazardous, etc.) generated and managed across the complex.

As discussed in the introductory remarks of this guidance, an objective of national level waste management plans is to optimize the use of technologies and facilities across the complex. Achieving this objective requires comparing streams across all of the sites to determine common technology needs and to determine whether a stream at one site might be acceptable for management in a facility at another site. Given the potentially large number of site-specific streams, these comparisons can seem rather ominous. However, by aggregating the streams into common groups based on characteristic parameters that influence waste management technology needs, these comparisons can be simplified. It is a logical extension that these are the same characteristic parameters that must be considered when initially defining the streams.

\subsection{PURPOSE AND SCOPE}

The primary objectives of this guidance are to (a) provide a method for defining site-specific waste stream data sets that can support various end use activities, including, at a minimum, the preparation of technically valid waste management plans, and (b) establish a consistent approach for aggregating the site-specific streams into groups to facilitate comparisons of streams both within and across site boundaries for common technology needs and facility acceptance. To achieve these objectives, the guidance:

- Establishes a set of characteristic parameters that influence waste management technology needs

- Establishes categories and definitions that reflect variations of characteristics within those parameters

- Provides guidelines for implementing the categories and definitions of the characteristic parameters as part of the basis for defining streams, and as the sole basis for assigning the streams into treatability groups.

a. Based on Phase II, Revision 1, of the May 1994 Mixed Waste Inventory Report Database System. 
Beginning with waste stream definition, implementation of this guidance will lead to assignment of waste to treatability groups based on similarities of characteristics that influence treatment, storage, or disposal technology needs. The treatability group assignments will enable identifying candidate matches between waste and management facilities. However, because the characteristic parameter categories defined in this guidance do not address every specific attribute that may affect the acceptability of waste for management at a given facility, the viability of these candidate matches may require further assessments of the waste per detailed characteristics beneath the level considered in treatability group assignments. 


\section{TERM DEFINITIONS}

This section provides definitions for terms used frequently in this guidance. It is not intended to cover all terminology used herein, but an attempt has been made to address unique terms as defined for this guidance that readers may find confusing.

Parameter

A parameter addresses a specific type of waste characteristic within a treatability group. A parameter is represented in a treatability group by an associated category. Complete treatability groups are defined by a series, or "string," of one or more parameter categories. Currently, there are three parameters considered in this guidance for defining treatability groups.

- Radiological Parameter - This treatability group parameter addresses the radiological characteristics of the waste, if applicable. The categories that may represent this parameter in the treatability group are defined by one or more components that address specific aspects of the radiological characteristics.

- Matrix Parameter - This treatability group parameter addresses the overall, bulk physical/chemical form of the waste.

- Regulated Contaminant Parameter - This treatability group parameter addresses the external (i.e., non-DOE) regulations governing the waste and the associated contaminants or characteristics that are present. The external regulations considered in this parameter are those promulgated by the EPA and States under the Resource Conservation and Recovery Act (RCRA) and those promulgated by the EPA for polychlorinated biphenyls (PCBs) under the Toxic Substances Control Act (TSCA). The categories that may represent this parameter in the treatability group are defined by one or more components that identify the applicable external regulations and the type of associated contaminants or characteristics that are present.

\section{Waste Type}

Waste generated or managed at DOE sites can be generally classified as radioactive, hazardous, mixed, or sanitary waste. In this guidance, these are referred to as "primary" waste types. Except for sanitary waste, each primary type has associated secondary types. These primary and associated secondary types are defined as follows:

- Radioactive Waste - As defined in DOE Order 5820.2A, this is "Solid, liquid, or gaseous material that contains radionuclides regulated under the Atomic Energy Act of 1954, as amended ... The secondary types of waste within this primary type are also defined in DOE Order 5820.2A as follows:

- High-Level Waste - "The highly radioactive waste material that results from the reprocessing of spent nuclear fuel, including liquid waste produced directly in reprocessing and any solid waste derived from the liquid, that contains a combination of transuranic waste and fission products in concentrations requiring permanent isolation."

- Transuranic (TRU) Waste - "Without regard to source or form, waste that is contaminated with alpha-emitting transuranium radionuclides with half-lives greater than 20 years and concentrations greater than $100 \mathrm{nCi} / \mathrm{g}$ at the time of assay. Heads of Field Elements can 
determine that other alpha contaminated waste, peculiar to a specific site, must be managed as transuranic waste."

- $\quad$ Low-Level Waste - "Waste that contains radioactivity and is not classified as high-level waste, transuranic waste, or spent nuclear fuel or $11 \mathrm{e}(2)$ byproduct material as defined by this Order. Test specimens of fissionable material irradiated for research and development only, and not for the production of power or plutonium, may be classified as low-level waste, provided the concentration of transuranic is less than $100 \mathrm{nCi} / \mathrm{g}$."

- Mill Tailings - DOE waste containing uranium and thorium mill tailings defined as residual radioactive material by Section 101(7) of the Uranium Mill Tailings Radiation Control Act or as byproduct material by Section 11e(2) of the Atomic Energy Act, or similarly contaminated waste derived from DOE remedial actions.

- Hazardous Waste - For purposes of this guidance document, this is waste that is subject to either (a) EPA regulations promulgated under RCRA, (b) EPA regulations for PCBs promulgated under TSCA, or (c) State hazardous waste regulations promulgated under RCRA. The inclusion of waste regulated under TSCA for PCBs expands beyond the regulatory definition of hazardous waste (i.e., waste defined by and subject to Subtitle $C$ of RCRA). However, given the intended use of treatability groups, this is a logical extension. Often, the management of this waste requires the same technologies and facilities as waste that is RCRA hazardous.

Between the three regulatory authorities (i.e., RCRA-EPA, TSCA-EPA, and RCRA-State), there are six regulatory (i.e., secondary) classifications of hazardous waste defined in this guidance. These do not account for every possible scenario that could be envisioned, particularly with respect to State regulated waste. As will be evidenced in Section 6 of this guidance, these six classifications are key considerations in the assignment of regulated contaminant parameter categories.

- $\quad$ RCRA Regulated - Per this guidance, this is waste regulated under RCRA that is assigned at least one EPA waste code for which either (a) land disposal restriction (LDR) treatment standards have not been met, or (b) LDR treatment standards have not been established by the EPA. This waste may also be assigned State waste codes indicative of regulations more stringent than the EPA's. This waste is not TSCA regulated for PCBs.

- $\quad$ TSCA Regulated - Per this guidance, this is waste that is regulated under TSCA for PCBs. This waste is not assigned any EPA codes, but may be assigned State waste codes indicative of regulations more stringent than the EPA's.

- $\quad$ RCRA/TSCA Regulated - Per this guidance, this is waste regulated by the EPA under both TSCA for PCBs, and RCRA. At least one or more EPA codes are assigned to this waste, regardless of whether LDR treatment standards have been met or established. This waste may also be assigned State waste codes indicative of regulations more stringent than the EPA's.

- State Regulated - Per this guidance, this is waste that is regulated under RCRA only because the State regulations are more stringent than the EPA's. At least one State waste code is assigned to this waste, regardless of the LDR status, if applicable. There are no EPA codes assigned to this waste, nor is the waste regulated under TSCA for PCBs. 
- $\quad$ RCRA Regulated-Meets LDRs - Per this guidance, this is waste regulated by the EPA under RCRA for which LDR treatment standards have been established and met for all of the assigned EPA codes. An example is waste that has been treated to LDR standards but remains listed because of the EPA's derived-from rule. This waste may also be assigned. State waste codes indicative of regulations more stringent than the EPA's. This waste is not regulated under TSCA for PCBs.

- $\quad$ Suspect Regulated - Per this guidance, this is waste suspected of being regulated for which no EPA or State codes have been assigned, or it is uncertain whether the waste is regulated under TSCA for PCBs. The impetus for defining this classification lies in the history of waste data, particularly on RCRA regulated mixed waste, reported by the sites to DOE-HQ. Historically, in reporting these data, many sites have included waste for which no EPA or State codes have been assigned. Typically, this is considered "suspect" mixed waste and, presumably, is managed in accordance to applicable RCRA regulations. As will be evidenced in Section 6, this classification will enable maintaining this waste in separate treatability groups from waste that is known to be regulated.

It is recognized that some waste that has been assigned EPA or State codes may, in reality, only be considered suspect of being regulated. However, presumably, the assignment of codes is documented in site records that "officially" designate the waste as regulated. Until such records are revised to reflect otherwise, this waste should be considered regulated for the purposes of treatability group assignment to ensure consistency with official site documentation.

- Mixed Waste - Per this guidance, this is waste that meets the criteria of the above definitions for both the radioactive and hazardous primary waste types. It follows, therefore, that several secondary classifications may be defined for mixed waste based on combinations of those defined above for radioactive and hazardous waste. These secondary classifications, albeit not all very probable, are listed below.

High-Level, RCRA Regulated

High-Level, TSCA Regulated

High-Level, RCRA/TSCA Regulated

High-Level, State Regulated

High-Level, RCRA Regulated-Meets LDRs

High-Level, Suspect Regulated

Low-Level, RCRA Regulated

Low-Level, TSCA Regulated

Low-Level, RCRA/TSCA Regulated

Low-Level, State Regulated

Low-Level, RCRA Regulated-Meets LDRs

Low-Level, Suspect Regulated
Transuranic, RCRA Regulated

Transuranic, TSCA Regulated

Transuranic, RCRA/TSCA Regulated

Transuranic, State Regulated

Transuranic, RCRA Regulated-Meets LDRs

Transuranic, Suspect

Mill Tailings, RCRA Regulated

Mill Tailings, TSCA Regulated

Mill Tailings, RCRA/TSCA Regulated

Mill Tailings, State Regulated

Mill Tailings, RCRA Regulated-Meets LDRs

Mill Tailings, Suspect Regulated

- Sanitary - This is a municipal-type waste that is neither radioactive nor hazardous. This waste may be managed (including treatment and disposal) on site by DOE, turned over to a commercial service, or taken to a municipal facility. In any case, DOE is responsible for ensuring that applicable solid waste regulations are met. 


\section{METHODOLOGY OVERVIEW}

The treatability group concept presented in this guidance is based on the premise that the technology needs for managing a waste are mainly influenced, depending on the primary waste type, by up to three parameters. These parameters are the radiological, bulk physical/chemical form (i.e., matrix), and regulated contaminant characteristics. The treatability group assignment process involves categorizing the waste per each of these characteristic parameters, as applicable. Figure 3-1 illustrates the concept premise and the treatability group assignment logic. The following sections provide an overview of the characteristic parameters and address key implementation guidelines.

\subsection{OVERVIEW - TREATABILITY GROUP PARAMETERS}

Each of the three characteristic parameters considered in assigning treatability groups influences either, or both, of the technologies needed to manage the waste and the design of facilities that provide the technology. This guidance defines several categories that may represent each of the parameters in the treatability group. These categories and definitions are presented in Sections 4, 5, and 6 . The following discussions provide an overview of each characteristic parameter and its associated categories.

\subsubsection{RADIOLOGICAL PARAMETER}

The categories defined in this guidance to represent the radiological parameter serve to identify the secondary radiological classification of the waste as defined in Section 2. Depending on this classification, the categories further identify key broad, or general, radiological characteristics that primarily influence the design of waste management facilities to control radioactive releases and mitigate personnel exposure. These characteristics include the beta-gamma and alpha activity levels in the waste. The categories, and associated definitions, that may represent this parameter in a treatability group are presented in Section 4.

\subsubsection{MATRIX PARAMETER}

The categories defined in this guidance to represent the matrix parameter serve to describe the overall, bulk physical/chemical form of the waste. The bulk physical/chemical form influences both the technology and design of facilities necessary to manage the waste. An array of categories that may represent this parameter are defined in this guidance. The array begins with very broad, or summary, categories (liquids, solids, etc.) and progresses to successively more definitive categories (e.g., halogenated organic liquids, paper/plastic debris). The design and logic of the array enables performing aggregates, or rollups, of treatability groups based on the matrix categories to support waste management planning and reporting needs at various levels of detail. The categories, and associated definitions, that may represent the matrix parameter in a treatability group are presented in Section 5.

\subsubsection{REgUlATED CONTAMINANT PARAMETER}

The categories defined in this guidance to represent the regulated contaminant parameter serve to identify the regulatory classification of the waste as defined in Section 2. If the waste is regulated by the EPA under RCRA, the categories further identify the type of hazardous contaminants or characteristics associated with the waste. More specifically, the categories for waste regulated by the EPA under RCRA further identify whether the waste is contaminated with hazardous (a) organics, (b) metals, excluding mercury, or (c) mercury, and whether the waste exhibits the hazardous characteristics of ignitability, corrosivity, or reactivity. Coupled with the matrix, these can influence the technology necessary to manage (primarily treat) the waste from both a technical and regulatory perspective. The categories, and associated definitions, that may represent this parameter in a treatability group are presented in Section 6. 
Figure 3-1. Concept Logic

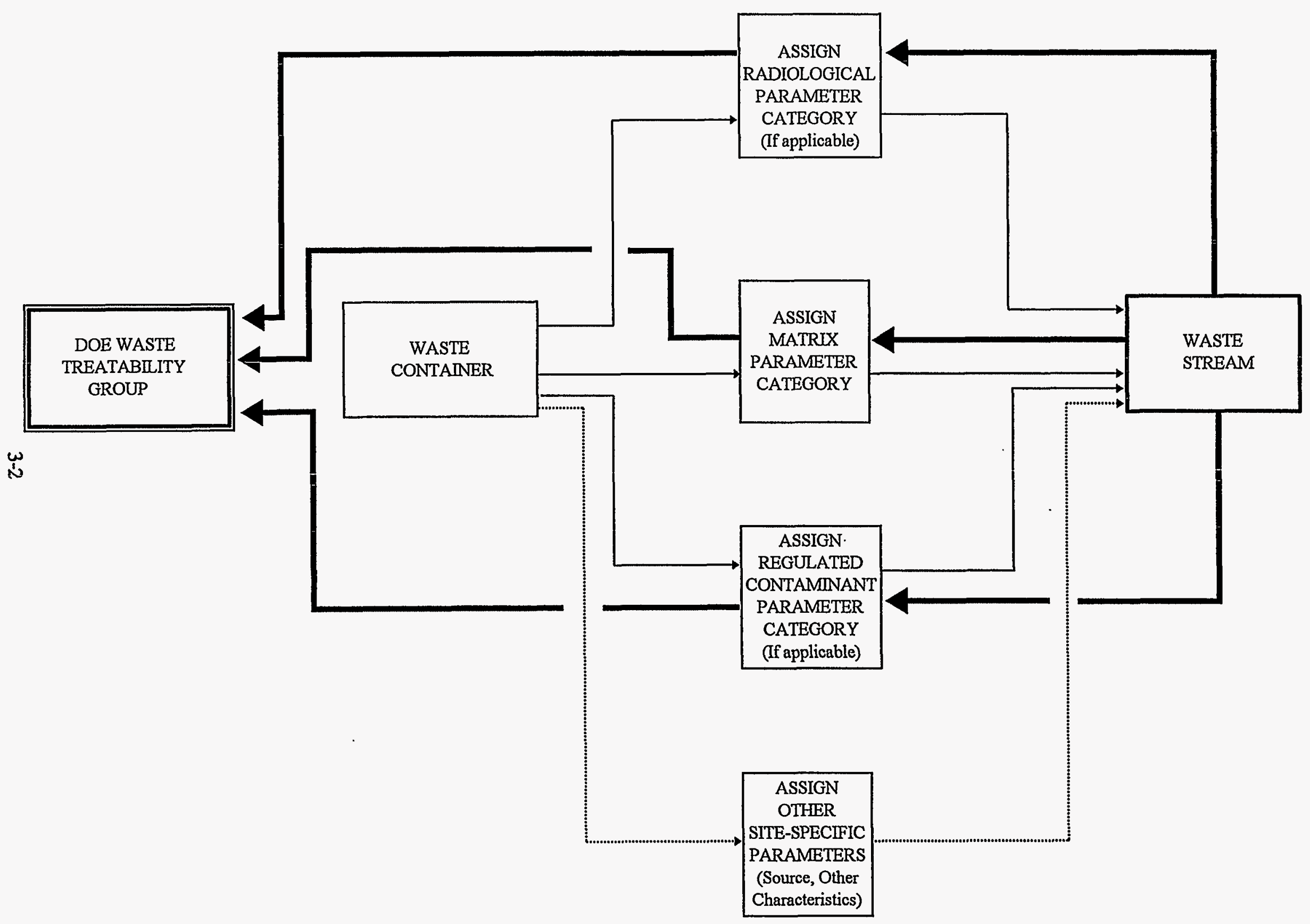

DOE Waste Treatability Group Guidance - January 1995 
Throughout development of this guidance, questions have arisen regarding the benefit of the regulated contaminant parameter category within a treatability group. The argument has been that the EPA codes themselves indicate the specific hazardous contaminants or characteristics associated with the waste. While obviously true, the primary motivator behind regulated contaminant parameter categories is to group the EPA codes according to types of contaminants or characteristics. The benefit of this approach is best envisioned by considering the prospect of manipulating waste information within a database.

Consider, for example, a database with information on the characteristics, including EPA codes, of numerous containers of hazardous or mixed waste. Suppose one was interested in determining which of the containers might require thermal, or some other destructive treatment technology, because of contamination with hazardous organics. This determination might be made by sorting the containers based on their assigned EPA codes. However, this data manipulation would have to be performed considering each of the numerous EPA codes that would indicate the presence of hazardous organic contamination. If each container assigned one or more of those numerous EPA codes were designated as such in a separate data field (e.g., regulated contaminant parameter category code), this manipulation would be greatly simplified. This, in essence, is the motivation behind including the regulated contaminant parameter in the treatability groups.

\subsection{IMPLEMENTATION GUIDELINES}

As illustrated in Figure 3-1, treatability groups are assigned by categorizing waste per each of the applicable characteristic parameters. Figure 3-1 depicts several key guidelines regarding treatability group assignments. These, along with other guidelines, are discussed below.

\section{Guideline 1}

The characteristic parameters considered in treatability group assignment depend on the primary waste type. As defined in Section 2, there are four primary waste types. These are radioactive, hazardous, mixed, and sanitary waste. The characteristic parameters considered in treatability group assignments for each are:

- Assignments for radioactive waste require categorization according to the radiological and matrix parameters only

- Assignments for hazardous waste require categorization according to the matrix and regulated contaminant parameters only

- Assignments for mixed waste require categorization according to all three parameters

- Assignments for sanitary waste require categorization according to only the matrix parameter.

Guideline 2

As discussed in Section 1.1, technically valid assignments of containerized waste streams to treatability groups require that the treatability group concept be implemented as part of the criteria for defining the streams.

Guideline 3

Also as discussed in Section 1.1, use of the treatability group concept in defining waste streams does not preclude consideration of other parameters. Figure 3-1 illustrates the idea of considering other site-specific parameters in waste stream definitions via connection to the concept logic with a dotted 
line. These additional parameters may address issues other than the waste characteristics (e.g., source) to accommodate end uses of the waste stream data not involving technology and capacity needs assessments. The additional parameters may also address detailed characteristics not considered in the categories defined for the three main characteristic parameters to increase segregation of containers into streams for more definitive technology and capacity needs assessments. Ultimately, the inclusion of additional parameters in defining waste streams will result in multiple streams for a given site being assigned the same treatability group.

\section{Guideline 4}

Beginning with alignment into waste streams, implementation of the treatability group concept for containerized waste should be performed at the outer container level as the waste is, or will be, packaged for transfer to long-term storage, treatment, or disposal. In other words, even though the waste within the containers is often comprised of discreet items or inner packages, evaluations for treatability group assignments should be performed by viewing the waste contents within the container as a whole, resulting in a single, composite treatability group assignment for the container. The one exception to this is overpacks. Implementation for overpacks should be performed per the outer container level of the inner, overpacked container.

The basis for this guideline is that the receiving treatment, storage, or disposal facility must manage the entire container as collectively packaged. Therefore, technology and capacity needs assessments need to consider the entire container as collectively packaged. For example, if such containerized waste required treatment, the necessary technology may include sorting the discreet waste items within the container.

\section{Guideline 5}

The outer waste container is not considered when assigning the treatability group matrix parameter category. Rigid polyethylene liners are considered part of the outer waste container.

Guideline 6

Internal packaging materials within outer containers are considered part of the waste matrix. Examples of these packaging materials are plastic bagging, bottles, and filler materials. 


\section{RADIOLOGICAL PARAMETER}

This section presents the radiological parameter categories (RPCs) and definitions. This parameter is only considered in treatability group assignments for the radioactive and mixed primary waste types. The RPC describes broad radiological characteristics of the waste that can affect the manner in which the waste is treated or otherwise managed.

\subsection{OVERVIEW OF RADIOLOGICAL CATEGORIES}

The RPCs are defined by one or more components that represent various broad, radiological characteristics of the waste. The initial component in the RPCs designates the secondary radiological classification of the waste. As defined in Section 2, the secondary radiological classifications of radioactive and mixed waste are mill tailings, low-level waste, transuranic (TRU) waste, and high-level waste. Except for high-level waste, the RPCs are further defined by one or more descriptive components that represent more definitive radiological characteristics. These components are shown in Figure 4-1.

Complete RPCs for radioactive and mixed waste that are low-level or transuranic include three and one descriptive components, respectively. The descriptive components for low-level waste address the beta-gamma and alpha, both TRU and non-TRU, activity levels. The single descriptive component for waste that is transuranic addresses the beta-gamma activity level. Complete RPCs for mill tailings waste include one descriptive component that addresses the regulations under which the waste is managed for radioactivity. As shown in Figure 4-1, each descriptive component has two or more associated elements. The descriptive components are represented in the RPCs by selection of the appropriate element.

Sections 4.2 through 4.5 provide guidelines and definitions for selecting the appropriate secondary radiological classification component and associated descriptive component elements. Complete RPCs are defined by a "string" of the secondary radiological classification component and one element from each associated descriptive component. The generation of complete RPCs is discussed further in Section 4.6.

\subsection{MULL TAILINGS RPC COMPONENTS}

As indicated in Figure 4-1, the RPC begins with the component MT, or MILL TAILINGS, if the secondary radiological classification of the radioactive or mixed waste is mill tailings as defined in Section 2. The RPCs for this waste are further defined by a single descriptive component to indicate the regulations under which the waste is managed for radioactivity.

\subsubsection{MANAGEMENT COMPONENT}

The management component is represented in the RPCs for mill tailings radioactive or mixed waste by selecting, as appropriate, one of the following elements.

\section{MT10 LL Managed}

The management component is represented by this element if the waste is managed for its radioactivity as low-level waste. Per DOE Order 5820.2A, small quantities of DOE waste that contain uranium or thorium mill tailings may be managed as low-level waste. The definition for "small quantity" currently being considered in determining whether such waste can be managed as low-level waste is as follows: 


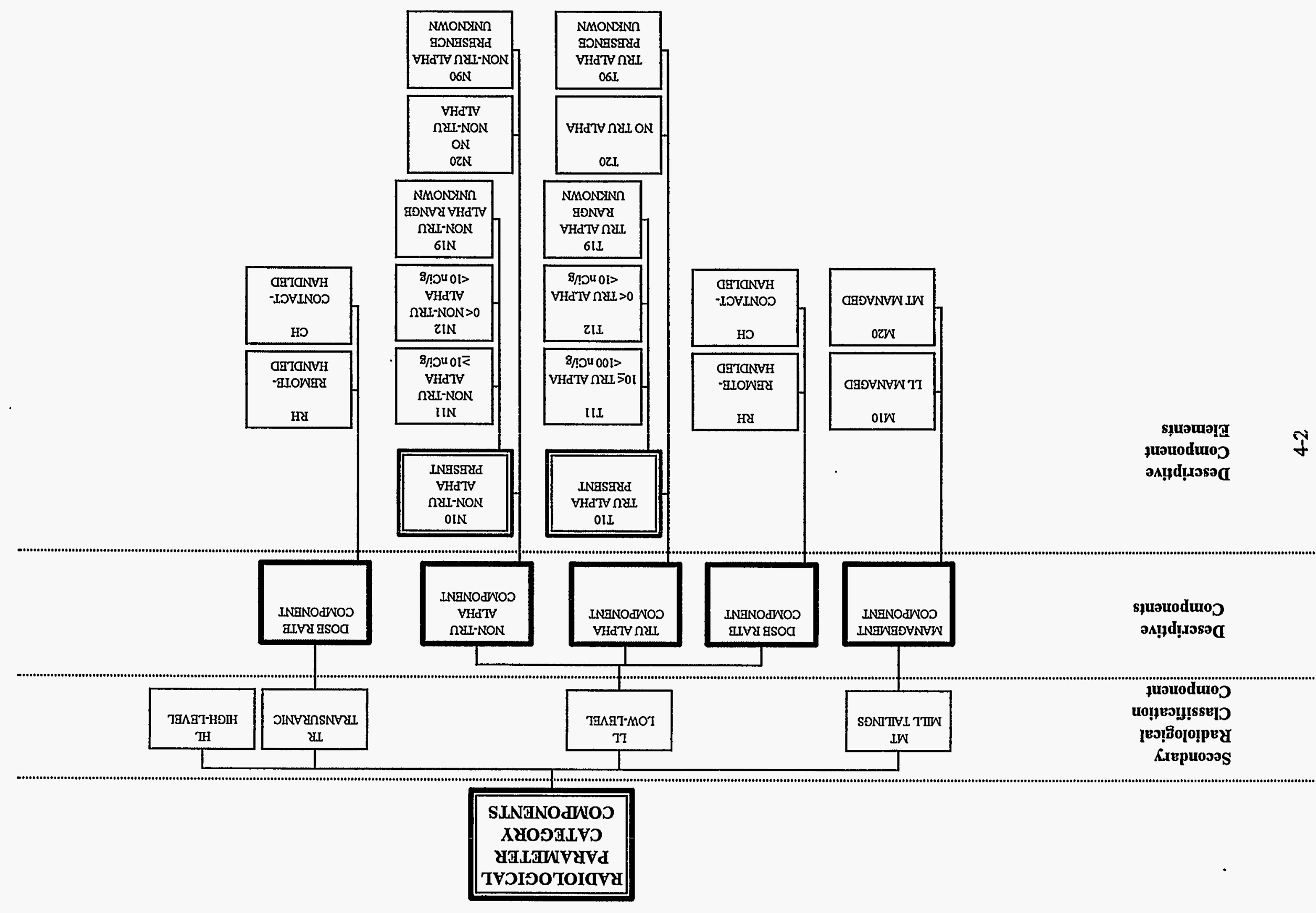


Less than or equal to $10,000 \mathrm{~kg}$ and containing less than or equal to $5 \mathrm{mCi}$ of radium-226" as derived from 10 CFR 61.1(b).

\section{MT20 MT Managed}

The management component is represented by this element if the waste is managed for its radioactivity as mill tailings waste. This includes DOE waste containing uranium and thorium mill tailings that, because of its large quantities or for other reasons, is managed in accordance with DOE Order 5820.2A strictly as mill tailings and not as low-level waste.

\subsection{LOW-LEVEL WASTE RPC COMPONENTS}

As indicated in Figure 4-1, the RPC begins with the component LL, or LOW-LEVEL, if the secondary radiological classification of the radioactive or mixed waste is low-level waste as defined in Section 2. The RPCs for this waste are further defined by three descriptive components that indicate general, key radiological characteristics that may affect the manner in which the waste is treated or otherwise managed.

\subsubsection{DOSE RATE COMPONENT}

The first descriptive component in the RPC for low-level radioactive or mixed waste indicates whether the waste is considered contact-handled or remote-handled. This designation is generally based on the millirem per hour exposure or dose rates that would be received at the exterior surface of the waste container and, therefore, provides an indication of the beta-gamma activity levels of the waste. Facilities that manage waste with high surface dose rates (i.e., remote-handled) generally require special design features (such as extensive shielding, robotics) to mitigate personnel exposure. The dose rate component is represented in the RPCs for low-level radioactive or mixed waste by selecting, as appropriate, one of the following elements.

\section{RH Remote-Handled}

The dose rate component is represented by this element if the waste is considered remote-handled based on site-specific procedures and policies.

\section{CH Contact-Handled}

The dose rate component is represented by this element if the waste is considered contact-handled based on site-specific procedures and policies.

\subsubsection{TRU ALPHA COMPONENT}

The second descriptive component in the RPC for low-level radioactive or mixed waste addresses the presence and relative concentration, if known, of TRU alpha-emitting radionuclides. Per the definition of TRU waste in DOE Order 5820.2A, TRU alpha-emitters are defined in this document as alpha-emitting radionuclides with an atomic number greater than 92 and a half-life of greater than 20 years. Examples of these radionuclides are certain isotopes of plutonium, americium, curium, californium, and neptunium.

Low-level radioactive or mixed waste containing these radionuclides presents unique management challenges. With respect to treatment, facilities may require special design features to safeguard against personnel exposure from airborne releases. In addition, treatment may result in the generation of secondary TRU waste as defined in Section 2 (i.e., TRU alpha $\geq 100 \mathrm{nCi} / \mathrm{g}$ ). Both of these concerns depend not only on the concentration of the TRU alpha-emitters in the waste, but on a variety of other factors, including the treatment technology to be applied. Therefore, there is no "hard and fast" concentration at which the presence of TRU alpha-emitters becomes a primary concern. As indicated in the following discussions, a criteria of $10 \mathrm{nCi}$ per gram of waste is used in this guidance to distinguish 
between low-level radioactive or mixed waste with relatively high and low concentrations of TRU alpha-emitting radionuclides.

The TRU alpha component is represented in the RPCs for low-level radioactive or mixed waste by selecting, as appropriate, one of the five following elements. As shown in Figure 4-1, three of the five elements indicate that TRU alpha-emitters are present and the relative concentration, if known. These three elements "roll" to a summary element (i.e., T10 TRU ALPHA PRESENT). This summary element is reserved for performing database rollups of waste that contain TRU alpha-emitters, regardless of the concentration. The summary element is only shown in Figure 4-1 to illustrate this logic and should not be used in assigning the RPC.

T11 $10 \mathrm{nCi} / \mathrm{g} \leq$ TRU Alpha $<100 \mathrm{nCi} / \mathrm{g}$

The TRU alpha component is represented by this element if the waste contains one or more TRU alpha-emitting radionuclides with a combined concentration $\geq 10$, but $<100 \mathrm{nCi}$ per gram of waste. This element should be selected for waste that was considered TRU when initially generated and subsequently reclassified as low-level because of the change in criteria for classification as TRU from waste containing $\geq 10$ to waste containing $\geq 100 \mathrm{nCi} / \mathrm{g}$ of TRU alpha-emitting radionuclides.

T12 0 nCi/g $<$ TRU Alpha $<10$ nCi/g

The TRU alpha component is represented by this element if the waste contains one or more TRU alpha-emitting radionuclides with a combined concentration $<10 \mathrm{nCi}$ per gram of waste.

\section{T19 TRU Alpha Range Unknown}

The TRU alpha component is represented by this element if the waste is known to contain one or more TRU alpha-emitting radionuclides, but it is unknown if the combined concentration is $<10$ or $\geq 10$, but $<100 \mathrm{nCi}$ per gram of waste.

\section{T20 No TRU Alpha}

The TRU alpha component is represented by this element if the waste does not contain any TRU alpha-emitting radionuclides.

\section{T90 TRU Alpha Presence Unknown}

The TRU alpha component is represented by this element if it is unknown whether the waste contains any TRU alpha-emitting radionuclides.

\subsubsection{NON-TRU ALPHA COMPONENT}

The third descriptive component in the RPC for low-level radioactive or mixed waste addresses the presence and relative concentration of alpha-emitting radionuclides not defined as TRU per Section 4.3.2. Examples of these radionuclides are most isotopes of uranium and thorium, and certain isotopes of radionuclides with atomic numbers $>92$ that have half-lives of 20 years or less.

As with the TRU alpha-emitters, treatment facilities for low-level radioactive or mixed waste containing these radionuclides may require special design features to safeguard against personnel exposure from airborne releases. Again, this concern depends not only on their concentration in the waste, but on a variety of other factors, including the treatment technology to be applied. Consistent with the TRU alpha component, a criterion of $10 \mathrm{nCi}$ per gram of waste is used in this guidance to distinguish between low-level radioactive or mixed waste with relatively high and low concentrations of non-TRU alpha-emitting radionuclides. 
The non-TRU alpha component is represented in the RPCs for low-level radioactive or mixed waste by selecting, as appropriate, one of the five following elements. As shown in Figure 4-1, three of the five elements indicate that non-TRU alpha-emitters are present and the relative concentration, if known. These three elements "roll" to a summary element (i.e., N10 NON-TRU ALPHA PRESENT). This summary element is reserved for performing database rollups of waste that contains non-TRU alpha-emitters, regardless of the concentration. The summary element is only shown in Figure 4-1 to illustrate this logic and should not be used in assigning the RPC.

\section{N11 Non-TRU Alpha $\geq 10 \mathrm{nCi} / \mathrm{g}$}

The non-TRU alpha component is represented by this element if the waste contains one or more non-TRU alpha-emitting radionuclides with a combined concentration $\geq 10 \mathrm{nCi}$ per gram of waste.

\section{N12 0 nCi/g $<$ Non-TRU Alpha $<10$ nCi/g}

The non-TRU alpha component is represented by this element if the waste contains one or more non-TRU alpha-emitting radionuclides with a combined concentration $<10 \mathrm{nCi}$ per gram of waste.

\section{N19 Non-TRU Alpha Range Unknown}

The non-TRU alpha component is represented by this element if the waste is known to contain one or more non-TRU alpha-emitting radionuclides, but it is unknown if the combined concentration is $<10$ or $\geq 10 \mathrm{nCi}$ per gram of waste.

\section{N20 No Non-TRU Alpha}

The non-TRU alpha component is represented by this element if the waste does not contain any non-TRU alpha-emitting radionuclides.

\section{N90 Non-TRU Alpha Presence Unknown}

The non-TRU alpha component is represented by this element if it is unknown whether the waste contains any non-TRU alpha-emitting radionuclides.

\subsection{TRANSURANIC WASTE RPC COMPONENTS}

As indicated in. Figure 4-1, the RPC begins with the component TR, or TRANSURANIC, if the secondary radiological classification of the radioactive or mixed waste is TRU as defined in Section 2. The RPCs for this waste are further defined by a single, descriptive dose rate component that indicates whether the waste is contact-handled or remote-handled. As discussed previously for low-level radioactive or mixed waste, facilities that manage remote-handled waste generally require special design features (e.g., extensive shielding, robotics) to mitigate personnel exposure.

\subsubsection{DOSE RATE COMPONENT}

The dose rate component is represented in the RPCs for TRU radioactive or mixed waste by selecting, as appropriate, one of the following elements.

\section{RH Remote-Handled}

The dose rate component is represented by this element if the exposure rate at the external surface of the waste container is greater than $200 \mathrm{mR} / \mathrm{hr}$ on contact.

\section{CH Contact-Handled}

The dose rate component is represented by this element if the exposure rate at the external surface of the waste container is equal to or less than $200 \mathrm{mR} / \mathrm{hr}$ on contact. 


\subsection{HIGH-LEVEL WASTE RPC COMPONENTS}

As indicated in Figure 4-1, the RPC begins with the component ML, or HIGH-LEVEL, if the secondary radiological classification of the radioactive or mixed waste is high-level waste as defined in Section 2. There are no additional descriptive components defined in this guidance for the high-level waste RPCs. Typically, high-level waste contains relatively high concentrations of alpha-emitting radionuclides (both TRU and non-TRU) and has high beta-gamma activity levels (i.e., remote-handled).

\subsection{COMPLETE RADIOLOGICAL PARAMETER CATEGORIES}

As indicated in Section 4.1, the complete RPC for a waste is defined by the secondary radiological classification component followed by an element from each associated descriptive component. The RPC is represented by a "string" of the codes or titles for those components and elements. The codes (MT, $\mathrm{RH}, \mathrm{T} 11, \mathrm{~N} 12$, etc.) and titles are shown in Figure 4-1. The following discussions summarize the complete RPCs that may be applicable to waste within each of the four secondary radiological classifications.

\subsubsection{MIIL TAIIINGS}

Only one descriptive component with two elements was defined for this secondary radiological classification. Therefore, there are two possible RPCs for mill tailings radioactive or mixed waste. These are:

\section{MT|M10 Mill Tailings|LL Managed \\ MT|M20 Mill Tailings|MT Managed}

\subsubsection{LOW-LEVEL WASTE}

Three descriptive components, each with at least two elements, were defined in Section 4.3 for this secondary radiological classification. The numerous possible combinations of the descriptive component elements can result in several unique RPCs for low-level radioactive or mixed waste. Table 4-1 summarizes the descriptive component elements that may define the RPCs for this waste.

The complete RPC is defined by a "string" of the secondary radiological classification component followed by one element from each of the descriptive components. The descriptive component elements appear in the RPC per the order presented in Table 4-1. For example, low-level radioactive or mixed waste that is contact-handled and contains no TRU or non-TRU alpha-emitting radionuclides would have an RPC code of LL|CH|T20|N20.

Multiplying the number of variables (i.e., elements) for each descriptive component reveals that 50 unique RPCs can be defined for low-level radioactive or mixed waste. A complete listing of these 50 RPCs is provided in Appendix A.

\subsubsection{TRANSURANIC WASTE}

As with mill tailings, only one descriptive component with two elements was defined for this secondary radiological classification. Therefore, there are two possible RPCs for TRU radioactive or mixed waste. These are:

TR|RH Transuranic|Remote-Handled TR|CH Transuranic|Contact-Handled 
Table 4-1. Low-Level Waste Radiological Parameter Category Variables

\begin{tabular}{|c|c|c|c|}
\hline \multirow{2}{*}{$\begin{array}{c}\text { Secondary } \\
\text { Radiological } \\
\begin{array}{c}\text { Classification } \\
\text { Component }\end{array}\end{array}$} & \multicolumn{3}{|c|}{ Descriptive Components } \\
\cline { 2 - 4 } & Dose Rate & TRU Alpha & Non-TRU Alpha \\
\hline LL & RH & Descriptive Component Element Codes \\
\hline & CH & T11 & N11 \\
& & T19 & N12 \\
& & T20 & N19 \\
& & T90 & N90 \\
\hline
\end{tabular}

\subsubsection{HIGH-LEVEL WASTE}

There were no descriptive components defined for this secondary radiological classification. Therefore, the RPC code and title for high-level waste are HL and HIGH-LEVEL. 


\section{MATRIX PARAMETER}

This section presents the matrix parameter categories (MPCs) and definitions. This parameter is common to treatability group assignments for all four primary, and associated secondary, waste types. The MPC describes the overall, composite physical/chemical form (i.e., matrix) of the waste. The matrix can affect all facets of management.

\subsection{OVERVIEW OF MATRIX CATEGORIES}

Figure B-1 of Appendix B provides a foldout chart depicting all of the MPCs currently defined in this guidance. Figures 5-1 through 5-7 of this section highlight different portions of the foldout chart to facilitate discussion of the MPC definitions. As indicated in Figure B-1 and Figures 5-1 through 5-7, each MPC is identified by a title and a single-character alpha or five-character alphanumeric code. Furthermore, each is designated as being either a "summary," "specific-detailed," or "unknown/ other-detailed" MPC.

The array of MPCs is arranged in a logical hierarchy beginning with four broad, summary categories and one associated unknown/other-detailed category. The summary categories are Liquids (S), Solids (S), Specific Waste Forms (X), and Final Waste Forms (Z), while the unknown/other-detailed category is Unknown/Other Matrix (U9999). Each of the initial four summary MPCs is followed by levels of successively more definitive, or waste form specific, categories. The first successive level includes the MPCs for which the last non-zero digit in the numeric portion of their codes is in the $1000 \mathrm{~s}$. These are referred to as the "Level 1000" MPCs. Each of the Level 1000 MPCs that is a summary category is, in turn, followed by yet more definitive Level 100 MPCs. This logic continues until reaching a final level that consists of only detailed MPCs. The associated MPCs at any given level include one unknown/other-detailed category. Inherent within the logical hierarchy of the complete array is the ability to perform aggregates by rolling the more definitive MPCs up to their associated, less definitive summary MPCs (i.e., Level $1 \Rightarrow$ Level $10 \Rightarrow$ Level $100 \Rightarrow$ Level 1000 ).

Definitions for the MPCs are provided in Sections 5.3 through 5.7. Defining the MPCs, particularly for the Solids (S) categories, required the establishment of physical/chemical form "concentration" criteria. As indicated in the opening remarks of Section 5, the MPC is intended to describe the overall, composite matrix of the waste. Containerized, solid waste often does not consist of a single physical/chemical form. This is perhaps most true for debris. This waste frequently contains multiple debris materials that are organic (e.g., plastic, rags) and inorganic (e.g., metal, glass, ceramic materials). Because of this, definitions for the Debris (S5000s) and other more definitive Solids (S) MPCs include criteria specifying how much of the physical/chemical form described by the category must be contained in the waste for assignment to the category. For example, the specific-detailed Organic Debris (S5100s) and Inorganic Debris (S5300s) categories specify that for a waste to be categorized as such, it must contain $80 \%$ or more of the subject debris material. These physical/chemical form concentration criteria are volume based. In the interest of performing technical waste management studies, it might be preferred that these criteria be mass based. However, more often than not, the available waste information more readily supports MPC assignment per these volume-based criteria. 


\subsection{MATRIX CATEGORY SELECTION GUIDELINES}

Matrix category selection essentially involves a process of successive evaluations whereby the characteristic information on the waste matrix is compared with the definitions of the appropriate summary and specific-detailed MPCs. As implied in Figures B-1 and 5-1, the process begins with evaluating the waste per the criteria of the initial Liquids (L), Solids (S), Specific Waste Forms (X), and Final Waste Forms (Z) summary MPCs. If the waste is insufficiently characterized to enable this evaluation or does not meet the criteria specified for any of the four summary categories, it is assigned to the Unknown/Other Matrix (U9999) detailed category. If the waste is determined to meet the criteria for one of the initial summary categories, the evaluation process proceeds to the more definitive Level 1000 MPCs associated with that initial summary level category. For example, if the waste was determined to be a liquid, it would be evaluated per the criteria of the Aqueous Liquids/Slurries (L1000) and Organic Liquids (L2000) summary categories.

Repetition of the evaluation process per the criteria of the summary and specific-detailed categories, as applicable, in the successively more definitive levels (i.e., Level $1000 \Rightarrow$ Level $100 \Rightarrow$ Level $10 \Rightarrow$ Level 1) leads to eventual selection of the MPC. The appropriate MPC is selected when one of the following situations arises:

- A level is reached where the waste meets the criteria of a specific-detailed category. In this situation, that specific-detailed category is selected.

- A level is reached where either (a) it cannot be determined whether the waste meets the criteria for any of the summary or specific-detailed categories, or (b) the waste does not meet the criteria for any of the summary or specific-detailed categories. The former case would typically arise because of a lack of characteristic information on the waste. The latter. case would arise if the waste is of a physical/chemical form not within the criteria specified for the summary or specific-detailed categories. In either case, the associated unknown/other-detailed category is selected.

Actual selection of the MPCs is not as laborious as might be implied by the above discussion. While the process of successive evaluations is inherently part of MPC selection, once a user is familiar with the categories and definitions, selecting the appropriate MPC is relatively straightforward, depending on the availability and quality of documentation on the matrix characteristics of the waste.

The two key guidelines implicit in the above discussions are that (a) the MPC should be selected from the most definitive, or lowest, applicable category level that can be supported by available characteristic data on the waste matrix, and (b) waste should not be assigned the summary MPCs. The time and effort involved to assign the MPCs, or any of the treatability group parameters, is primarily expended in evaluating the available, applicable data on the waste. Once the data are reviewed and the MPCs are assigned, aggregation to less definitive, upper-level summary categories is easily performed given the logic in the MPC codes. However, separation to more definitive, lower-level categories would require revisiting the available data on the waste and reassigning the MPC. Aggregates to the summary categories can be misconstrued if waste is actually assigned to those MPCs.

Sections 5.3 through 5.6 present the definitions for the four initial summary MPCs and their associated, more definitive categories. Section 5.7 presents the definition for the Unknown/Other Matrix (U9999) MPC. 
Figure 5-1. Matrix Parameter Categories - Initial Categories






\subsection{DEFINITIONS - LIQUIDS AND ASSOCIATED CATEGORIES}

The initial Liquids $(L)$ summary category addresses wastes that are liquids, including slurries. Slurries are defined as liquids with a total suspended/settled solids (TSS) content of $\geq 1 \%$ and $\leq 30 \%$. Waste with a TSS content $>30 \%$ is defined as sludges (see Section 5.4). Only liquids and slurries packaged in bulk, free form (e.g., drum, tank) are included in this category. Liquids and slurries packaged as lab packs are assigned to other MPCs (see Section 5.5).

As shown in Figure 5-2, liquids are initially evaluated per the criteria of the Aqueous Liquids/Slurries (L1000) and Organic Liquids (L2000) summary categories. Liquids that are insufficiently characterized to enable this evaluation are assigned to the Unknown/Other Liquid (L9000) detailed category.

\subsubsection{L1000 AQUEOUS LIQUIDS/SLURRIES}

This summary category includes liquids and slurries containing less than $1 \%$ total organic carbon (TOC). This waste is further evaluated per the criteria of the Wastewaters (L1100) and Aqueous Slurries (L1200) summary categories.

\section{L1100 Wastewaters}

This summary category includes aqueous liquids and slurries that meet the EPA LDR criteria for wastewaters ( $<1 \%$ TSS). The appropriate detailed MPCs for this waste are selected from the following categories.

\section{L1110 Acidic Wastewaters}

This specific-detailed category includes wastewaters with a $\mathrm{pH} \leq 2.0$.

\section{L1120 Basic Wastewaters}

This specific-detailed category includes wastewaters with a pH $\geq 12.5$. Basic wastewaters that contain cyanides at or above applicable LDR treatment standard levels are assigned to category L1140.

\section{L1130 Neutral Wastewaters}

This specific-detailed category includes wastewaters with $2.0<\mathrm{pH}<12.5$. Neutral wastewaters that contain cyanides at or above applicable LDR treatment standard levels are assigned to category L1140.

\section{L1140 Cyanide Wastewaters}

This specific-detailed category includes wastewaters containing cyanides at or above applicable LDR treatment standard levels, regardless of the $\mathrm{pH}$.

\section{L1190 Unknown/Other Wastewaters}

This unknown/other-detailed category includes waste that is consistent with the definition for the Wastewaters (L1100) summary category, but:

- Is insufficiently characterized to enable more definitive assignment into one of the L1110 through L1140 specific-detailed categories, or

- Does not meet the criteria for assignment into one of the L1110 through L1140 specific-detailed categories. 
Fiqure 5-2. Matrix Parameter Categories- Liquids

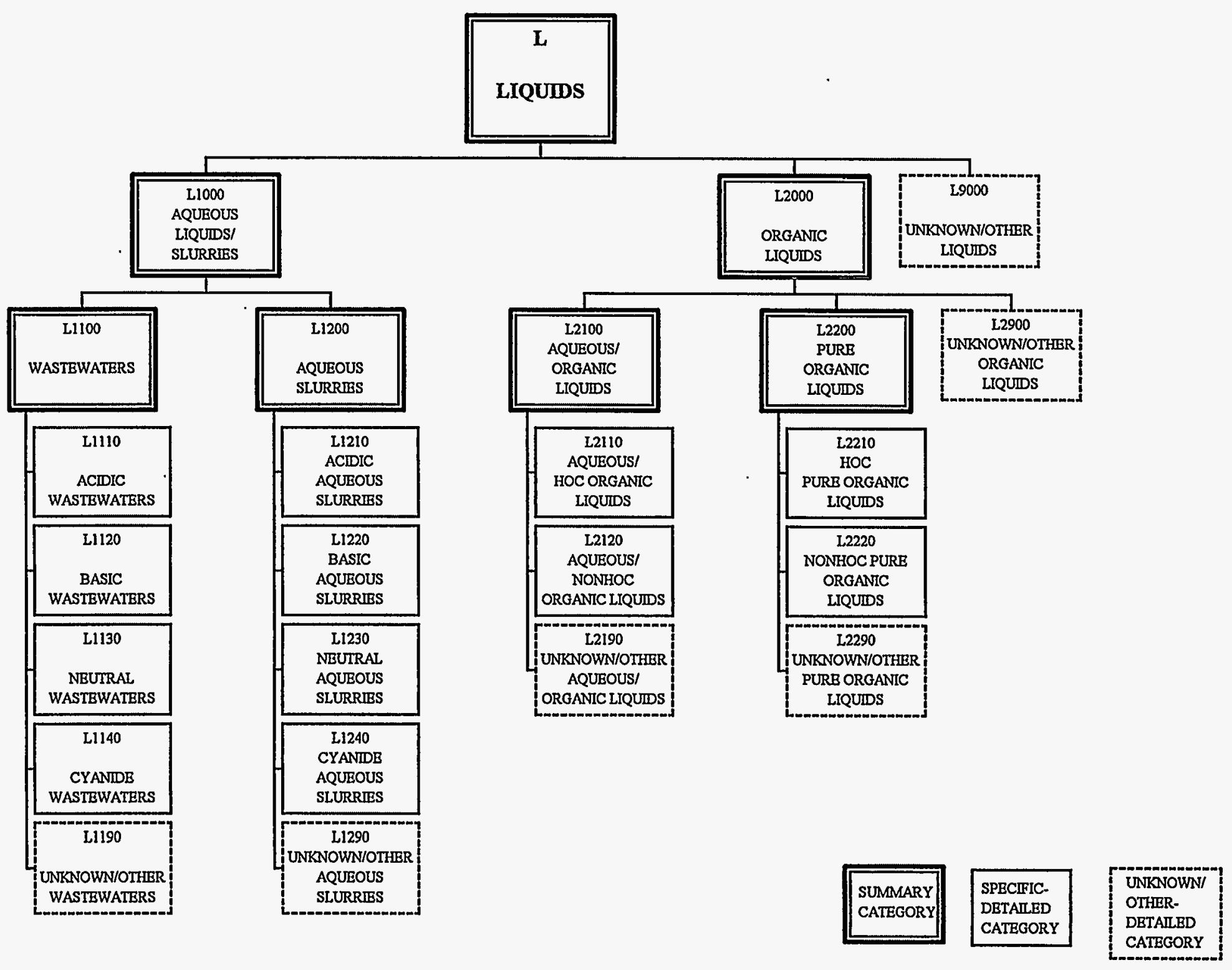




\section{L1200 Aqueous Slurries}

This summary category includes aqueous liquids and slurries for which either (a) the TSS is known to be $\geq 1 \%$, or (b) it is unknown if the TSS is $\geq 1 \%$. The appropriate detailed MPCs for this waste are selected from the following categories.

\section{L1210 Acidic Aqueous Slurries}

This specific-detailed category includes aqueous slurries with a $\mathrm{pH} \leq 2.0$.

\section{L1220 Basic Aqueous Slurries}

This specific-detailed category includes aqueous slurries with a $\mathrm{pH} \geq 12.5$. Basic aqueous slurries that contain cyanides at or above applicable LDR treatment standard levels are assigned to category L1240.

\section{L1230 Neutral Aqueous Slurries}

This specific-detailed category includes aqueous slurries with $2.0<\mathrm{pH}<12.5$. Neutral aqueous slurries that contain cyanides at or above applicable LDR treatment standard levels are assigned to category L1240.

\section{L1240 Cyanide Aqueous Slurries}

This specific-detailed category includes aqueous slurries containing cyanides at or above applicable LDR treatment standard levels, regardless of the $\mathrm{pH}$.

\section{L1290 Unknown/Other Aqueous Slurries}

This unknown/other-detailed category includes waste that is consistent with the definition for the Aqueous Slurries (L1200) summary category, but:

- Is insufficiently characterized to enable more definitive assignment into one of the L1210 through L1240 specific-detailed categories, or

- Does not meet the criteria for assignment into one of the L1210 through L1240 specific-detailed categories.

\subsubsection{L2000 ORGANIC LIQUIDS}

This summary category includes liquids and slurries containing $\geq 1 \%$ TOC. As shown in Figure 5-2, this waste is further evaluated per the criteria of the Aqueous/Organic Liquids (L2100) and Pure Organic Liquids (L2200) summary categories. Organic liquids that are insufficiently characterized to enable this evaluation are assigned to the Unknown/Other Organic Liquid (L2900) detailed category.

\section{L2100 Aqueous/Organic Liquids}

This summary category includes mixtures, both miscible and immiscible, of aqueous and organic liquids. The appropriate detailed MPCs for this waste are selected from the following categories.

\section{L2110 Aqueous/Halogenated Organic Liquids}

This specific-detailed category includes aqueous and organic liquids that contain at least $1,000 \mathrm{ppm}$ halogenated organic compounds (HOC).

\section{L2120 Aqueous/Nonhalogenated Organic Liquids}

This specific-detailed category includes aqueous and organic liquids that contain less than $1,000 \mathrm{ppm}$ HOC. 
L2190 Unknown/Other Aqueous and Organic Liquids

This unknown/other-detailed category includes waste that is consistent with the definition for the Aqueous/Organic Liquids (L2100) summary category, but it is not known whether the HOC content is less than, equal to, or greater than $1,000 \mathrm{ppm}$.

L2200 Pure Organic Liquids

This summary category includes liquids that are essentially purely organic. The appropriate detailed MPCs for this waste are selected from the following categories.

L2210 Halogenated Pure Organic Liquids

This specific-detailed category includes pure organic liquids that contain at least $1,000 \mathrm{ppm}$ HOC.

L2220 Nonhalogenated Pure Organic Liquids

This specific-detailed category includes pure organic liquids that contain less than $1,000 \mathrm{ppm}$ HOC.

L2290 Unknown/Other Pure Organic Liquids

This unknown/other-detailed category includes waste that is consistent with the definition for the Pure Organic Liquids (L2200) summary category, but it is not known whether the HOC content is less than, equal to, or greater than $1,000 \mathrm{ppm}$.

\section{L2900 Unknown/Other Organic Liquids}

This unknown/other-detailed category includes waste that is consistent with the definition of the Organic Liquids (L2000) summary category, but insufficient information is available to enable evaluation per the criteria of the Aqueous/Organic Liquids (L2100) and Pure Organic Liquids (L2200) summary categories.

\subsubsection{L9000 UNKNOWN/OTHER LIQUIDS}

This unknown/other-detailed category includes waste that is consistent with the definition for the Liquids (L) summary category, but insufficient information is available to enable evaluation per the criteria of the Aqueous Liquid/Slurry (L1000) and Organic Liquid (L2000) summary categories.

\subsection{DEFINITIONS - SOLIDS AND ASSOCIATED CATEGORIES}

The initial Solids (S) summary category addresses waste with physically solid matrices, including sludges. Sludges are defined as having a TSS $>30 \%$. Certain waste with physically solid matrices are excluded from this category. These include solids that meet the criteria for assignment to the Specific (X) and Final (Z) Waste Forms summary categories (see Sections 5.5 and 5.6).

As shown in Figure 5-3, solids are initially evaluated per the criteria of the Homogeneous Solids (S3000), Soil/Gravel (S4000), and Debris (S5000) summary categories. Solids that are insufficiently characterized to enable this evaluation, or that do not meet the criteria specified for any of these summary categories are assigned the Unknown/Other Solids ( 9900$)$ detailed category.

\subsubsection{S3000 HOMOGENEOUS SOLIDS}

Homogeneous solids are defined in this guidance as solid waste materials, excluding soil/gravel (see Section 5.4.2), that do not meet the EPA LDR criteria for classification as debris. Homogeneous 
Figure 5-3. Matrix Parameter Categories - Solids

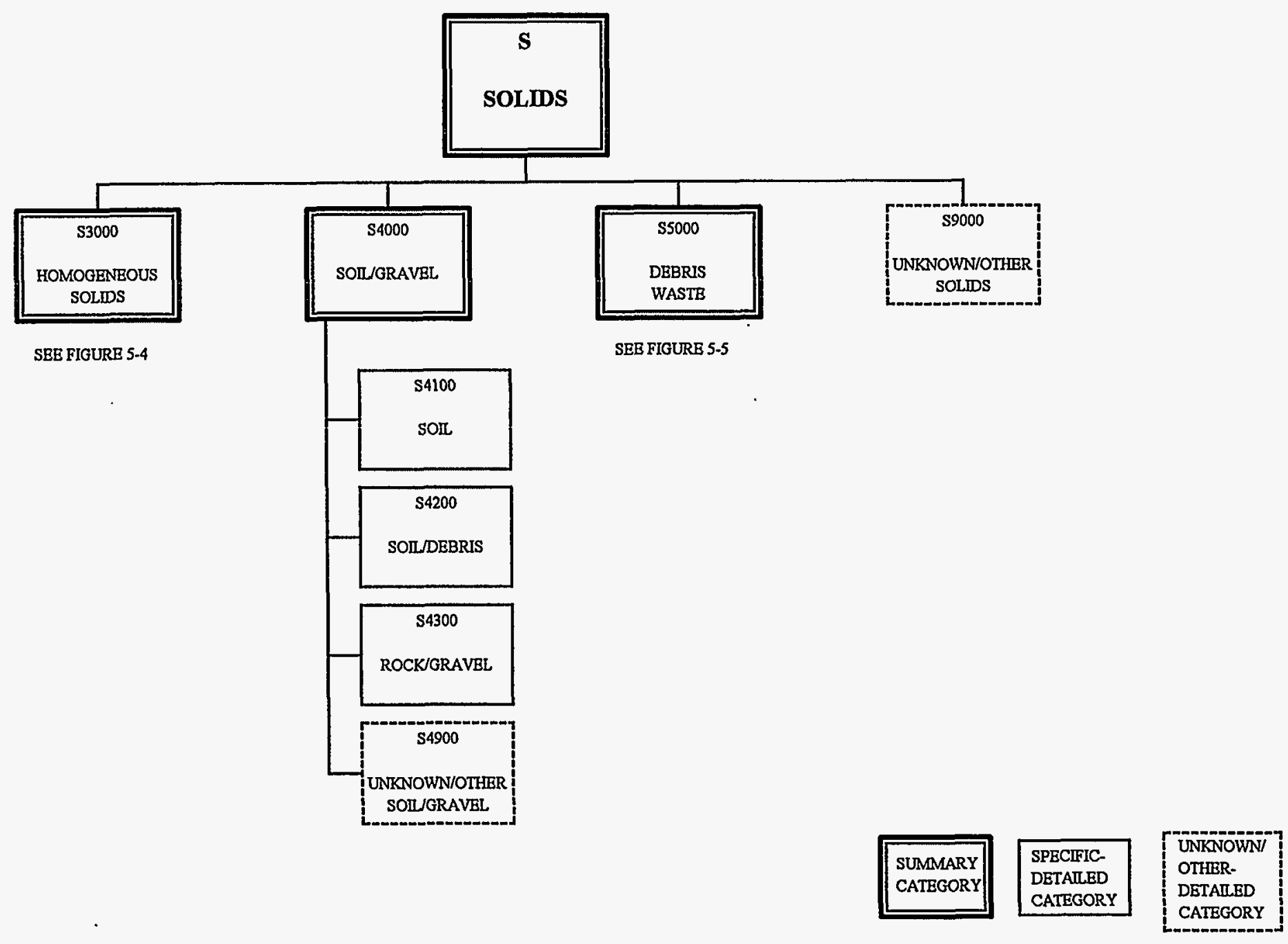


solids may include water or other residual or absorbed liquids. Examples of homogeneous solids are sludges and particulate-type materials.

This summary category includes waste that is at least $50 \%$ by volume homogeneous solids. The balance of the matrix may be other solid physical/chemical forms. For example, a drum of waste from a spill cleanup may contain particulate absorbents and debris (e.g., rags, paper). The drum would be assigned to the appropriate homogeneous solids category provided the particulate absorbents, including any absorbed liquids, account for at least $50 \%$ of the waste volume. [If the waste volume were $50 \%$ or more debris, then the drum would be assigned to the appropriate debris category (see Section 5.4.3)].

As shown in Figure 5-4, this waste is further evaluated per the criteria of the Inorganic Homogeneous Solids (S3100) and Organic Homogeneous Solids (S3200) summary categories. Homogeneous solids that are insufficiently characterized to enable this evaluation or that do not meet the criteria specified for either of these summary categories are assigned the Unknown/Other Homogeneous Solids (S3900) detailed category.

\section{S3100 Inorganic Homogeneous Solids}

Homogeneous solids with sufficient inorganic solids content such that a minimum of approximately $20 \%$ by weight would remain as residue (i.e., ash or solids) following incineration are defined in this guidance as inorganic. This summary category includes waste that is at least $50 \%$ by volume inorganic homogeneous solids.

As shown in Figure 5-4, this waste is further evaluated per the criteria of the Inorganic Particulates (S3110), Inorganic Sludges (S3120), Paint Waste (S3130), and Salt Waste (S3140) summary MPCs, and the Solidified Homogeneous Solids (S3150) and Inorganic Chemicals (S3160) specific-detailed MPCs. Inorganic homogeneous solids that are insufficiently characterized to enable this evaluation or that do not meet the criteria specified for any of these categories are assigned the Unknown/Other Inorganic Homogeneous Solid (S3190) detailed category.

\section{S3110 Inorganic Particulates}

This summary category includes waste that is at least $50 \%$ by volume inorganic particulates, including any residual or absorbed liquids. Typical examples of inorganic particulates are incinerator ash, dust, sandblasting residue, vermiculite, and ion-exchange media. The appropriate detailed MPCs for this waste are selected from the following categories.

\section{S3111 Ash}

This specific-detailed category includes waste that is primarily (i.e., $\geq 50 \%$ by volume) bottom or fly ash resulting from incineration.

\section{S3112 Sandblasting Media}

This specific-detailed category includes waste that is primarily (i.e., $\geq 50 \%$ by volume) unused or spent surface cleaning or decontamination particulate material. Typical examples of surface cleaning or decontamination particulate materials are coarse sand and glass beads.

\section{S3113 Inorganic Particulate Absorbents}

This specific-detailed category includes waste that is primarily (i.e., $\geq 50 \%$ by volume) inorganic particulate absorbent materials, including absorbed aqueous liquids, if 
Figure 5-4. Matrix Parameter Categories - Homogeneous Solids

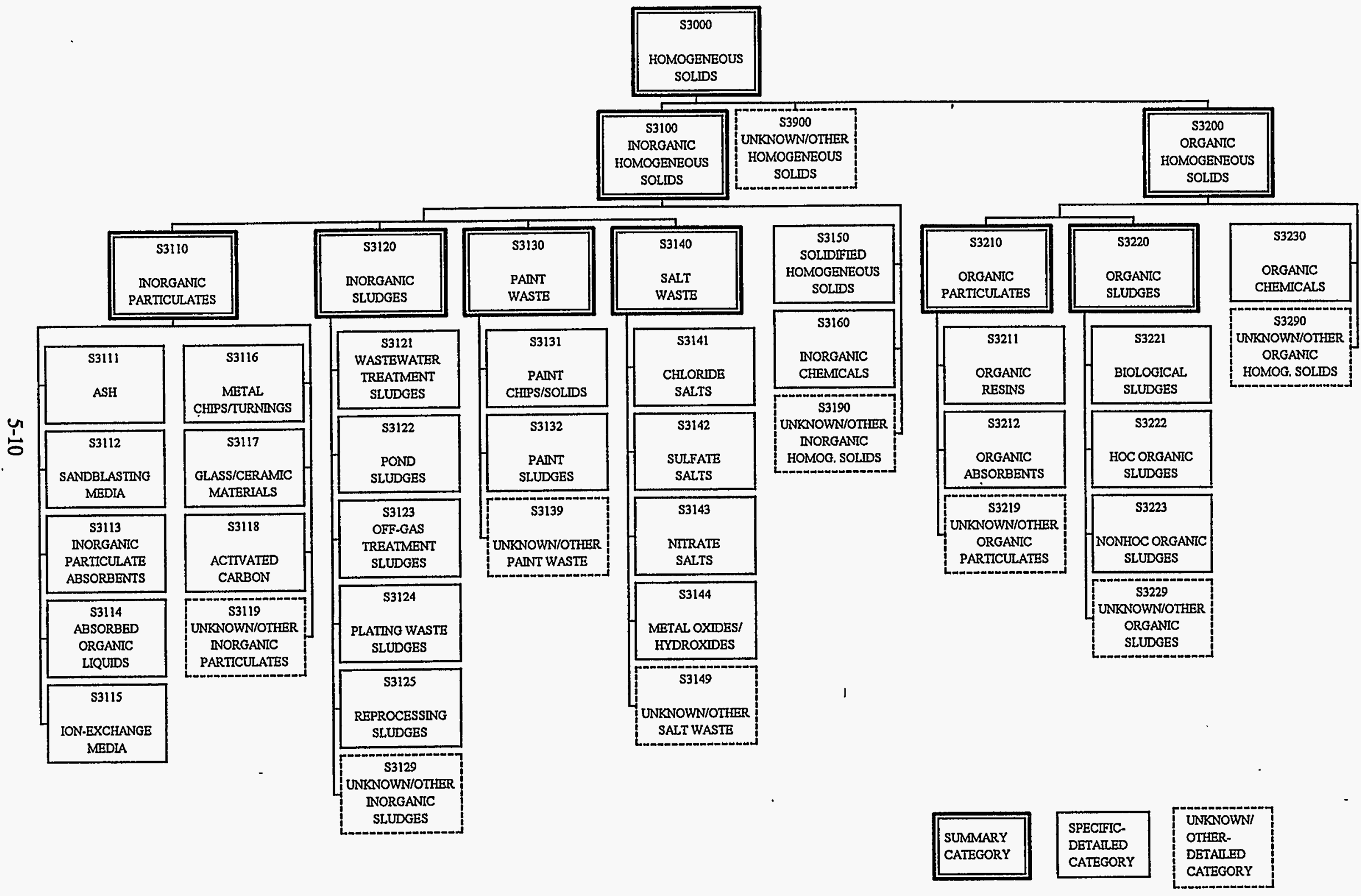


present. Typical examples of inorganic particulate absorbent materials are clay, vermiculite, and diatomaceous earth.

\section{S3114 Absorbed Organic Liquids}

This specific-detailed category includes waste that is primarily (i.e., $\geq 50 \%$ by volume) inorganic particulate absorbent materials with absorbed organic liquids. Typical examples of inorganic particulate absorbent materials are clay, vermiculite, and diatomaceous earth.

\section{S3115 Ion-Exchange Media}

This specific-detailed category includes waste that is primarily (i.e., $\geq 50 \%$ by volume) unused or spent inorganic ion-exchange resins.

\section{S3116 Metal Chips/Turnings}

This specific-detailed category includes waste that is primarily (i.e., $\geq 50 \%$ by volume) metal chips, turnings, fines, and powders, including any machining coolants, oils, etc. This category would not be selected for certain metal chips or turnings waste. This includes waste meeting the criteria for classification as Debris (S5000), Beryllium Dust (X7300), or Reactive Metals (X7500) (see Sections 5.4.3 and 5.5.2). Also, if the metals exist as oxides or hydroxides, the Metal Oxides/Hydroxides (S3144) category should be selected.

\section{S3117 Glass/Ceramic Materials}

This specific-detailed category includes waste that is primarily (i.e., $\geq 50 \%$ by volume) glass or ceramic material too small to qualify as debris (i.e., $\leq 60-\mathrm{mm}$ particle size). Examples of this waste may be broken glassware, crushed light tubes, and ceramic packing material, such as raschig rings. (If the waste is glass beads used as the media for sandblasting, it should be assigned to $\mathbf{S 3 1 1 2}$ as a more descriptive matrix category.)

\section{S3118 Activated Carbon}

This specific-detailed category includes waste that is primarily (i.e., $\geq 50 \%$ by volume) spent or unused activated carbon, including any residual liquids. The activated carbon may be in powdered (typically 50 to $100 \mu \mathrm{m}$ ) or granular (typically 0.1 to $1 \mathrm{~mm}$ ) form.

\section{S3119 Unknown/Other Inorganic Particulates}

This unknown/other-detailed category includes waste that is consistent with the definition for the Inorganic Particulates (S3110) summary category, but:

- Is insufficiently characterized to enable more definitive assignment into one of the S3111 through S3118 specific-detailed categories, or

- Does not meet the criteria for assignment into one of the S3111 through S3118 specific-detailed categories.

\section{S3120 Inorganic Sludges}

This summary category includes waste that is at least $50 \%$ by volume inorganic sludges, including water content. As previously mentioned, sludges are defined as having a TSS $>30 \%$. The inorganic sludge may be mixed with stabilization agents, such as cement, provided the mixture has not properly cured to form a solidified monolith (see category S3150). The inorganic sludge may also be mixed with inorganic particulate absorbent materials. The appropriate detailed MPCs for this waste are selected from the following categories. 


\section{S3121 Wastewater Treatment Sluclges}

This specific-detailed category includes waste that is at least $50 \%$ by volume secondary sludge, or filtercake from wastewater treatment processes or heavy metal sludges resulting from recovery processes, excluding high-level waste (S3125).

\section{S3122 Pond Sludges}

This specific-detailed category includes waste that is at least $50 \%$ by volume inorganic sludge generated from the remediation of surface impoundments, such as evaporation or sedimentation basins.

\section{S3123 Off-Gas Treatment Sludges}

This specific-detailed category includes waste that is at least $50 \%$ by volume inorganic sludge generated from wet off-gas treatment systems.

\section{S3124 Plating Waste Sludges}

This specific-detailed category includes waste that is at least $50 \%$ by volume inorganic sludge generated from plating operations.

\section{S3125 Reprocessing Sludges}

This specific-detailed category includes waste that is at least $50 \%$ by volume inorganic sludge generated from nuclear fuel reprocessing operations.

\section{S3129 Unknown/Other Inorganic Sludges}

This unknown/other-detailed category includes waste that is consistent with the definition for the Inorganic Sludges (S3120) summary category, but:

- Is insufficiently characterized to enable more definitive assignment into one of the S3121 through S3125 specific-detailed categories, or

- Does not meet the criteria for assignment into one of the S3121 through S3125 specific-detailed categories.

\section{S3130 Paint Waste}

This summary category includes waste that is at least $50 \%$ by volume new, used, or removed paint. This includes such paint waste packaged in a lab pack configuration (see Section 5.5.1). The appropriate detailed MPCs for this waste are selected from the following categories.

\section{S3131 Paint Chips/Solids}

This specific-detailed category includes waste that is at least $50 \%$ by volume solid, or unpourable, paint. Examples of waste that might be included in this category are dried paint chips or containers filled with dried paint. This category does not include waste that is $50 \%$ by volume, or more, paint-related solids, such as empty paint cans, depressurized spray paint cans, or other painting equipment (brushes, rollers, etc.). The appropriate debris category (see Section 5.4.3) would be selected for this waste. Pressurized spray paint cans are categorized as Compressed Gases/Aerosols (X7700) (see Section 5.5.2).

\section{S3132 Paint Sludges}

This specific-detailed category includes waste that is at least $50 \%$ by volume paint sludge. An example of waste that might be included in this category is opened or unopened cans of heavy, viscous paint. Paints cut sufficiently with thinners (i.e., TSS $<<30 \%$ ) would 
be more correctly considered liquids and categorized appropriately depending on whether packaged in bulk or lab packed (see Sections 5.3 or 5.5.1).

\section{S3139 Unknown/Other Paint Waste}

This unknown/other-detailed category includes waste that is consistent with the definition for the Paint Waste (S3130) summary category, but:

- Is insufficiently characterized to enable more definitive assignment into either of the S3131 or S3132 specific-detailed categories, or

- Does not meet the criteria for assignment into either of the S3131 or S3132 specific-detailed categories.

\section{S3140 Salt Waste}

This summary category includes waste that is at least $50 \%$ by volume salts, including interstitial liquids, if present. The appropriate detailed MPCs for this waste are selected from the following categories.

\section{S3141 Chloride Salts}

This specific-detailed category includes waste that is at least $50 \%$ by volume salts and contains more than trace (i.e., $>1,000 \mathrm{ppm}$ ) levels of chlorides or other halogens.

\section{S3142 Sulfate Salts}

This specific-detailed category includes waste that is at least $50 \%$ by volume salts and contains more than trace (i.e., $>1,000 \mathrm{ppm}$ ) levels of sulfur compounds.

\section{S3143 Nitrate Salts}

This specific-detailed category includes waste that is at least $50 \%$ by volume salts. The salts are predominantly (i.e, $>50 \%$ by volume of salt) nitrates.

\section{S3144 Metal Oxides/Hydroxides}

This specific-detailed category includes waste that is at least $50 \%$ by volume metal oxides or hydroxides. Metal oxides resulting from roasting or other treatment processes are included in this category. Solid materials generated from the calcination of liquids, such as high-level waste calcine at the Idaho National Engineering Laboratory, are also included in this category. An example of metal hydroxides included in this category is dry chemical reagents such as sodium hydroxide. Metal hydroxide precipitation sludges should not be assigned to this category; these should be assigned to the appropriate Inorganic Sludges (S3120s) category.

\section{S3149 Unknown/Other Salt Waste}

This unknown/other-detailed category includes waste that is consistent with the definition for the Salt Waste (S3140) summary category, but:

- Is insufficiently characterized to enable more definitive assignment into one of the S3141 through S3144 specific-detailed categories, or

- Does not meet the criteria for assignment into one of the S3141 through S3144 specific-detailed categories. 


\section{S3150 Solidified Homogeneous Solids}

This specific-detailed category includes waste that is at least $50 \%$ by volume solidified forms that require further treatment before disposal. An example might be a particulate or sludge waste that has been immobilized with cement and cured into a solidified form, but that does not meet LDR treatment standards, if applicable, or other relevant disposal criteria.

\section{S3160 Inorganic Chemicals}

This specific-detailed category includes waste that is at least $50 \%$ by volume discarded inorganic solid chemicals that do not meet the criteria for assignment into a more prescriptive Inorganic Homogeneous Solids category. The inorganic chemicals may be particulate- or granular-type materials, or monolithic-type chunks.

Only inorganic chemicals packaged in bulk, free form (e.g., drum, tank) are included in this category. Inorganic chemicals packaged as lab packs, or that are in temporary storage and will be packaged as lab packs before transfer to long-term storage or treatment, are assigned to other MPCs (see Section 5.5.1). Inorganic chemicals that meet the criteria for assignment into a more prescriptive Inorganic Homogeneous Solids category should be categorized as such. (For example, bulk sodium chloride should be assigned to category S3141).

\section{S3190 Unknown/Other Inorganic Homogeneous Solids}

This unknown/other-detailed category includes waste that is consistent with the definition for the Inorganic Homogeneous Solids (S3100) summary category, but:

- Is insufficiently characterized to enable evaluation per the criteria of the $\$ 3110$ through S3140 summary categories and the S3150 and S3160 specific-detailed categories, or

- Does not meet the criteria specified for any of the S3110 through S3140 summary categories or the $\$ 3150$ and $\mathbf{S 3 1 6 0}$ specific-detailed categories.

\section{S3200 Organic Homogeneous Solids}

Homogeneous solids with a base structure that is primarily organic such that a maximum of approximately $20 \%$ by weight would remain as residue (i.e., ash or solids) following incineration are defined in this guidance as organic. This summary category includes waste that is at least $50 \%$ by volume organic homogeneous solids.

As shown in Figure 5-4, this waste is further evaluated per the criteria of the Organic Particulates (S3210) and Organic Sludges (S3220) summary MPCs, and the Organic Chemicals (S3230) specific-detailed MPC. ' Organic homogeneous solids that are insufficiently characterized to enable this evaluation or that do not meet the criteria specified for any of these categories are assigned the Unknown/Other Organic Homogeneous Solid (S3290) detailed category.

\section{S3210 Organic Particulates}

This summary category includes waste that is at least $50 \%$ by volume organic particulates, including any residual or absorbed liquids. Examples of organic particulates are certain resins used in wastewater treatment and particulate organic absorbent materials. The appropriate detailed MPCs for this waste are selected from the following categories. 


\section{S3211 Organic Resins}

This specific-detailed category includes waste that is primarily (e.g., $\geq 50 \%$ by volume) spent or unused organic based resins used in wastewater treatment or other applications. An example of waste that might be included in this category is organic ion-exchange resins.

\section{S3212 Organic Absorbents}

This specific-detailed category includes waste that is primarily (e.g., $\geq 50 \%$ by volume) organic particulate absorbent materials, including any absorbed aqueous or organic liquids. Examples of organic particulate absorbents are sawdust and ground corn cobs.

\section{S3219 Unknown/Other Organic Particulates}

This unknown/other-detailed category includes waste that is consistent with the definition for the Organic Particulates (\$3210) summary category, but:

- Is insufficiently characterized to enable more definitive assignment into either of the S3211 or S3212 specific-detailed categories, or

- Does not meet the criteria for assignment into either of the $\$ 3211$ or $\$ 3212$ specific-detailed categories.

\section{S3220 Organic Sludges}

This summary category includes waste that is at least $50 \%$ by volume organic sludges, including liquids, if present. Examples of waste included in this category are biological sludges and heavy, unpourable organic materials, such as tars or greases. The appropriate detailed MPCs for this waste are selected from the following categories.

\section{S3221 Biological Sludges}

This specific-detailed category includes waste that is at least $50 \%$ by volume biological materials generated in treating wastewater from animals or people, or other biological materials that cannot be classified as debris.

\section{S3222 Halogenated Organic Sludges}

This specific-detailed category includes waste that is at least $50 \%$ by volume organic sludges that contain at least $1,000 \mathrm{ppm}$ HOC.

\section{S3223 Nonhalogenated Organic Sludges}

This specific-detailed category includes waste that is at least $50 \%$ by volume organic sludges that contain less than 1,000 ppm HOC.

\section{S3229 Unknown/Other Organic Sludges}

This unknown/other-detailed category includes waste that is consistent with the definition for the Organic Sludges (S3220) summary category, but:

- Is insufficiently characterized to enable more definitive assignment into one of the S3221 through S3223 specific-detailed categories, or

- Does not meet the criteria for assignment into one of the S3221 through S3223 specific-detailed categories. 



\section{S4900 Unknown/Other Soil/Gravel}

This unknown/other-detailed category includes waste that is consistent with the definition for the Soil/Gravel (S4000) summary category, but:

- Is insufficiently characterized to enable more definitive assignment into one of the $\$ 4100$ through $\mathbf{\$ 4 3 0 0}$ specific-detailed categories, or

- Does not meet the criteria for assignment into one of the $\$ 4100$ through $\$ 4300$ specific-detailed categories.

\subsubsection{S5000 DEBRIS WASTE}

This summary category includes waste that is at least $50 \%$ by volume materials that meet the EPA LDR criteria for classification as debris. These criteria are as follows:

"Debris means solid material exceeding a $60 \mathrm{~mm}$ particle size that is intended for disposal and that is: 1) a manufactured object, or 2) plant or animal matter, or 3) natural geologic material. However, the following materials are not debris: 1) any material for which a specific treatment standard is provided in Subpart D, Part 268, 2) process residuals such as smelter slag and residues from the treatment of waste, wastewater, sludges, or air emission residues; and 3) intact containers of hazardous waste that are not ruptured and that retain at least $75 \%$ of their original volume. A mixture of debris that has not been treated to the standards provided by $\$ 268.45$ and other material is subject to regulation as debris if the mixture is comprised primarily of debris, by volume, based on visual inspection." [40 CFR $\$ 268.2(\mathrm{~g})]$

While specifically written to address EPA regulated hazardous debris, these criteria, particularly particle size, are equally applicable to nonhazardous waste.

This summary category includes waste that is at least $50 \%$ by volume materials that meet the above criteria. The balance of the matrix may be other physical or chemical waste forms. For example, the drum of spill cleanup waste discussed in the definition for Homogeneous Solids (S3000) (see Section 5.4.1) would be assigned to the appropriate debris category, provided the debris materials account for at least $50 \%$ of the bulk matrix volume.

As shown in Figure 5-5, this waste is further evaluated per the criteria of the Inorganic Debris (\$5100), Organic Debris (S5300), and Heterogeneous Debris (S5400) summary categories. Debris that is insufficiently characterized to enable this evaluation is assigned the Unknown/Other Debris (S5900) detailed category.

\section{S5100 Inorganic Debris}

This summary category includes waste that is estimated to be $80 \%$ by volume, or more, inorganic debris materials. Examples of inorganic debris materials include scrap metal, concrete, brick, and glass.

As shown in Figure 5-5, this waste is further evaluated per the criteria of the Metal Debris (S5110) and Inorganic Nonmetal Debris (S5120) summary categories. Inorganic debris that is insufficiently characterized to enable this evaluation, or that does not meet the criteria specified for either of these summary categories is assigned to the Unknown/Other Inorganic Debris (\$5190) detailed category. 
Figure 5-5. Matrix Parameter Categories - Debris

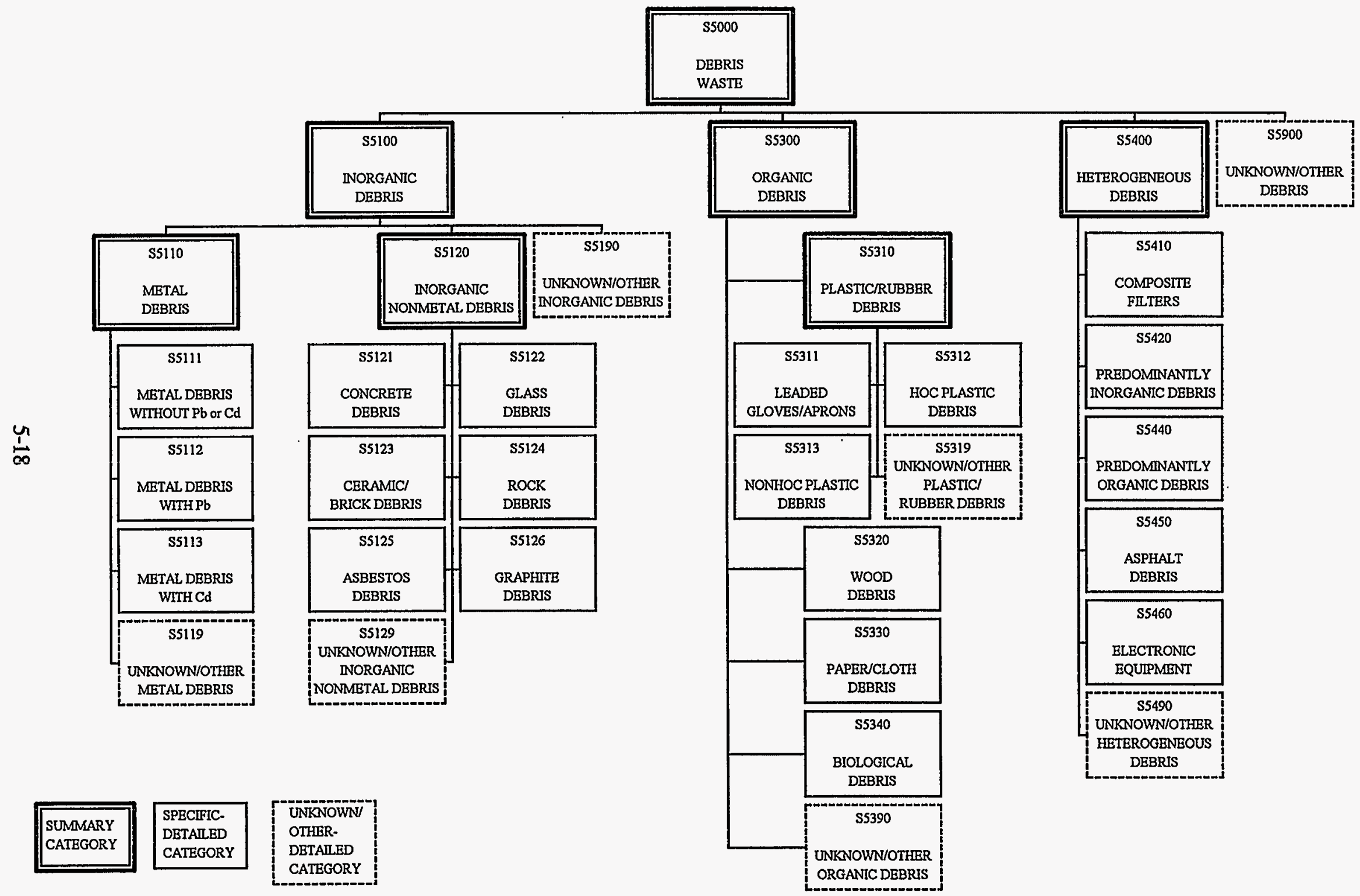




\section{S5110 Metal Debris}

This summary category includes waste that is estimated to be $80 \%$ by volume, or more, metal debris materials. The appropriate detailed MPCs for this waste are selected from the following categories.

\section{S5111 Metal Debris without Pb or Cd}

This specific-detailed category includes waste that is estimated to be $80 \%$ by volume, or more, metal debris and does not contain any bulk, separable or bonded, lead or cadmium as part of the matrix.

\section{S5112 Metal Debris with Pb}

This specific-detailed category includes waste that is estimated to be $80 \%$ by volume, or more, metal debris and contains bulk, separable or bonded, lead as part of the matrix. Examples of waste that might be included in this category are glovebox parts with lead clad in stainless steel or scrap metal that includes some lead bricks. This category does not include waste that meets the criteria for categorization as elemental lead (i.e., $\geq 50 \%$ by volume elemental lead) or lead acid batteries (see Section 5.5 ).

\section{S5113 Metal Debris with Cd}

This specific-detailed category includes waste that is estimated to be $80 \%$ by volume, or more, metal debris and contains bulk, separable or bonded, cadmium as part of the matrix. This category does not include waste that meets the criteria for categorization as elemental cadmium (i.e., $\geq 50 \%$ by volume elemental cadmium) or cadmium batteries (see Section 5.5).

\section{S5119 Unknown/Other Metal Debris}

This unknown/other-detailed category includes waste that is consistent with the definition for the Metal Debris (S5110) summary category, but:

- Is insufficiently characterized to enable more definitive assignment into one of the S5111 through S5113 specific-detailed categories, or

- Contains both lead and cadmium, separable or bonded, as part of the bulk matrix.

\section{S5120 Inorganic Nonmetal Debris}

This summary category includes waste that is estimated to be $80 \%$ by volume, or more, inorganic nonmetal debris. The appropriate detailed MPCs for this waste are selected from the following categories.

\section{S5121 Concrete Debris}

This specific-detailed category includes waste that is estimated to be $80 \%$ by volume, or more, concrete debris. An example of waste that might be included in this category is concrete chunks and blocks from decontamination and decommissioning activities. This category does not include waste solidified with cement or other stabilization agents (see Sections 5.4.1 and 5.6.1). 


\section{S5122 Glass Debris}

This specific-detailed category includes waste that is estimated to be $80 \%$ by volume, or more, glass debris. Examples of waste that might be included in this category are leaded glass windows, bottles, or lightbulbs.

\section{S5123 Ceramic/Brick Debris}

This specific-detailed category includes waste that is estimated to be $80 \%$ by volume, or more, ceramic or brick debris materials. Examples of waste that might be included in this category are bricks, ceramic crucibles, and ceramic refractories.

\section{S5124 Rock Debris}

This specific-detailed category includes waste that is estimated to be $80 \%$ by volume, or more, rock or gravel materials provided the particle size meets the EPA LDR criteria for classification as debris.

\section{S5125 Asbestos Debris}

This specific-detailed category includes waste that is estimated to be $80 \%$ by volume, or more, asbestos or asbestos-based debris materials. Examples of waste that might be included in this category are asbestos-containing gloves, firehoses, aprons, flooring tiles, pipe insulation, boiler jackets, and laboratory tabletops.

\section{S5126 Graphite Debris}

This specific-detailed category includes waste that is estimated to be $80 \%$ by volume, or more, graphite-based debris materials. Examples of waste that might be included in this category are crucibles, graphite components, and pure graphite.

\section{S5129 Unknown/Other Inorganic Nonmetal Debris}

This unknown/other-detailed category includes debris that is consistent with the definition for the Inorganic Nonmetal Debris (S5120) summary category, but:

- Is insufficiently characterized to enable more definitive assignment into one of the S5121 through S5126 specific-detailed categories, or

- Does not meet the criteria for assignment into one of the S5121 through S5126 specific-detailed categories.

\section{S5190 Unknown/Other Inorganic Debris}

This unknown/other-detailed category includes waste that is consistent with the definition for the Inorganic Debris (S5100) summary category, but:

- Is insufficiently characterized to enable evaluation per the criteria of the Metal Debris (S5110) and Inorganic Nonmetal Debris (S5120) summary categories, or

- Does not meet the criteria specified for either of the Metal Debris (S5110) or Inorganic Nonmetal Debris (S5120) summary categories.

\section{S5300 Organic Debris}

This summary category includes waste that is estimated to be $80 \%$ by volume, or more, organic debris materials. Examples of organic debris are materials constructed of plastic, rubber, wood, paper, cloth, and biological materials. 
As shown in Figure 5-5, this waste is further evaluated per the criteria of the Plastic/Rubber Debris (S5310) summary category and the Wood Debris (S5320), Paper/Cloth Debris (S5330), and Biological Debris (S5340) specific-detailed categories. Organic debris that is insufficiently characterized to enable this evaluation, or that does not meet the criteria specified for any of these categories is assigned the Unknown/Other Organic Debris (S5390) detailed category.

\section{S5310 Plastic/Rubber Debris}

This summary category includes waste that is estimated to be $80 \%$ by volume, or more, plastic or rubber debris materials. Examples of plastic and rubber debris materials are plastic or rubber sheeting, containers, gloves, gaskets, and components of benelex or plexiglass. The appropriate detailed MPCs for this waste are selected from the following categories.

\section{S5311 Leaded Gloves/Aprons}

This specific-detailed category includes waste that is estimated to be $80 \%$ by volume, or more, rubber debris materials that contain a high fraction of lead or lead compounds. Examples of waste that might be included in this category are leaded glovebox gloves or aprons.

\section{S5312 Halogenated Plastic Debris}

This specific-detailed category includes waste that is estimated to be $80 \%$ by volume, or more, plastic or rubber debris materials that contain halogenated plastics, such as PVC, as part of the matrix.

\section{S5313 Nonhalogenated Plastic Debris}

This specific-detailed category includes waste that is estimated to be $80 \%$ by volume, or more, plastic or rubber debris materials, excluding leaded gloves and aprons, that do not contain halogenated plastics as part of the matrix.

\section{S5319 Unknown/Other Plastic/Rubber Debris}

This unknown/other-detailed category includes waste that is consistent with the definition for the Plastic/Rubber Debris (S5310) summary category, but:

- Is insufficiently characterized to enable more definitive assignment into one of the S5311 through S5313 specific-detailed categories, or

- Does not meet the criteria for assignment into one of the S5311 through S5313 specific-detailed categories.

\section{S5320 Wood Debris}

This specific-detailed category includes debris that is estimated to be $80 \%$ by volume, or more, wood or wood products other than paper. Examples of waste that might be included in this category are structural timbers, boxes, or pallets.

\section{S5330 Paper/Cloth Debris}

This specific-detailed category includes waste that is estimated to be $80 \%$ by volume, or more, paper or cloth debris materials. Examples of waste that might be included in this category are protective clothing, rags, or wipes. Rags and wipes may contain some absorbed organic or aqueous liquids. 


\section{S5340 Biological Debris}

This specific-detailed category includes waste that is estimated to be $80 \%$ by volume, or more, biological debris materials, including any chemical agents such as lime or formaldehyde. Examples of waste that might be included in this category are biological samples and animal carcasses.

\section{S5390 Unknown/Other Organic Debris}

This unknown/other-detailed category includes waste that is consistent with the definition for the Organic Debris (S5300) summary category, but:

- Is insufficiently characterized to enable evaluation per the criteria of the S5310 summary category and the $\mathbf{S 5 3 2 0}$ through $\mathbf{S 5 3 4 0}$ specific-detailed categories, or

- Does not meet the criteria specified for the $\$ 5310$ summary category or any of the S5320 through S5340 specific-detailed categories.

\section{S5400 Heterogeneous Debris}

This summary category includes waste that is at least $50 \%$ by volume debris materials that do not meet the criteria for assignment as either an Inorganic Debris (S5100) or Organic Debris (S5300). An example is waste that is essentially entirely debris, but is not dominant (i.e., estimated to be $80 \%$ by volume or more) in either inorganic or organic debris materials. Another example is waste that is at least $50 \%$ by volume debris materials, with the balance being soil or homogeneous solids. The appropriate detailed MPCs for this waste are selected from the following categories.

\section{S5410 Composite Filter Debris}

This specific-detailed category includes debris that is estimated to be $50 \%$ by volume, or more, high-efficiency particulate air filters (HEPA) or other filters constructed of more than one material type (e.g., metal, inorganic nonmetal, and organic materials). Filters constructed of a single material type are assigned into the appropriate inorganic, organic, or heterogeneous debris category depending on the composition of the entire waste matrix.

\section{S5420 Predominantly Inorganic Debris}

This specific-detailed category includes waste that is estimated to contain at least $50 \%$, but less than $80 \%$, by volume inorganic debris materials. The balance of the matrix may be organic debris materials, soil, or homogeneous solids.

\section{S5440 Predominantly Organic Debris}

This specific-detailed category includes waste that is estimated to contain at least $50 \%$, but less than $80 \%$, by volume organic debris materials. The balance of the matrix may be inorganic debris materials (i.e., metal, inorganic nonmetal), soil, or homogeneous solids.

\section{S5450 Asphalt Debris}

This specific-detailed category includes debris that is estimated to be $50 \%$ by volume, or more, asphalt or other bituminous materials. Examples of waste that might be included in this category are asphalt materials from roadways, shingles, bituminous cement, or other materials containing both tar and gravel.

\section{S5460 Electronic Equipment}

This specific-detailed category includes waste that is estimated to be $50 \%$ by volume, or more, electronic equipment constructed of more than one material type (e.g., metal, inorganic 
nonmetal, and organic materials). Examples may include circuit boards, electronic laboratory equipment, computers and ancillary equipment, process controllers, etc. Electronic equipment constructed of a single material type is assigned into the appropriate inorganic, organic, or heterogeneous debris category depending on the composition of the entire waste matrix.

\section{S5490 Unknown/Other Heterogeneous Debris}

This unknown/other-detailed category includes waste that is consistent with the definition for the Heterogeneous Debris (S5400) summary category, but:

- Is insufficiently characterized to enable more definitive assignment into any of the S5410, S5420, S5440, S5450, or S5460 specific-detailed categories, or

- Does not meet the criteria for assignment into any of the S5410, S5420, S5440,S5450, or $\$ 5460$ specific-detailed categories.

\section{S5900 Unknown/Other Debris}

This unknown/other-detailed category includes waste that is consistent with the definition for the Debris (S5000) summary MPC, but insufficiently characterized to enable evaluation per the criteria of the Inorganic Debris (S5100), Organic Debris (S5300), and Heterogeneous Debris (S5400) summary categories (i.e., insufficient data exist to estimate whether the waste is $80 \%$ by volume, or more, inorganic or organic debris materials).

\subsubsection{S9000 UNKNOWN/OTHER SOLIDS}

This unknown/other-detailed category includes waste that is consistent with the definition for the Solids (S) summary category, but:

- Is insufficiently characterized to enable evaluation per the criteria of the Homogeneous Solids (S3000), Soil/Gravel (S4000), and Debris (S5000) summary categories, or

- Does not meet the criteria for any of the Homogeneous Solids (S3000), Soil/Gravel (S4000), or Debris (S5000) summary categories.

\subsection{DEFINITIONS - SPECIFIC WASTE FORMS AND ASSOCIATED CATEGORIES}

The initial Specific Waste Forms (X) summary category addresses waste that is of certain specific forms. These forms include waste with matrices that are liquids, solids, or combinations of both. As shown in Figure 5-6, specific waste forms are initially evaluated per the criteria of the Lab Packs (X6000) and Special Waste (X7000) summary categories.

\subsubsection{X6000 LAB PACKS}

Per this guidance, a lab pack configuration is defined as two or more waste containers packaged within a larger outer container. Typically, the inner containers are surrounded by absorbent materials; however, this is not an absolute criterion. If present, the absorbents can be homogeneous solids or debris materials. Examples may include rags, vermiculite, diatomaceous earth, and paper wipes.

This summary category includes waste that either (a) is packaged as a lab pack upon generation, or (b) will be packaged as a lab pack before transfer to long-term storage or treatment. The reason for inclusion of the second item is that many sites maintain inventories of small waste volumes (e.g., 
excessed or expired chemicals) in temporary storage. Often, this waste is lab packed before transfer for long-term storage or treatment.

This category does not include lab packs of elemental liquid mercury (see Section 5.5.2) or paint waste (see Section 5.4.1). In addition, waste packaged in a lab pack configuration that is considered overpacked is excluded. A typical example of an overpack is a single 55-gallon drum of waste that is placed in a 85-gallon drum because of deterioration of the 55-gallon container. This waste should be assigned the appropriate category based on the waste within the inner, overpacked container(s). The appropriate detailed MPCs for lab packs are selected from the following categories.

\section{X6100 Organic Lab Packs}

This specific-detailed category includes lab packs for which the inner waste packages contain only organic liquids. This category does not include organic scintillation fluids in containers (i.e., vials) that are packaged in a lab pack configuration.

\section{X6200 Aqueous Lab Packs}

This specific-detailed category includes lab packs for which the inner waste packages contain only aqueous liquids. This category does not include aqueous scintillation fluids in containers (i.e., vials) that are packaged in a lab pack configuration.

\section{X6300 Solid Lab Packs}

This specific-detailed category includes lab packs for which the inner waste packages contain only solid chemicals or other solid materials.

\section{X6400 Scintillation Cocktails}

This specific-detailed category includes scintillation fluids in containers (i.e., vials) that are packaged in a lab pack configuration.

\section{X6900 Unknown/Other Lab Packs}

This unknown/other-detailed category includes waste that is consistent with the definition for the

Lab Packs (X6000) summary category, but:

- Is insufficiently characterized to enable more definitive assignment into one of the X6100 through X6400 specific-detailed categories, or

- Does not meet the criteria for assignment into one of the X6100 through X6400 specific-detailed categories.

\subsubsection{X7000 SPECIAL WASTE}

In general, this summary category includes waste that (a) is inherently hazardous (i.e., the bulk material itself is RCRA hazardous), often with specific LDR treatment technology requirements, or (b) presents unique treatment concerns. As shown in Figure 5-6, this waste is further evaluated per the criteria of the Elemental Hazardous Metals (X7200), Batteries (X7400), and Reactive Metals (X7500) summary categories, and the Elemental Mercury (X7100), Beryllium Dust (X7300), Explosives/Propellants (X7600), and Compressed Gases/Aerosols (X7700) specific-detailed categories. Special waste that does not meet the criteria specified for any of these categories is assigned to the Unknown/Other Special Waste (X7900) detailed category. 
Figure 5-6. Matrix Parameter Categories - Specific Waste Forms

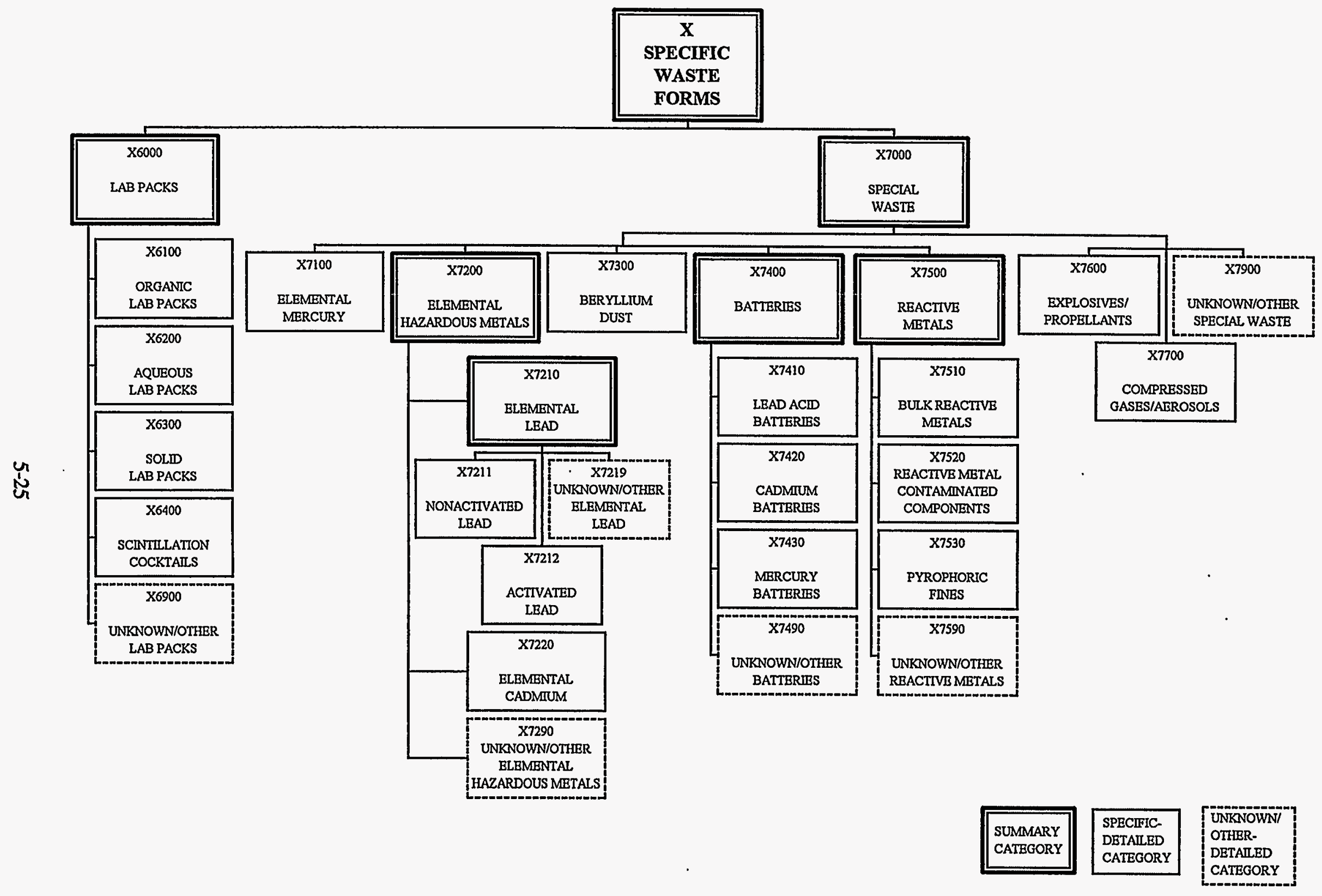




\section{X7100 Elemental Mercury}

This specific-detailed category includes waste that is bulk, pourable liquid mercury. The liquid mercury may be packaged in a lab pack configuration. Manometers, or other equipment, that contain small residual amounts of mercury should be assigned to the appropriate debris category (see Section 5.4.3).

\section{X7200 Elemental Hazardous Metals}

This summary category includes waste that contains at least $50 \%$ by volume solid, bulk elemental hazardous metals that meet the EPA size criteria for classification as debris. Waste that contains at least $50 \%$ by volume solid, bulk elemental hazardous metals that do not meet the EPA size criteria for classification as debris are assigned into the Metal Chips/Turnings (S3116) category. Also, beryllium dust is excluded from this category (X7300).

This waste is further evaluated per the criteria of the Elemental Lead (X7210) summary MPC and the Elemental Cadmium (X7220) specific-detailed MPC. Elemental hazardous metals that do not meet the criteria specified for either of these two categories are assigned to the Unknown/Other Elemental Hazardous Metals (X7290) detailed category.

\section{X7210 Elemental Lead}

This summary category includes waste that contains at least $50 \%$ by volume bulk elemental lead. Examples of waste in this category are lead bricks, sheets, and pipes. The appropriate detailed MPCs for this waste are selected from the following categories.

\section{X7211 Nonactivated Lead}

This specific-detailed category includes waste meeting the above criteria for categorization as elemental lead in which the elemental lead shapes are only surface contaminated with radionuclides.

\section{X7212 Activated Lead}

This specific-detailed category includes waste meeting the above criteria for categorization as elemental lead in which the elemental lead shapes are activated.

\section{X7219 Unknown/Other Elemental Lead}

This unknown/other-detailed category includes waste that is consistent with the definition of the Elemental Lead (X7210) summary category, but it is not known whether the lead is activated or nonactivated. This category also includes elemental lead that is not radioactive.

\section{X7220 Elemental Cadmium}

This specific-detailed category includes waste that contains at least $50 \%$ by volume bulk elemental cadmium. Examples of waste in this category are cadmium bricks, sheets, and pipes.

\section{X7290 Unknown/Other Elemental Hazardous Metals}

This unknown/other-detailed category includes waste that contains at least $50 \%$ by volume solid, bulk elemental hazardous metals, other than lead or cadmium, that meet the EPA size criteria for classification as debris. This category also includes waste that is at least $50 \%$ by volume a mixture of two or more bulk elemental hazardous metals that meet the EPA size criteria for classification as debris. 
X7300 Beryllium Dust

This specific-detailed category includes beryllium waste that is subject to the metal recovery treatment standard as specified in the Third Third LDR rule (55 FR 22545). Waste contaminated with beryllium but not subject to the metal recovery treatment standard should be assigned to the appropriate category based on the bulk matrix composition.

\section{X7400 Batteries}

This summary category includes waste consisting of batteries. The batteries may be packaged with absorbent materials (e.g., particulates, rags). The appropriate detailed MPCs for this waste are selected from the following categories.

\section{X7410 Lead Acid Batteries}

This specific-detailed category addresses battery waste as defined for the X7400 summary category in which only drained or undrained lead acid batteries are included.

\section{X7420 Cadmium Batteries}

This specific-detailed category addresses battery waste as defined for the X7400 summary category in which only cadmium batteries are included.

\section{X7430 Mercury Batteries}

This specific-detailed category addresses battery waste as defined for the X7400 summary category in which only mercury batteries are included.

\section{X7490 Unknown/Other Batteries}

This unknown/other-detailed category includes waste that is consistent with the definition for the Batteries (X7400) summary category, but:

- Is insufficiently characterized to enable more definitive assignment into one of the X7410 through X7430 specific-detailed categories, or

- Does not meet the criteria for assignment into any one of the X7410 through X7430 specific-detailed categories.

\section{X7500 Reactive Metals}

This summary category includes reactive metals waste. In this guidance, reactive metals are defined as waste meeting the criteria for classification as water reactive or ignitable reactive per the Third Third LDR rule (55 FR 22545 and 22553). Typically, this waste is sodium metal or sodium metal alloys, but can also include particulate fines of aluminum, uranium, zirconium, or other pyrophoric materials. The waste may be mixed with stabilizing materials. The appropriate detailed MPCs for this waste are selected from the following categories.

\section{X7510 Bulk Reactive Metals}

This specific-detailed category includes waste that is essentially bulk reactive metals and meets the criteria for classification as water reactive per the Third Third LDR rule. Typically, this waste is sodium metal or sodium metal alloys.

\section{X7520 Reactive Metal Contaminated Components}

This specific-detailed category includes piping, pumps, and other retired equipment waste that is considered water reactive per the Third Third LDR rule because of reactive metal 
contamination. The bulk of the material is not reactive metals, but the reactive metals require treatment before disposal.

\section{X7530 Pyrophoric Fines}

This specific-detailed category includes waste that is essentially bulk materials that meet the criteria for classification as ignitable reactive per the Third Third LDR rule. Examples are fines of aluminum, uranium, zirconium, or other pyrophoric materials. The waste may be mixed with stabilizing materials.

\section{X7590 Unknown/Other Reactive Metals}

This unknown/other-detailed category includes reactive metal waste with characteristics that are not consistent with the definitions for the X7510 through X7530 specific-detailed MPCs.

\section{X7600 Explosives/Propellants}

This specific-detailed category includes waste consisting of substances that undergo rapid chemical transformations that produce large amounts of gases and heat. The gases rapidly expand at velocities exceeding the speed of sound (due to the heat of reaction), which creates a shock wave and explosion. Waste that meets this definition should be identified here regardless of the specific physical form. Liquid nitroglycerine, for instance, should be categorized as an explosive and not as an organic liquid. Similarly, TNT would be categorized as explosive rather than as a homogeneous solid.

\section{X7700 Compressed Gases/Aerosols}

This specific-detailed category includes waste consisting of pressurized gas cylinders, including aerosols. Waste consisting of depressurized gas cylinders or aerosol cans would not be assigned to this category. This waste would be assigned to the appropriate debris category (see Section 5.4.3).

\section{X7900 Unknown/Other Special Waste}

This unknown/other-detailed category includes waste that is consistent with the definition for the Special Waste (X7000) summary category, but inconsistent with the definitions for the X7200, $X 7400$, and X7500 summary categories and the $X 7100, X 7300, X 7600$, and X7700 specific-detailed categories.

\subsection{DEFINITIONS - FINAL WASTE FORMS AND ASSOCIATED CATEGORIES}

The initial Final Waste Forms $(Z)$ summary category addresses waste that is in final form and meets applicable disposal criteria, including applicable LDR and PCB treatment standards. The final waste form categories currently defined in this guidance are shown in Figure 5-7. These categories are primarily intended for assignment to final waste forms resulting from the treatment of hazardous or mixed waste. Typically, preparing radioactive or sanitary waste for disposal does not require the rigorous treatments that produce these final waste forms. In other words, the final disposable forms of these primary waste types may be one of the previously defined solid MPCs (see Section 5.4). However, if applicable, the final waste form MPCs may be applied to waste other than that resulting from treatment of hazardous or mixed waste.

As shown in Figure 5-7, final waste forms are initially evaluated per the criteria of the Immobilized Forms (Z1000) and Decontaminated Solids (Z2000) summary categories. Final waste forms that do not meet the criteria specified for either of these summary categories are assigned to the Other Final Forms (Z9000) detailed category. 
Figure 5-7. Matrix Parameter Categories - Final Waste Forms

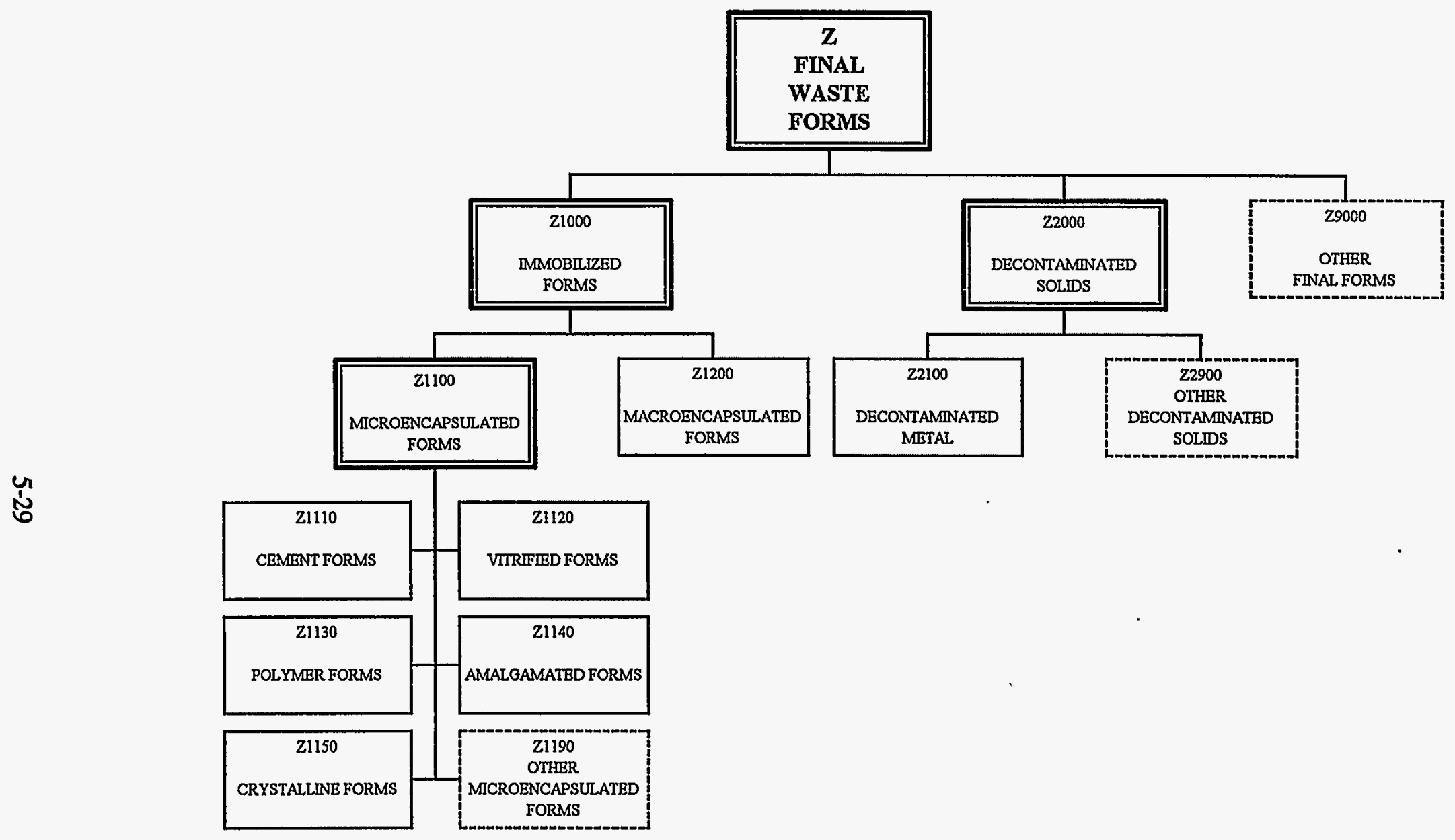




\subsubsection{Z1000 IMMOBILIZED FORMS}

This summary category includes waste forms that are immobilized. Immobilized final forms are further evaluated per the criteria of the Microencapsulated Forms (Z1100) and Macroencapsulated Forms (Z1200) categories. As defined in this guidance, the key distinction between microencapsulation and macroencapsulation is the matrix characteristics of the waste before immobilization. In general, immobilized forms resulting from the treatment of liquids and slurries, or solids with relatively small particle sizes (e.g., not meeting the EPA particle size criteria for classification as debris) are considered microencapsulated. Immobilized forms resulting from the treatment of solids with large particle sizes (e.g., debris) are considered macroencapsulated. This represents a deviation from more stringent definitions of microencapsulation used by the EPA and others.

\section{Z1100 Microencapsulated Forms}

This summary category includes waste that has been immobilized via microencapsulation. The appropriate detailed MPCs for this waste are selected from the following categories.

\section{Z1110 Cement Forms}

This specific-detailed category includes waste that has been immobilized with grout or other cement-type binders.

\section{Z1120 Vitrified Forms}

This specific-detailed category includes waste that has been immobilized via vitrification.

\section{Z1130 Polymer Forms}

This specific-detailed category includes waste that has been microencapsulated with organic binders.

\section{Z1140 Amalgamated Forms}

This specific-detailed category includes waste that has been immobilized via amalgamation.

\section{Z1150 Crystalline Forms}

This specific-detailed category includes waste that has been immobilized via methods that produce a crystalline final waste form. Example methods are microwave solidification and the Synrock process.

\section{Z1190 Other Microencapsulated Forms}

This unknown/other-detailed category includes microencapsulated forms other than those addressed by the Z1110 through Z1150 specific-detailed categories.

\section{Z1200 Macroencapsulated Forms}

This specific-detailed category includes waste that has been immobilized via macroencapsulation.

\subsubsection{Z2000 DECONTAMINATED SOLIDS}

This summary category includes waste that has been decontaminated and is ready for disposal or recycling. The appropriate detailed MPCs for this waste are selected from the following categories.

\section{Z2100 Decontaminated Metal}

This specific-detailed category includes metal waste that has been decontaminated and is ready for disposal or recycling. 
Z2900 Other Decontaminated Solids

This unknown/other-detailed category includes waste, other than metal materials, that has been decontaminated and is ready for disposal or recycling.

\subsubsection{Z9000 OTHER FINAL FORMS}

This unknown/other-detailed category includes final waste forms other than immobilized forms and decontaminated solids.

\subsection{DEFINITION - UNKNOWN/OTHER MATRIX (U9999) CATEGORY}

This category includes waste for which insufficient characterization is known to enable evaluation per the criteria of the initial Liquids (L), Solids (S), Specific Waste Form (X), and Final Waste Form (Z) summary categories, or waste that does not meet the criteria specified for any of those categories. 


\section{REGULATED CONTAMINANT PARAMETER}

This section presents the regulated contaminant parameter categories (CPCs) and definitions. This parameter is only considered in treatability group assignments for the hazardous and mixed primary waste types. The CPC serves to indicate the regulatory classification of the waste. In addition, for waste regulated by the EPA under RCRA, the CPC identifies the type of hazardous contaminants or characteristics associated with the waste. The type of hazardous contaminants or characteristics influences the management, particularly treatment, needs of the waste from both a regulatory and technical perspective.

\subsection{OVERVIEW OF REGULATED CONTAMINANT CATEGORIES}

Similar to the RPCs discussed in Section 4, the CPCs are defined by one or more components. These components are shown in Figure 6-1. The initial component designates the regulatory classification of the waste. As discussed in Section 2, there are six regulatory classifications defined in this guidance. These classifications are RCRA Regulated, TSCA Regulated, RCRA/TSCA Regulated, State Regulated, RCRA Regulated-Meets LDRs, and Suspect Regulated. With the exception of the RCRA and RCRA/TSCA classifications, the complete CPCs are simply defined by this initial component.

The complete CPCs for RCRA and RCRA/TSCA regulated hazardous or mixed waste include three additional descriptive components. These components address whether the waste is contaminated with EPA regulated hazardous organics or metals, or exhibits the EPA hazardous characteristics of ignitability, corrosivity, and reactivity. As shown in Figure 6-1, each descriptive component has two or more associated elements. The descriptive components are represented in the CPCs by selection of the appropriate element.

Sections 6.2 through 6.7 provide guidelines and definitions for selecting the appropriate regulatory classification component and, if applicable, the associated descriptive component elements. Complete CPCs are defined by a "string" of the regulatory classification component and one element from each associated descriptive component. The generation of complete CPCs is discussed in Section 6.8.

\subsection{RCRA REGULATED WASTE CPC COMPONENTS}

As indicated in Figure 6-1, the CPC begins with the component RC, or RCRA, if the regulatory classification of the hazardous or mixed waste is RCRA Regulated. As defined in Section 2, this is waste that meets all of the following criteria:

- The waste is assigned at least one EPA code for which all LDR treatment standards have either (a) not been met, or (b) not been established

- The waste is not TSCA regulated for PCBs.

The CPCs for this waste are further defined by three descriptive components. As indicated in Figure 6-1, these components address whether the waste is contaminated with EPA regulated hazardous organics or metals, or exhibits the EPA hazardous characteristics of ignitability, corrosivity, and reactivity. Each of these components is represented in the CPCs by selecting one of its associated elements. Selection of the appropriate element to represent each component is based on the EPA codes assigned to the waste and whether or not LDR treatment standards have been established and met. 
Figure 6-1. Regulated Contaminant Parameter Category Components

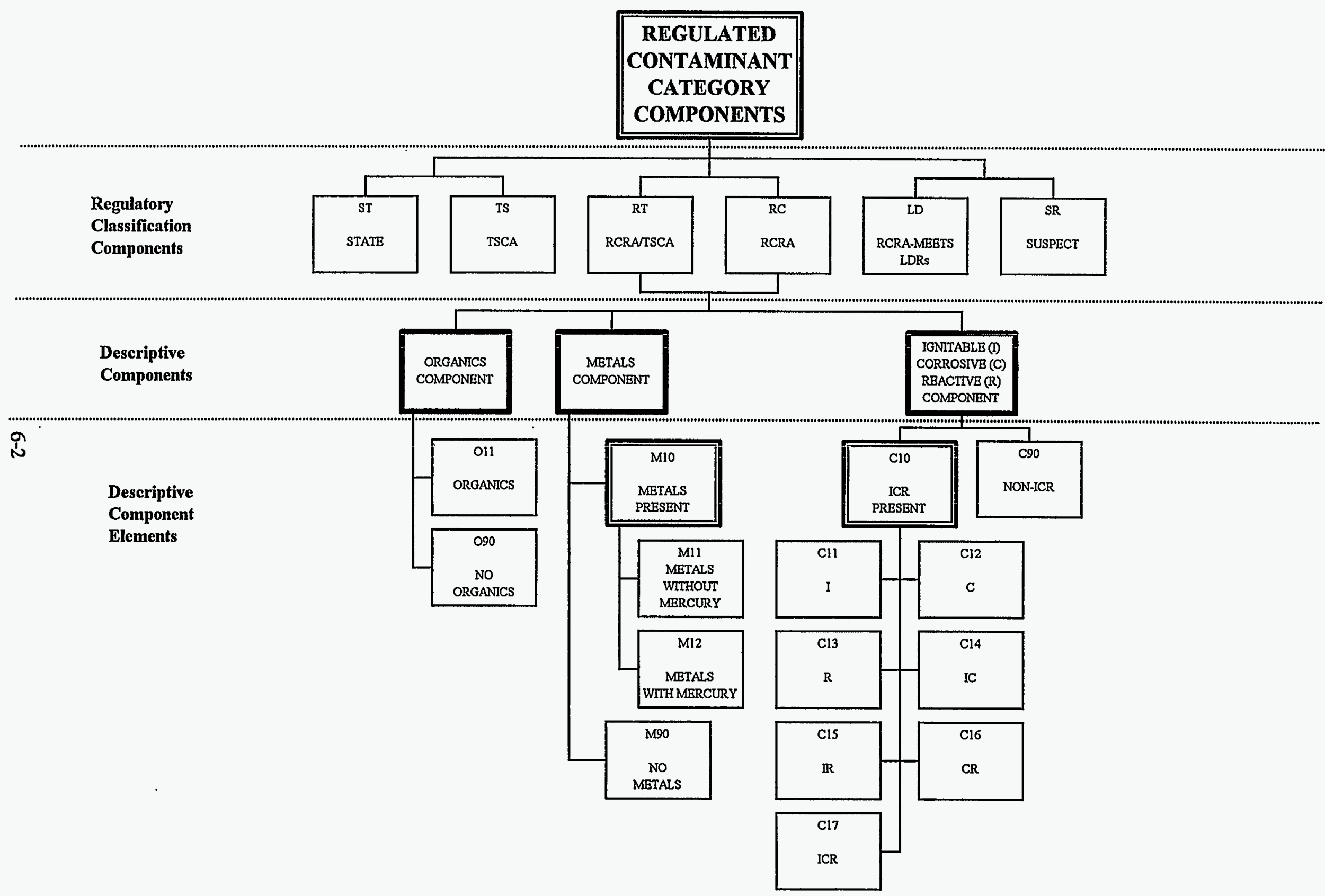


Tables C-1 through C-7 of Appendix $\mathrm{C}$ are provided to facilitate selection of the appropriate elements. These tables present the EPA codes according to the following criteria:

- Indicative of hazardous organic contaminants (Tables C-1 and C-2)

- Indicative of hazardous metal contaminants, excluding mercury (Table C-3)

- Indicative of mercury contamination (Table C-4)

- Indicative of the corrosive characteristic (Table C-5)

- Indicative of the reactive characteristic (Table C-6)

- Indicative of cyanide contamination (Table C-7).

A few listed EPA codes do not map to any of the above criteria. These EPA codes, shown in Table C-8 of Appendix C, include gases and other waste listed by the EPA due solely to toxicity that are not indicative of organics, metals, or cyanides.

\subsubsection{ORGANICS COMPONENT}

The first descriptive component in the CPCs for RCRA regulated waste indicates whether any EPA regulated hazardous organics are present for which LDR treatment standards have not been met or established. This component is represented in the CPC by selecting, as appropriate, one of the two elements described below.

\section{Organics}

The organics component is represented by this element provided that the waste is assigned one or more EPA codes that indicate the presence of hazardous organics for which LDR treatment standards have either (a) not been met, or (b) not been established. Tables C-1 and C-2 in Appendix $C$ provide listings of the EPA codes that would indicate the presence of hazardous organics.

\section{O90 No Organics}

The organics component is represented by this element provided that the waste is not assigned any EPA codes that indicate the presence of hazardous organics for which LDR treatment standards have either (a) not been met, or (b) not been established.

\subsubsection{METALS COMPONENT}

The second descriptive component in the CPCs for RCRA regulated waste indicates whether any EPA regulated hazardous metals are present for which LDR treatment standards have not been met or established. This component is represented in the CPC by selecting, as appropriate, one of the three elements described below.

As shown in Figure 6-1, two of the three elements indicate whether EPA regulated hazardous metals for which LDR treatment standards have not been met or established are present and whether those metals include mercury. These two elements "roll" to a summary element (i.e., M10 METALS PRESENT). This summary element is reserved for performing database rollups of waste containing EPA regulated hazardous metals, regardless of whether the metals include mercury. The summary element is only shown in Figure 6-1 to illustrate this logic and should not be used in assigning the CPC. 
M11 Metals without Mercury

The metals component is represented by this element provided the following two criteria are met:

- The waste is assigned at least one EPA code indicating the presence of hazardous metals, other than mercury, for which LDR treatment standards have either (a) not been met, or (b) not been established

- The waste is not assigned any EPA codes indicating the presence of mercury for which LDR treatment standards have either (a) not been met, or (b) not been established

Table C-3 in Appendix C provides a listing of the EPA codes that would indicate the presence of hazardous metals, excluding mercury. Table $\mathrm{C}-4$ provides a listing of the EPA codes that would indicate the presence of mercury.

M12 Metals with Mercury

The metals component is represented by this element provided that the waste is assigned at least one EPA code indicating the presence of mercury for which LDR treatment standards have either (a) not been met, or (b) not been established.

M90 No Metals

The metals component is represented by this element provided that the waste is not assigned any EPA codes indicating the presence of hazardous metals for which LDR treatment standards have either (a) not been met, or (b) not been established.

\subsubsection{IGNITABLE, CORROSIVE, REACTIVE (ICR) COMPONENT}

The third, and final, descriptive component in the CPCs for RCRA regulated waste indicates whether the waste exhibits any one or more of the ignitable, corrosive, or reactive (ICR) hazardous characteristics. This component is represented in the CPC by selecting, as appropriate, one of the eight elements described below. Selection of the appropriate element is based on whether the waste is assigned any one or more of the D001, D002, or D003 EPA codes. In addition, for purposes of this guidance, waste assigned certain listed EPA codes may be considered corrosive or reactive even if neither of the D002 or D003 EPA codes are assigned. These codes, shown in Tables C-5 through C-7 of Appendix C, are either indicative of cyanides or were listed by the EPA because of the characteristics of corrosivity or reactivity.

As shown in Figure 6-1, seven of the eight elements indicate that one or more of the characteristics are exhibited. These seven elements "roll" to a summary element (i.e., C10 ICR PRESENT). This summary element is reserved for performing database rollups of waste that exhibits one or more of the characteristics. The summary element is only shown in Figure 6-1 to illustrate this logic and should not be used in assigning the CPC.

\section{C11 Ignitable}

The ICR component is represented by this element provided that all of the following criteria are met:

- The waste is assigned the EPA code D001, but not D002 or D003

- The waste is not assigned any of the listed EPA codes in Tables C-5, C-6, or C-7 of Appendix $C$ for which LDR treatment standards have either (a) not been met, or (b) not been established (consider only cyanide LDR treatment standards for EPA codes in Table C-7). 


\section{C12 Corrosive}

The ICR component is represented by this element provided that all of the following criteria are met:

- The waste is assigned the EPA code D002 or at least one of the listed EPA codes in Table C-5 of Appendix C for which LDR treatment standards have either (a) not been met, or (b) not been established

- The waste is not assigned either of the EPA codes D001 or D003

- The waste is not assigned any of the listed EPA codes in Tables C-6 or C-7 of Appendix C for which LDR treatment standards have either (a) not been met, or (b) not been established (consider only cyanide LDR treatment standards for EPA codes in Table C-7).

\section{C13 Reactive}

The ICR component is represented by this element provided that all of the following criteria are met:

- The waste is assigned the EPA code D003 or at least one of the listed EPA codes in Appendix C, Tables C-6 or C-7, for which LDR treatment standards have either (a) not been met, or (b) not been established (consider only cyanide LDR treatment standards for EPA codes in Table C-7)

- The waste is not assigned either of the EPA codes D001 or D002

- The waste is not assigned any of the listed EPA codes in Table C-5 of Appendix C for which LDR treatment standards have either (a) not been met, or (b) not been established.

\section{C14 Ignitable/Corrosive}

The ICR component is represented by this element provided that all of the following criteria are met:

- The waste is assigned the EPA code D001

- The waste is assigned the EPA code D002 or at least one of the listed EPA codes in Table C-5 of Appendix C for which LDR treatment standards have either (a) not been met, or (b) not been established

- The waste is not assigned the EPA code D003

- The waste is not assigned any of the listed EPA codes in Appendix C, Tables C-6 or C-7, for which LDR treatment standards have either (a) not been met, or (b) not been established (consider only cyanide LDR treatment standards for EPA codes in Table C-7).

\section{C15 Ignitable/Reactive}

The ICR component is represented by this element provided that all of the following criteria are met:

- The waste is assigned the EPA code D001 
- The waste is assigned the EPA code D003 or at least one of the listed EPA codes in Appendix C, Tables C-6 or C-7, for which LDR treatment standards have either (a) not been met, or (b) not been established (consider only cyanide LDR treatment standards for EPA codes in Table C-7)

- The waste is not assigned the EPA code D002

- The waste is not assigned any of the listed EPA codes in Table C-5 of Appendix C for which LDR treatment standards have either (a) not been met, or (b) not been established.

\section{C16 Corrosive/Reactive}

The ICR component is represented by this element provided that all of the following criteria are met:

- The waste is assigned the EPA code D002 or at least one of the listed EPA codes in Table C-5 of Appendix $C$ for which LDR treatment standards have either (a) not been met, or (b) not been established

- The waste is assigned the EPA code D003 or at least one of the listed EPA codes in Appendix C, Tables C- 6 or C-7, for which LDR treatment standards have either (a) not been met, or (b) not been established (consider only cyanide LDR treatment standards for EPA codes in Table C-7)

- The waste is not assigned the EPA code D001.

\section{C17 Ignitable/Corrosive/Reactive}

The ICR component is represented by this element provided that all of the following criteria are met:

- The waste is assigned the EPA code D001

- The waste is assigned the EPA code D002 or at least one of the listed EPA codes in Table C-5 of Appendix C for which LDR treatment standards have either (a) not been met, or (b) not been established

- The waste is assigned the EPA code D003 or at least one of the listed EPA codes in Appendix C, Tables C- 6 or C-7, for which LDR treatment standards have either (a) not been met, or (b) not been established (consider only cyanide LDR treatment standards for EPA codes in Table C-7).

\section{C90 Non-ICR}

The ICR component is represented by this element provided that all of the following criteria are met:

- The waste is not assigned the EPA code D001

- The waste is not assigned the EPA code D002

- The waste is not assigned any of the listed EPA codes in Table C-5 of Appendix C for which LDR treatment standards have either (a) not been met, or (b) not been established 
- The waste is not assigned the EPA code D003

- The waste is not assigned any of the listed EPA codes in Appendix C, Tables C-6 or C-7, for which LDR treatment standards have either (a) not been met, or (b) not been established (consider only cyanide LDR treatment standards for EPA codes in Table C-7).

\subsection{TSCA REGULATED WASTE CPC COMPONENTS}

As indicated in Figure 6-1, the CPC begins with the component TS, or TSCA, if the regulatory classification of the hazardous or mixed waste is TSCA Regulated. As defined in Section 2, this is waste regulated under TSCA for PCBs that has no assigned EPA codes. There are no additional descriptive components defined in this guidance for this waste.

\subsection{RCRA/TSCA REGULATED WASTE CPC COMPONENTS}

As indicated in Figure 6-1, the CPC begins with the component RT, or RCRA/TSCA, if the regulatory classification of the hazardous or mixed waste is RCRA/TSCA Regulated. As defined in Section 2, this is waste regulated under TSCA for PCBs that is assigned at least one or more EPA codes, regardless of whether LDR treatment standards have been met or established.

The CPCs for this waste-are further defined by the same three descriptive components and associated elements discussed in Section 6.2 for RCRA regulated waste. Guidelines for selecting the appropriate descriptive component elements are the same as those discussed in Sections 6.2.1 through 6.2.3.

\subsection{STATE REGULATED WASTE CPC COMPONENTS}

As indicated in Figure 6-1, the CPC begins with the component ST, or STATE, if the regulatory classification of the hazardous or mixed waste is State Regulated. As defined in Section 2, this waste is hazardous only because of State regulations that are more stringent than the EPA's. In addition, this waste is not regulated under TSCA for PCBs. There are no additional descriptive components defined in this guidance for this waste.

\subsection{RCRA REGULATED WASTE-MEETS LDRS CPC COMPONENTS}

As indicated in Figure 6-1, the CPC begins with the component LD, or RCRA-MEETS LDRs, if the regulatory classification of the hazardous or mixed waste is RCRA Regulated-Meets LDRs. As defined in Section 2, this is waste that meets all of the following criteria:

- The waste is assigned one or more EPA codes for which both (a) LDR treatment standards have been established by the EPA, and (b) the waste meets the established LDR treatment standards

- The waste is not assigned any EPA codes for which LDR treatment standards have either (a) not been met, or (b) not been established

- The waste is not regulated under TSCA for PCBs.

There are no additional descriptive components defined in this guidance for this waste. 


\subsection{SUSPECT REGULATED WASTE CPC COMPONENTS}

As indicated in Figure 6-1, the CPC begins with the component SR, or SUSPECT, if the regulatory classification of the hazardous or mixed waste is Suspect Regulated. As discussed in Section 2, this is waste suspected of being regulated for which no EPA or State codes have been assigned, or it is uncertain whether the waste is regulated under TSCA for PCBs. There are no additional descriptive components defined in this guidance for this waste.

\subsection{REGULATED CONTAMINANT PARAMETER CATEGORIES}

As indicated in the introductory discussion of Section 5 , the complete CPC for a waste is defined by the regulatory classification component followed by an element from each associated descriptive component. The CPC is represented by a "string" of the codes or titles for those components and elements. The codes (e.g., RC, O11, M12, C13) and titles are shown in Figure 6-1. The following discussions summarize the complete CPCs that may be applicable to waste within each of the six regulatory classifications.

\subsubsection{RCRA REGULATED}

Three descriptive components, each with at least two elements, were defined in Section 6.2 for this regulatory classification. These are summarized in Table 6-1. The numerous possible combinations of the descriptive component elements can result in several unique CPCs for this waste.

The complete CPC is defined by a "string" of the regulatory classification component followed by one element from each of the descriptive components. The descriptive component elements appear in the CPC in the order presented in Table 6-1. For example, an untreated RCRA regulated hazardous or mixed waste with EPA codes indicating the presence of hazardous organics and metals, excluding mercury, and the characteristics of corrosivity and reactivity would have a CPC code and title of RC|O11|M11|C16 and RCRA|ORGANICS|METALS WITHOUT MERCURY|CR.

Multiplying the number of variables (i.e., elements) for each descriptive component reveals that 48 unique CPCs can be defined for RCRA regulated hazardous or mixed waste. A complete listing of these 48 CPCs is provided in Appendix $D$.

\subsubsection{TSCA REGULATED}

There were no descriptive components defined for this regulatory classification. Therefore, the CPC code and title for this hazardous or mixed waste are TS and TSCA.

\subsubsection{RCRA/TSCA REGULATED}

The same descriptive components and elements defined in Section 6.2 for RCRA regulated hazardous or mixed waste are applicable to this regulatory classification. Therefore, the discussion in Section 6.8.1 on generation of complete CPCs for RCRA regulated waste is applicable to this waste. The only difference is the code and title of the regulatory classification component, which, in this case, are RT and RCRA/TSCA. A complete listing of the 48 possible CPCs for this waste is also provided in Appendix D.

\subsubsection{STATE REGULATED}

There were no descriptive components defined for this regulatory classification. Therefore, the CPC code and title for this hazardous or mixed waste are ST and STATE. 
Table 6-1. RCRA and RCRA/TSCA Contaminant Category Variables

\begin{tabular}{|c|c|c|c|}
\hline \multirow{2}{*}{$\begin{array}{c}\text { Regulatory } \\
\text { Classification } \\
\text { Component }\end{array}$} & \multicolumn{3}{|c|}{ Descriptive Components } \\
\cline { 2 - 4 } & Organics & Metals & ICR \\
\hline RC & \multicolumn{3}{|c|}{ Descriptive Component Element Codes } \\
\hline RT & 011 & M11 & C11 \\
& 090 & M12 & C12 \\
& & M90 & C13 \\
& & & C14 \\
& & & C15 \\
& & & C16 \\
& & & C17 \\
& & & C90 \\
\hline
\end{tabular}

\subsubsection{RCRA REGULATED-MEETS LDRS}

There were no descriptive components defined for this regulatory classification. Therefore, the CPC code and title for this hazardous or mixed waste are LD and RCRA-MEETS LDRs.

\subsubsection{SUSPECT REGULATED}

There were no descriptive components defined for this regulatory classification. Therefore, the CPC code and title for this hazardous or mixed waste are SR and SUSPECT. 


\section{APPLICATION EXAMPLES}

This section provides waste examples to illustrate the concepts and methods for defining waste streams and assigning treatability groups described in the previous sections of this guidance. The examples also illustrate the method for designating treatability groups. All of the examples address mixed waste to demonstrate waste stream definitions and treatability group assignments per all three of the characteristic parameters.

\section{EXAMPLE 1: DEBRIS WASTE}

This straightforward example illustrates treatability group assignment for a stream comprised of several 55-gallon drums of characteristically similar waste.

\section{Waste Data}

A site has several 55-gallon drums of "legacy" mixed waste in storage from past plutonium processing operations. Since the drums have very similar characteristics and are from the same source, the site has appropriately grouped the drums into a single waste stream. Physically, each drum contains over $75 \%$ by volume material meeting the EPA's criteria for classification as debris. Available data indicate that each drum contains approximately $60 \%$ by volume organic debris materials, such as plastic, paper, and rags. The balance of each drum is approximately $20 \%$ by volume metal debris materials and $20 \%$ by volume vermiculite added as a drum filler.

The drums were considered TRU when generated because of the presence of approximately $80 \mathrm{nCi} / \mathrm{g}$ of alpha-emitting, transuranic isotopes. However, subsequent to the change in criteria for classification as TRU waste, the drums were reclassified as low-level waste. The beta-gamma activity levels are negligible and the waste does not contain non-TRU alpha-emitting radionuclides. Based on process knowledge, each drum was assigned the F002 and D008 EPA codes. PCBs are not present in any of the drums.

\section{Parameter Category Assignments}

Radiological Parameter - Referring to Section 4, the radiological parameter category is defined by completing the steps as shown in Figure 7-1. In Step 1, the waste is assigned the appropriate secondary radiological classification of Low-Level (LL). Steps 2 through 4 then address the descriptive components specific to low-level radioactive or mixed waste. Since the beta-gamma activities for each drum are negligible, the drums are contact-handled. Therefore, in Step 2, the dose rate component is assigned by selecting the Contact-Handled (CH) element. The TRU alpha component is assigned in Step 3 by selecting the $10 \leq$ TRU Alpha $<100 \mathrm{nCi} / \mathrm{g}$ (T11) element. Finally, in Step 4, the non-TRU alpha component is assigned by selecting the No Non-TRU Alpha (N20) element. A string of the secondary radiological classification component and the descriptive component element codes represents the RPC, which, in this case, is LL|CH|T11|N20.

Matrix Parameter - The first step in assigning the matrix category is to determine whether the waste meets the criteria of one of the initial summary categories. Based on the data, these drums definitely meet the criteria for the initial Solids (S) summary category. Referring to Section 5 and Figure B-1, selection of the most definitive, detailed category that can be supported by the data proceeds as illustrated in Figure 7-1. Based on the supporting data, the waste is ultimately assigned to the specific-detailed category S5440, or Predominantly Organic Debris. 


\section{Figure 7-1. Example 1: Parameter Category Assignments}

Radiological Parameter Category

0 Waste

$1 \longrightarrow$ Secondary Radiological Classification

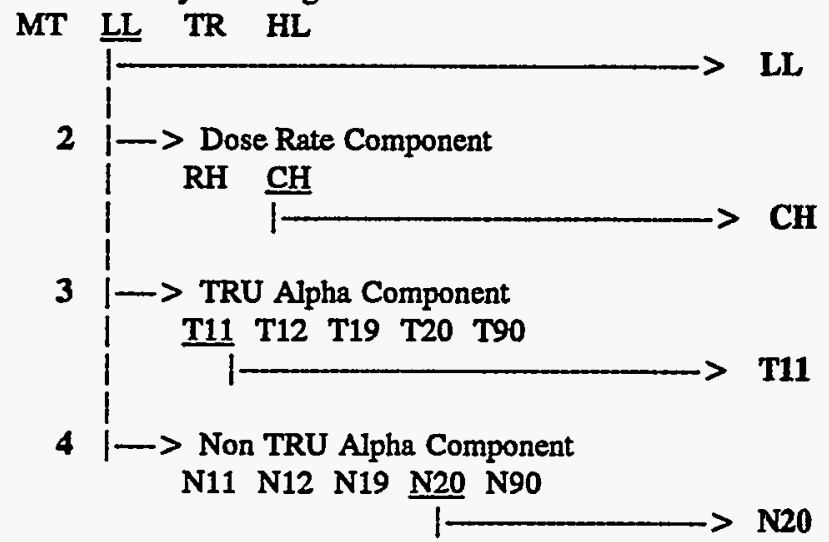

Matrix Parameter Category

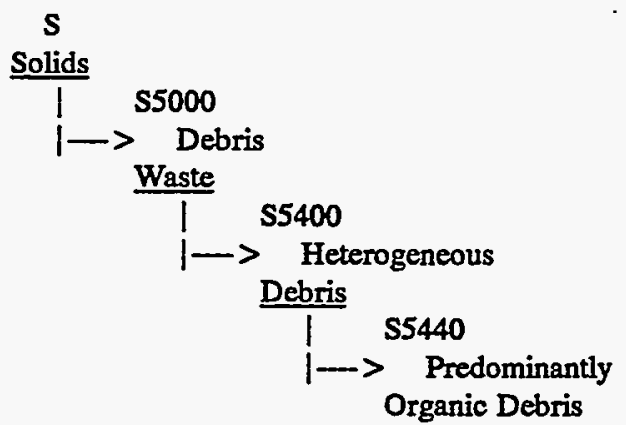

The waste contains more than $50 \%$ by volume materials that meet the criteria for debris.

The waste contains less than $80 \%$ by volume of either organic or inorganic debris materials.

The waste contains between $50 \%$ and $80 \%$ by volume organic debris materials. Therefore, the waste meets the criteria for Predominantly Organic Debris (S5440).

Regulated Contaminant Parameter Category

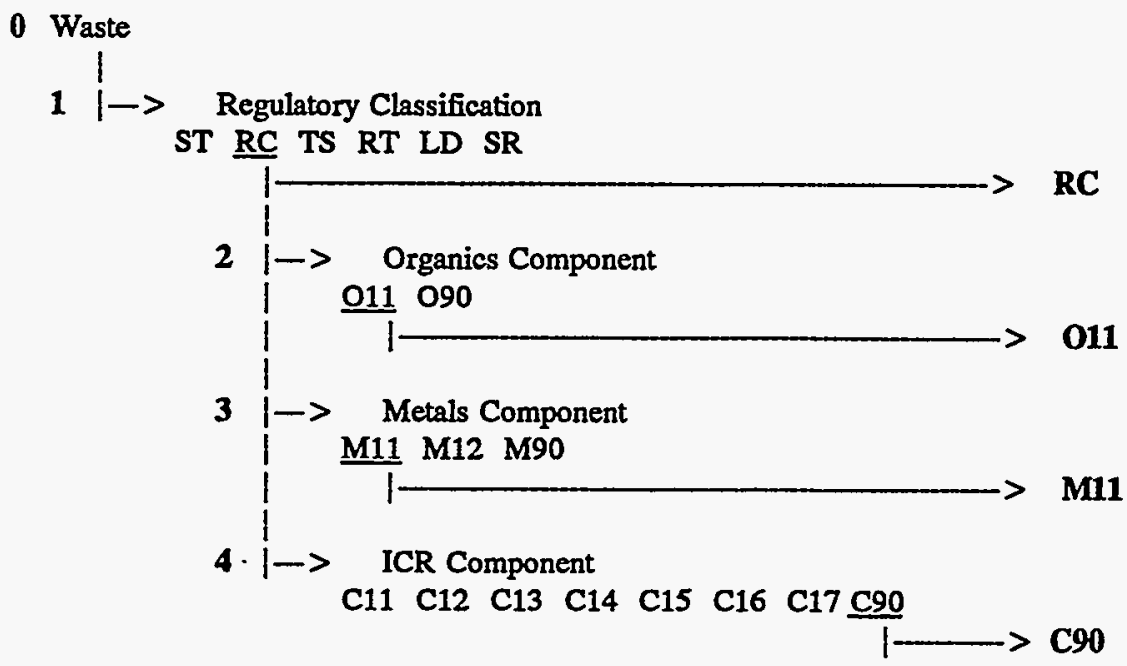


Regulated Contaminant Parameter - Each drum is assigned EPA codes F002 and D008. As is typical for debris waste, the contaminant concentrations are unknown. However, it is known that the D008 code is not assigned because of the presence of lead that has been macroencapsulated. With respect to the F002 code, prudent judgement would cause one to assume that the underlying constituents are present above LDR levels. Therefore, since PCBs are not present in any of the drums, the appropriate regulatory classification, as defined in this guidance, is RCRA Regulated. Referring to Section 6, completion of the regulated contaminant category assignment proceeds per the steps shown in Figure 7-1.

In Step 1, the waste is assigned the appropriate regulatory classification component of RCRA (RC). Steps 2 through 4 address the descriptive components specific to RCRA regulated waste. Because of the F002 code, the organics component is assigned in Step 2 by selecting the Organics (O11) element. The only EPA code indicative of hazardous metals is D008; therefore, the metals component is assigned in Step 3 by selecting the Metals Without Mercury (M11) element. There are no EPA codes assigned to the drums that indicate the presence of the ignitable, corrosive, or reactive characteristics. Therefore, the ICR component is assigned in Step 4 by selecting the Non-ICR (C90) element. A string of the regulatory classification component and descriptive component element codes represents the $\mathrm{CPC}$, which, in this case, is RC $|\mathbf{O} 11| \mathrm{MI1} \mid \mathbf{C} 90$.

\section{Treatability Group}

Treatability groups are designated, either in code or title, by a string of the codes or titles from the RPC, MPC, and CPC, as applicable. The order for representation of the parameters is RPC - MPC - CPC. For the waste in Example 1, the treatability group code is $\mathbf{L C}|\mathbf{C H}| \mathbf{T 1 1} \mid \mathbf{N 2 0}$ - S5440 RC|O11|M11|C90.

\section{EXAMPLE 2: SIMILAR LIQUID WASTE FROM DIFFERENT SOURCES}

This example addresses characteristically similar waste generated at a site from two separate sources. The example highlights the use of employing additional parameters for waste stream definition beyond those considered in treatability group assignments.

\section{Waste Data}

A site generates a methanol/water rinsate from cleaning laboratory analysis purge tubes in the Environmental Chemistry Laboratory (ECL) and from a similar activity in the Operation Support Laboratory (OCL). In both laboratories, the rinse solution is formulated with $43 \%$ methanol and $57 \%$ water. Rinsate waste from both laboratories contains radioactive and hazardous contaminants from the purge tubes.

Rinsate from the ECL contains trace quantities of Sb-125, Ru-105, Rh-106, Ce-144, and Co-60 (no TRU or non-TRU alpha-emitters). The waste is also contaminated with several toxicity characteristic organics (benzene, carbon tetrachloride, chlorobenzene, and methyl ethyl ketone) and has been assigned the D018, D019, D021, and D035 EPA codes. In addition, the waste has been assigned D001 because of the ignitability of the methanol. Combined, the concentration of halogenated organic compounds is less than $300 \mathrm{ppm}$ and no PCBs are present.

Rinsate from the OCL is contaminated with traces of Co-60 and Ce-144 (no TRU or non-TRU alpha-emitters) and with 1,1,1-trichloroethane. The waste has been assigned the EPA codes of F001 and D001. The concentration of halogenated organic compounds in this rinsate is less than $400 \mathrm{ppm}$ and no PCBs are present. 
The rinsate from both laboratories is bulked, separately, into 55-gallon containers. The beta-gamma activity levels of the waste from both laboratories is such that all of the containers are contact-handled.

\section{Parameter Category Assignments}

Radiological Parameter - Radiologically, the waste from both laboratories is low-level, contact-handled, and contains neither TRU nor non-TRU alpha-emitting radionuclides. Referring to Section 4, the radiological parameter category is defined by completing the steps as shown in Figure 7-2.

In Step 1, the waste is assigned the appropriate secondary radiological classification of Low-Level (LL). Steps 2 through 4 then address the descriptive components specific to low-level radioactive or mixed waste. In Step 2, the dose rate component is assigned by selecting the Contact-Handled (CH) element. The TRU alpha and non-TRU alpha components are assigned by selecting the No TRU Alpha (T20) and No Non-TRU Alpha (N20) elements, respectively. A string of the secondary radiological classification component and descriptive component element codes represents the RPC, which, for the waste from both laboratories, is $\mathbf{L L}|\mathbf{C H}| \mathbf{T 2 0} \mid \mathbf{N} 20$.

Matrix Parameter - The first step in assigning the matrix category is to determine whether the waste meets the criteria of one of the initial summary categories. Based on the data, waste from both laboratories definitely meets the criteria for the initial Liquids $(L)$ summary category. Referring to Section 5 and Figure B-1, selection of the most definitive, detailed category that can be supported by the data proceeds as illustrated in Figure 7-2. Based on the supporting data, the waste from both laboratories may be assigned the specific-detailed category L2120, or Aqueous/Nonhalogenated Organic Liquids.

Regulated Contaminant Parameter - The waste from both laboratories is regulated by the EPA under RCRA, with at least one assigned EPA code for which LDR treatment standards have not been met. PCBs are not present in the waste from either laboratory. Referring to Section 6 , the regulated contaminant category is defined by completing the steps shown in Figure 7-2.

In Step 1, the waste is assigned the appropriate regulatory classification of RCRA (RC). Steps 2, 3, and 4 address the descriptive components specific to RCRA regulated waste. In Step 2, since the waste from both laboratories is assigned at least one EPA code indicative of hazardous organics for which LDR treatment standards have not been met, the organics component is assigned by selecting the Organics (O11) element. Since the waste is not assigned any EPA codes indicating the presence of hazardous metals, the metals component is assigned by selecting the No Metals (M90) element. The only EPA code assigned to the waste indicating any of the ignitable, corrosive, or reactive characteristics is D001. Therefore, the ICR component is assigned by selecting the Ignitable (C11) element. A string of the regulatory classification and descriptive component element codes represents the CPC, which, for the waste from both laboratories, is RC $|\mathbf{O 1 1}| \mathrm{M} 90 \mid \mathrm{C11}$.

\section{Treatability Group}

Recalling the method for designating treatability groups discussed in Example 1, the treatability group code for both the ECL and OCL waste in this example is LL/CH|T20|N20 - L2120 RC|O11|M90|C11.

As discussed in Section 3, the site may elect to include a fourth parameter in defining streams for this containerized waste. In this case, a likely fourth parameter would be source, since the waste is generated from separate laboratories. This would result in two streams that may, for example, be named "ECL Rinsate" and "OCL Rinsate." However, both streams would be within the same treatability group as defined above. 
Figure 7-2. Example 2: Parameter Category Assignments

\section{Radiological Parameter Category}

0 Waste

$1 \mid \rightarrow$ Secondary Radiological Classification MT LL TR HL

$2 \longrightarrow \rightarrow$ Dose Rate Component RH CH

$3 \quad \longrightarrow$ TRU Alpha Component T11 T12 T19 T20 T90

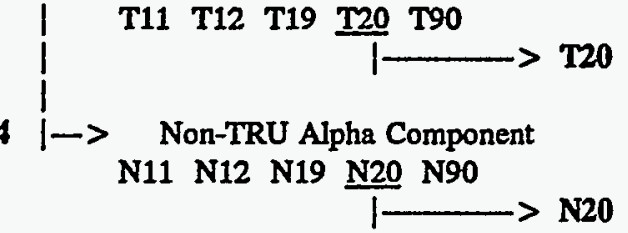

Matrix Parameter Categony

L

Liquids

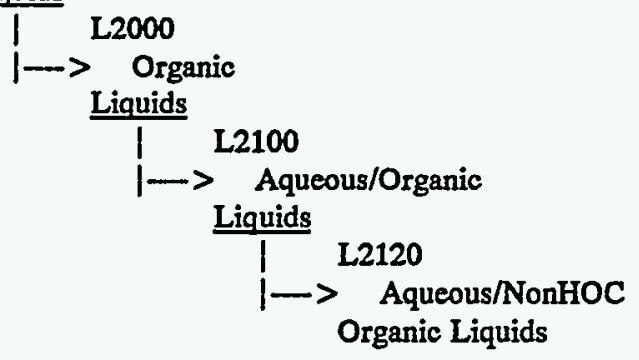

LL<smiles>[CH]</smiles>

N20

\section{Regulated Contaminant Parameter Category}

0 Waste

$1 \mid \rightarrow \quad$ Regulatory Classification

ST RC TS RT LD SR

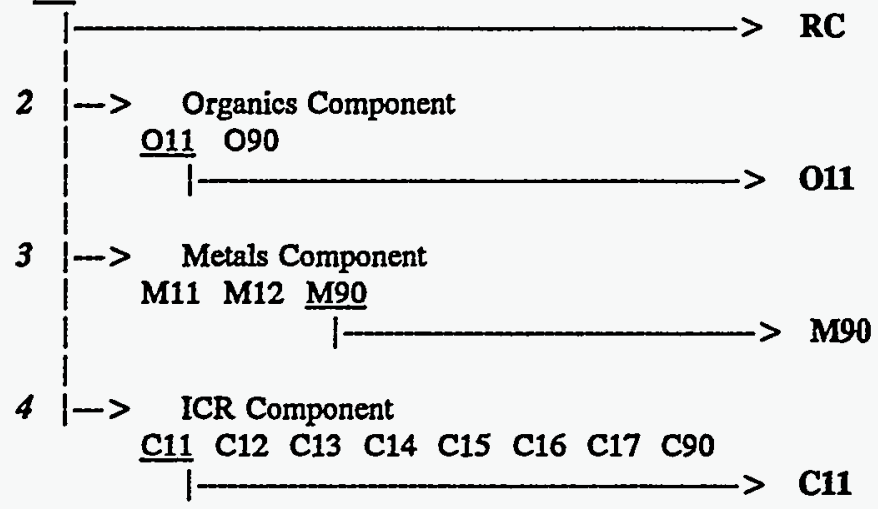




\section{EXAMPLE 3: SUMP DECOMMISSIONING WASTE}

This third, and final, example illustrates a situation where several containers of characteristically dissimilar waste were generated from the same process or activity to highlight the need for considering the treatability group concept in defining waste strearns.

\section{Waste Data}

A site generates twenty 55-gallon drums of waste, with identification numbers of D01 through D20, as a result of decommissioning a process sump in a wastewater treatment facility. Physically, the waste generated from the decommissioning activity includes the metal-bearing hydroxide precipitate sludge that was contained in the sump, and debris materials from the sump itself. Most of the sludge was removed from the sump and placed in the polyethylene lined drums with identification numbers D01 through D12. The debris materials resulting from destruction of the sump were packaged in drums D13 through D20, along with the remaining residual sludge that could not be initially removed. Drums D01 through D12 were essentially filled (i.e., $>50 \%$ by volume) with the sludge. The waste in drums D13 through D20 is well over $80 \%$ by volume inorganic debris materials, with each drum containing approximately $60 \%$ by volume concrete and $30 \%$ by volume metal debris.

Based on sampling and analysis, the sludge in the sump contained regulated levels of cadmium (D006) and chromium (D007). In addition, a one-time spill of hydraulic fluids contaminated the sludge with approximately $300 \mathrm{ppm}$ of PCBs. Based on process knowledge, the debris waste in drums D13 through D20 was also assigned the EPA codes D006 and D007, and was considered contaminated with regulated levels of PCBs. None of the waste was contaminated with hazardous organics regulated by EPA under RCRA. In addition, none of the waste exhibited any of the ignitable, corrosive, or reactive characteristics.

Radiologically, the influent wastewater treated at the facility was primarily a uranium-bearing waste. As such, the sump sludge and debris materials were contaminated with uranium at levels $<10 \mathrm{nCi} / \mathrm{g}$. TRU alpha-emitters were never introduced into the facility. Finally, based on the influent wastewater, the beta-gamma activity levels of the sump sludge and debris were negligible.

\section{Parameter Category Assignments}

Based on the above data, all of the drums have the same regulated contaminant and radiological characteristics. In other words, from a treatability group perspective, all would be assigned the same RPC and CPC. However, the matrices vary substantially between drums D01 through D12 and D13 through D20. Collectively, the overall waste between all of the drums is $>50 \%$ by volume sludge. Therefore, the collective matrix over all of the drums meets the criteria for assignment to the S3121 (Wastewater Treatment Sludges) MPC. Coupled with each drum having the same RPC and CPC, a single waste stream might be defined. However, given the substantial difference in the matrices between drums D01 through D12 and D13 through D20, subsequent assessments to determine treatment technology and capacity needs for this single stream would be misleading or, at least, confusing. Two streams should be defined for this waste: one comprised of drums D01 through D12 and the other comprised of drums D13 through D20. Both streams would have the same RPC and CPC, but different MPCs.

Radiological Parameter - Radiologically, all of the drums are low-level and contaminated with $<10 \mathrm{nCi} / \mathrm{g}$ uranium with no TRU alpha-emitters. Since the beta-gamma activities are negligible, the drums are contact-handled. Referring to Section 4, the RPCs for both streams are defined by completing the steps as shown in Figure 7-3.

In Step 1, the secondary radiological classification of Low-Level (LL) is assigned. Steps 2 through 4 address the descriptive components specific to low-level radioactive or mixed waste. In Step 2, the dose 
rate component is assigned by selecting the Contact-Handled $(\mathrm{CH})$ element. The TRU alpha component is assigned in Step 3 by selecting the No TRU Alpha (T20) element. Finally, the non-TRU alpha component is assigned in Step 4 by selecting the $0<$ Non-TRU Alpha $<10 \mathrm{nCi} / \mathrm{g}$ (N12) element. Therefore, the RPC code for both streams is $\mathbf{L L}|\mathbf{C H}| \mathbf{T 2 0} \mid \mathbf{N 1 2}$.

Regulated Contaminant Parameter - All of the drums are regulated by the EPA under RCRA, with at least one assigned EPA code for which LDR treatment standards have not been met. In addition, all of the drums contain TSCA regulated levels of PCBs. Therefore, per this guidance, the regulatory classification for both streams is RCRA/TSCA Regulated. Referring to Section 6, the CPC is defined by completing the steps as shown in Figure 7-3.

In Step 1, the regulatory classification of RCRA/TSCA (RT) is assigned. Steps 2, 3, and 4 address the descriptive components specific to RCRA/TSCA regulated waste. In Step 2, since none of the drums are assigned any EPA codes indicative of hazardous organics, the organics component is assigned by selecting the No Organics (090) element. All of the drums are assigned the EPA codes of D006 and D007, but not D009; therefore, the metals component is assigned in Step 3 by selecting the Metals Without Mercury (M11) element. No EPA codes were assigned to any of the drums that indicate the presence of the ignitable, corrosive, or reactive characteristics. Therefore, the ICR component is assigned in Step 4 by selecting the Non-ICR (C90) element. The complete CPC code for both streams is RT |O90|M11|C90.

Matrix Parameter - As discussed above, two streams will be defined for these drums, one for D01 through D12 and the other for D13 through D20. Both sets of drums meet the criteria of the initial Solids (S) summary category. Referring to Section 5 and Figure B-1, selection of the appropriate MPC for both sets proceeds as shown in Figures 7-4 and 7-5. Based on the data, the MPC for the stream comprised of drums D01 through D12 is S3121, or Wastewater Treatment Sludges. The MPC for the stream comprised of drums D13 through D20 is S5190, or Unknown/Other Inorganic Debris.

\section{Treatability Group}

The treatability group code for the stream comprised of drums D01 through D12 is LL $|\mathbf{C H}| \mathbf{T 2 0} \mid \mathbf{N 1 2}$ - S3121 - RT|090|M11|C90. The code for the stream comprised of drums D13 through D20 is LL|CH|T20|N12 - S5190 - RT|090|M11|C90. 
Figure 7-3. Example 3: RPC and CPC Assignments

\section{Radiological Parameter Category}

0 Waste

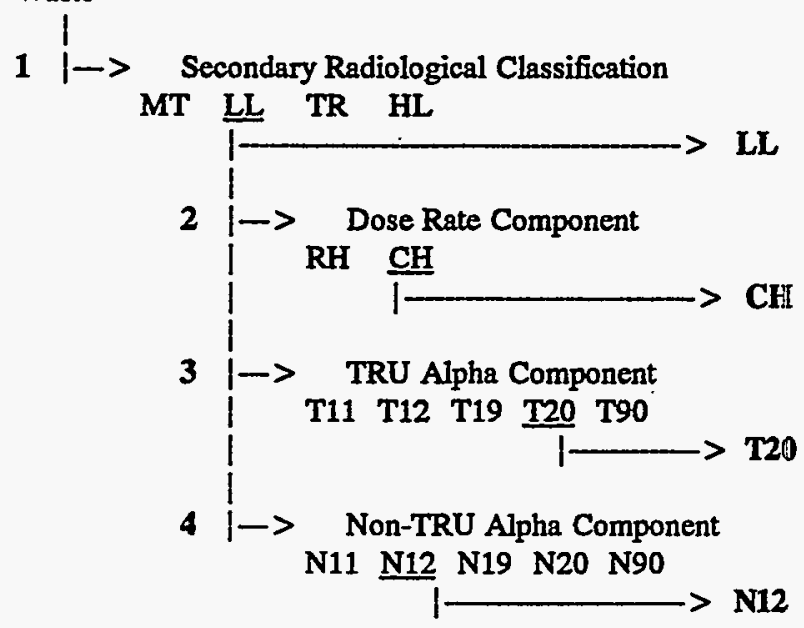

\section{Regulated Contaminant Parameter Category}

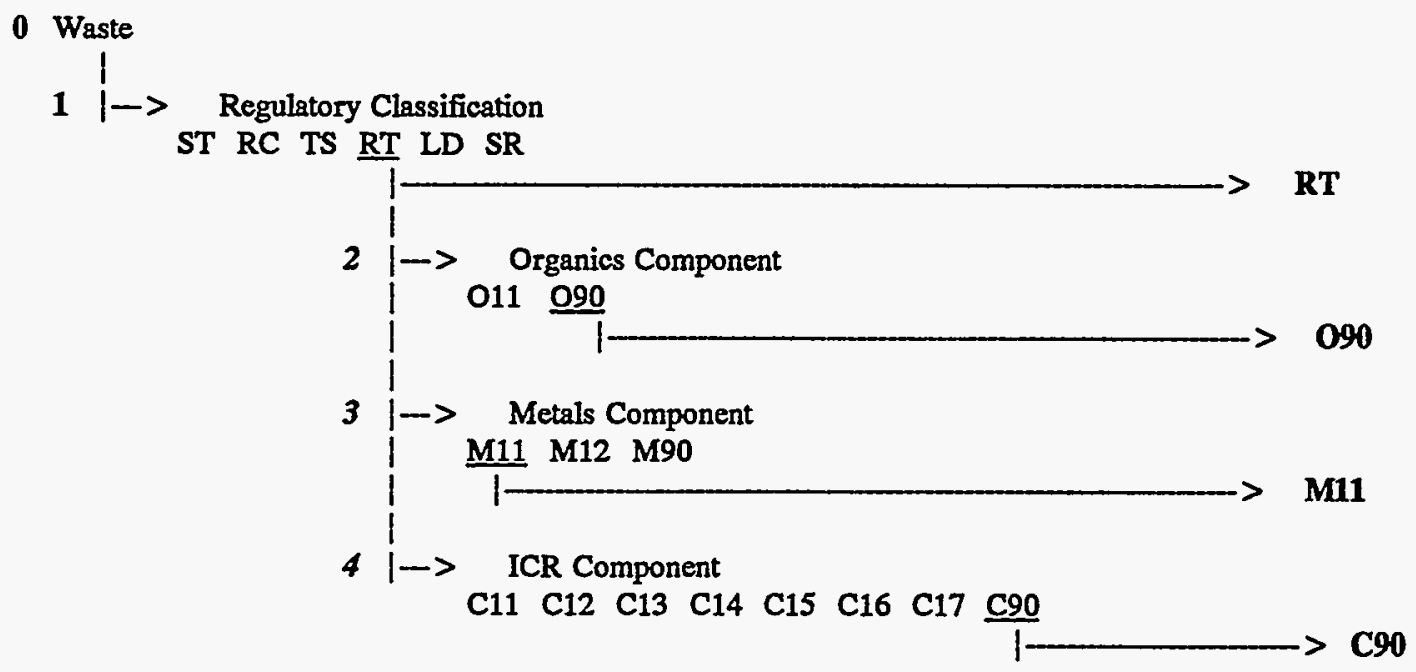


Figure 7-4. Example 3: MPC Assignments for Drums D01 through D12

$S$

Solids

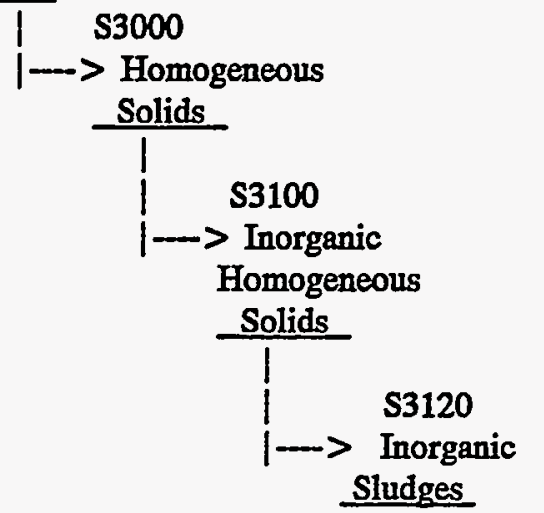

The drums contain more than $50 \%$ by volume materials that meet the criteria for homogeneous solids:

The homogeneous solids are metal-bearing sludges.

The inorganic homogeneous solids are sludges.

S3121

$\longrightarrow$ Wastewater The sludges are wastewater treatment sludges.

Treatment

Sludges

Figure 7-5. Example 3: MPC Assignments for Drums D13 through D20

\section{$S$}

Solids

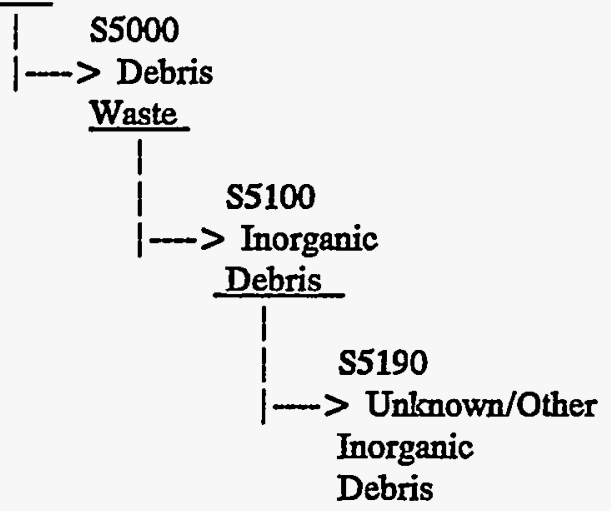

The drums contain more than $50 \%$ by volume materials that meet the criteria for debris.

The drums contain over $80 \%$ by volume inorganic debris materials.

The drums do not contain at least $80 \%$ by volume inorganic debris materials that are either metal or nonmetal. 


\section{APPENDIX A}

LOW-LEVEL RADIOLOGICAL PARAMETER CATEGORIES 
$\therefore=$ 
Table A-1. Low-Level Radiological Parameter Categories

\begin{tabular}{|c|c|}
\hline RPC CODE & RPC TITLE \\
\hline 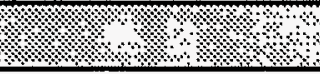 & REMOTO HANDLED WASTE. \\
\hline LL $\mid$ RH $\mid$ T11 | N11 & LOW-LEVEL | REMOTE-HANDLED | $10 \leq$ TRU ALPHA $<100 \mathrm{nCi} / \mathrm{g} \mid$ NON-TRU ALPHA $\geq 10 \mathrm{nCi} / \mathrm{g}$ \\
\hline LL $\mid$ RH $|\mathrm{T} 11| \mathrm{N} 12$ & LOW-LEVEL | REMOTE-HANDLED $\mid 10 \leq$ TRU ALPHA $<100 \mathrm{nCi} / \mathrm{g} \mid 0<$ NON-TRU ALPHA $<10 \mathrm{nCi} / \mathrm{g}$ \\
\hline LL | RH | T11 | N19 & LOW-LEVEL | REMOTE-HANDLED | $10 \leq$ TRU ALPHA $<100 \mathrm{nCi} / \mathrm{g} \mid$ NON-TRU ALPHA RANGE UNKNOWN \\
\hline LL $\mid$ RH $|\mathrm{T} 11| \mathbf{N} 20$ & LOW-LEVEL | REMOTE-HANDLED | $10 \leq$ TRU ALPHA $<100 \mathrm{nCi} / \mathrm{g} \mid$ NO NON-TRU ALPHA \\
\hline LL | RH | T11 | N90 & LOW-LEVEL | REMOTE-HANDLED $\mid 10 \leq$ TRU ALPHA $<100 \mathrm{nCi} / \mathrm{g} \mid$ NON-TRU ALPHA PRESENCE UNKNOWN \\
\hline LL $\mid$ RH $|\mathrm{T} 12| \mathrm{N} 11$ & LOW-LEVEL | REMOTE-HANDLED $\mid 0<$ TRU ALPHA $<10 \mathrm{nCi} / \mathrm{g} \mid$ NON-TRU ALPHA $\geq 10 \mathrm{nCi} / \mathrm{g}$ \\
\hline LL $\mid$ RH $|\mathrm{T} 12| \mathrm{N} 12$ & LOW-LEVEL | REMOTE-HANDLED | $0<$ TRU ALPHA $<10 \mathrm{nCi} / \mathrm{g} \mid 0<$ NON-TRU ALPHA $<10 \mathrm{nCi} / \mathrm{g}$ \\
\hline LL | RH $|\mathrm{T} 12| \mathrm{N} 19$ & LOW-LEVEL | REMOTE-HANDLED | $0<$ TRU ALPHA $<10 \mathrm{nCi} / \mathrm{g} \mid$ NON-TRU ALPHA RANGE UNKNOWN \\
\hline LL $|\mathrm{RH}| \mathrm{T} 12 \mid \mathrm{N} 20$ & LOW-LEVEL | REMOTE-HANDLED | $0<$ TRU ALPHA $<10 \mathrm{nCi} / \mathrm{g}$ | NO NON-TRU ALPHA \\
\hline LL $|R H| T 12 \mid$ N90 & LOW-LEVEL | REMOTE-HANDLED | $0<$ TRU ALPHA $<10 \mathrm{nCi} / \mathrm{g}$ | NON-TRU ALPHA PRESENCE UNKNOWN \\
\hline LL | RH | T19 | N11 & LOW-LEVEL | REMOTE-HANDLED | TRU ALPHA RANGE UNKNOWN | NON-TRU ALPHA $\geq 10 \mathrm{nCi} / \mathrm{g}$ \\
\hline LL $|\mathrm{RH}| \mathrm{T} 19 \mid \mathrm{N} 12$ & LOW-LEVEL | REMOTE-HANDLED | TRU ALPHA RANGE UNKNOWN $\mid 0<$ NON-TRU ALPHA $<10 \mathrm{nCi} / \mathrm{g}$ \\
\hline LL | RH | T19 | N19 & LOW-LEVEL | REMOTE-HANDLED | TRU ALPHA RANGE UNKNOWN | NON-TRU ALPHA RANGE UNKNOWN \\
\hline LL $\mid$ RH $|\mathrm{T} 19| \mathrm{N} 20$ & LOW-LEVEL | REMOTE-HANDLED | TRU ALPHA RANGE UNKNOWN | NO NON-TRU ALPHA \\
\hline LL $\mid$ RH $\mid$ T19 | N90 & LOW-LEVEL | REMOTE-HANDLED | TRU ALPHA RANGE UNKNOWN | NON-TRU ALPHA PRESENCE UNKNOWN \\
\hline LL $|\mathrm{RH}| \mathrm{T} 20 \mid \mathrm{N} 11$ & LOW-LEVEL | REMOTE-HANDLED | NO TRU ALPHA | NON-TRU ALPHA $\geq 10 \mathrm{nCi} / \mathrm{g}$ \\
\hline $\mathrm{LL}|\mathrm{RH}| \mathrm{T} 20 \mid \mathrm{N} 12$ & LOW-LEVEL | REMOTE-HANDLED | NO TRU ALPHA | $0<$ NON-TRU ALPHA $<10 \mathrm{nCi} / \mathrm{g}$ \\
\hline LL $|\mathrm{RH}| \mathrm{T} 20 \mid \mathrm{N} 19$ & LOW-LEVEL | REMOTE-HANDLED | NO TRU ALPHA | NON-TRU ALPHA RANGE UNKNOWN \\
\hline LL $|\mathrm{RH}| \mathrm{T} 20 \mid \mathrm{N} 20$ & LOW-LEVEL | REMOTE-HANDLED | NO TRU ALPHA | NO NON-TRU ALPHA \\
\hline LL $\mid$ RH $|\mathrm{T} 20| \mathrm{N} 90$ & LOW-LEVEL | REMOTE-HANDLED | NO TRU ALPHA | NON-TRU ALPHA PRESENCE UNKNOWN \\
\hline LL | RH | T90 | N11 & LOW-LEVEL | REMOTE-HANDLED | TRU ALPHA PRESENCE UNKNOWN | NON-TRU ALPHA $\geq 10 \mathrm{nCi} / \mathrm{g}$ \\
\hline
\end{tabular}


Table A-1. Low-Level Radiological Parameter Categories

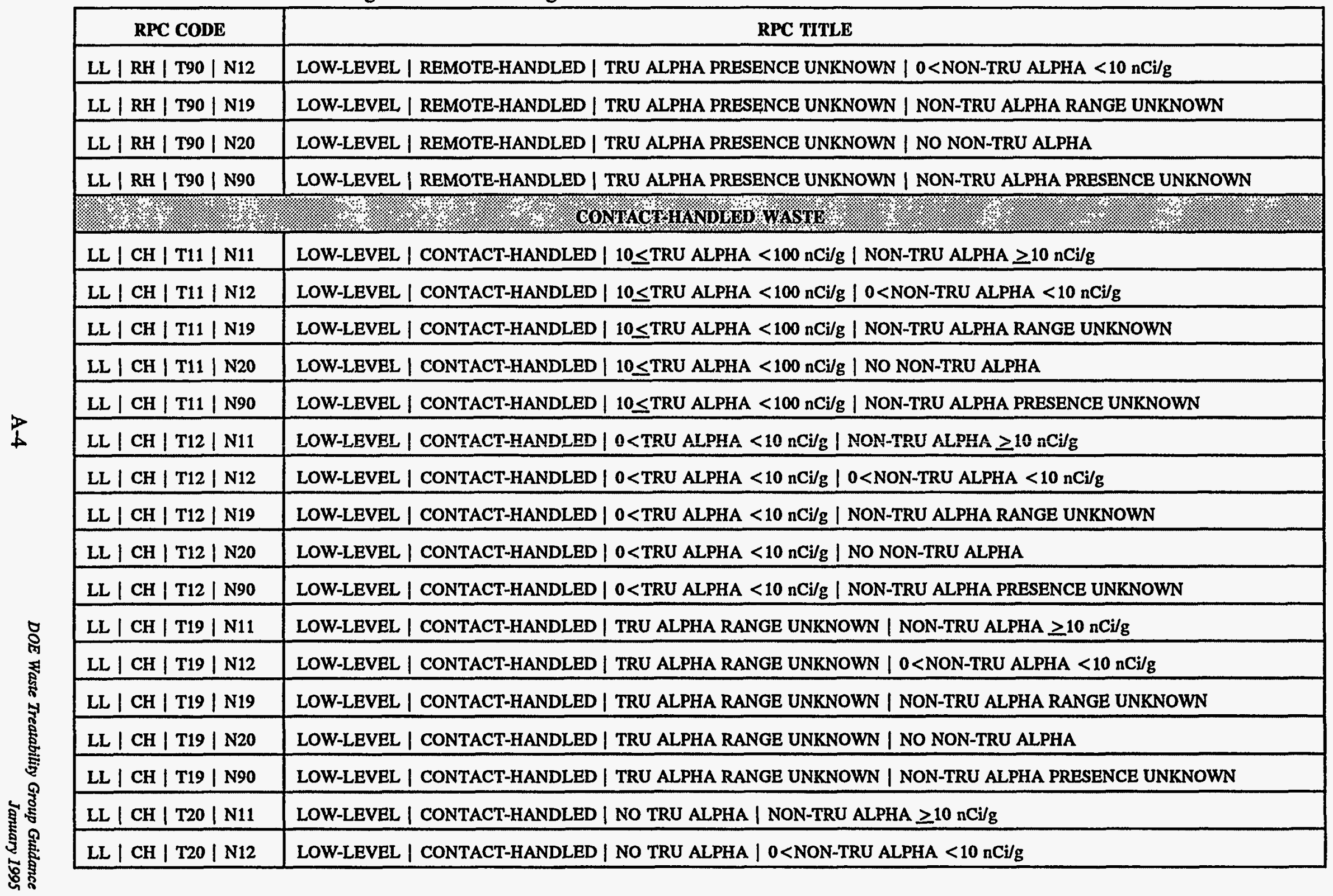


Table A-1. Low-Level Radiological Parameter Categories

\begin{tabular}{|c|c|}
\hline RPC CODE & RPC TITLE \\
\hline LL $|\mathrm{CH}| \mathrm{T} 20 \mid \mathrm{N} 19$ & LOW-LEVEL | CONTACT-HANDLED | NO TRU ALPHA | NON-TRU ALPHA RANGE UNKNOWN \\
\hline $\mathrm{LL}|\mathrm{CH}| \mathrm{T} 20 \mid \mathrm{N} 20$ & LOW-LEVEL | CONTACT-HANDLED | NO TRU ALPHA | NO NON-TRU ALPHA \\
\hline LL $|\mathrm{CH}| \mathrm{T} 20 \mid \mathrm{N} 90$ & LOW-LEVEL | CONTACT-HANDLED | NO TRU ALPHA | NON-TRU ALPHA PRESENCE UNKNOWN \\
\hline LL $|\mathrm{CH}| \mathrm{T} 90 \mid \mathrm{N} 11$ & LOW-LEVEL | CONTACT-HANDLED | TRU ALPHA PRESENCE UNKNOWN | NON-TRU ALPHA $\geq 10 \mathrm{nCi} / \mathrm{g}$ \\
\hline $\mathrm{LL}|\mathrm{CH}| \mathrm{T} 90 \mid \mathrm{N} 12$ & LOW-LEVEL | CONTACT-HANDLED | TRU ALPHA PRESENCE UNKNOWN $\mid 0<$ NON-TRU ALPHA $<10 \mathrm{nCi} / \mathrm{g}$ \\
\hline LL $|\mathrm{CH}| \mathrm{T} 90 \mid \mathrm{N} 19$ & LOW-LEVEL | CONTACT-HANDLED | TRU ALPHA PRESENCE UNKNOWN | NON-TRU ALPHA RANGE UNKNOWN \\
\hline $\mathrm{LL}|\mathrm{CH}| \mathrm{T} 90 \mid \mathrm{N} 20$ & LOW-LEVEL | CONTACT-HANDLED | TRU ALPHA PRESENCE UNKNOWN | NO NON-TRU ALPHA \\
\hline LL $|\mathrm{CH}| \mathrm{T} 90 \mid \mathrm{N} 90$ & OW-LEVEL | CONTACT-HANDLED | TRU ALPHA PRESENCE UNKNOWN | NON-TRU ALPHA PRESENCE UNKNO \\
\hline
\end{tabular}




\section{APPENDIX B}

\section{MATRIX PARAMETER CATEGORIES - FOLDOUT CHART}


$$
\text { . }
$$ 

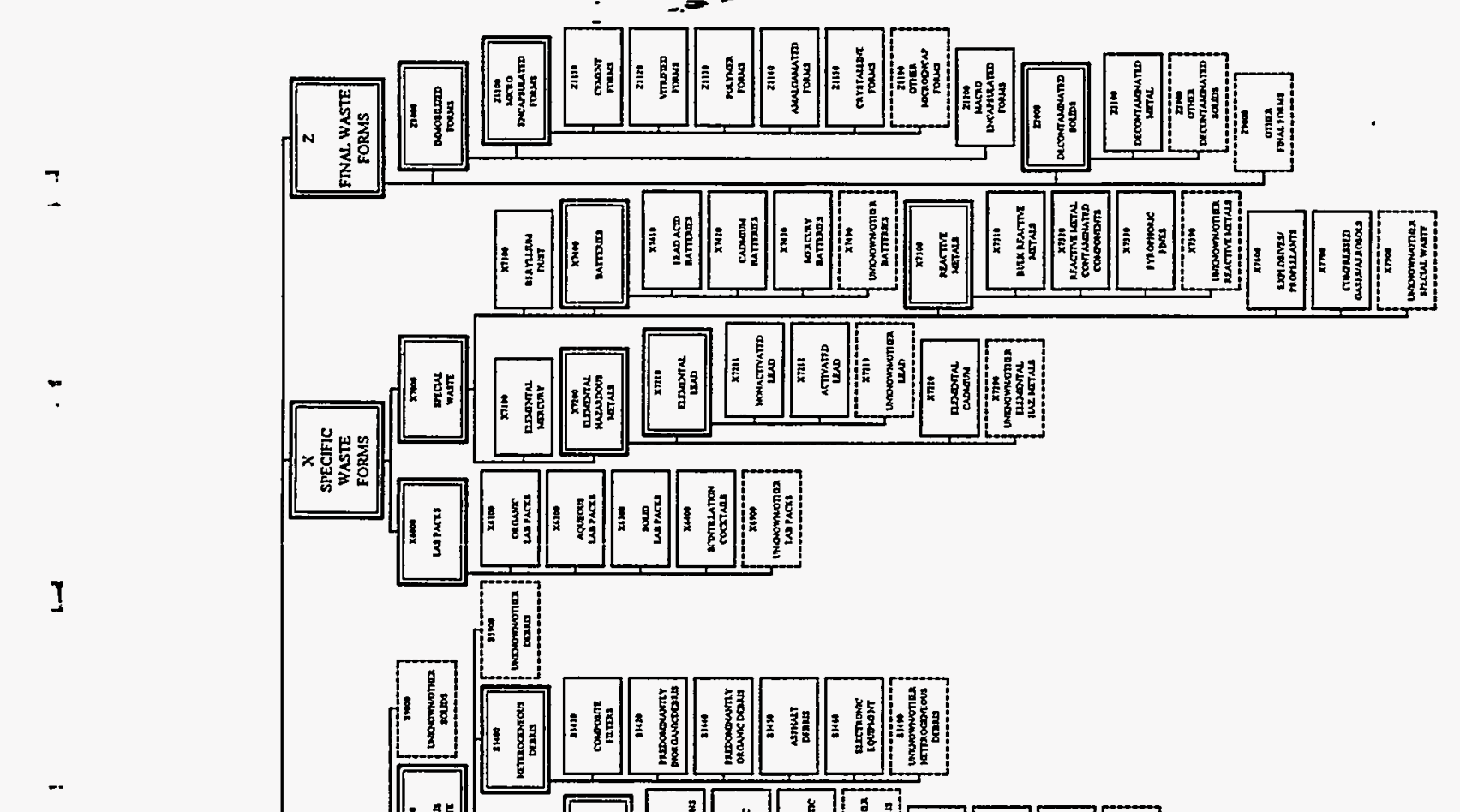

13

है

|

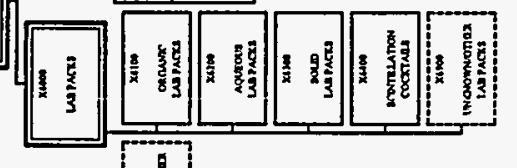

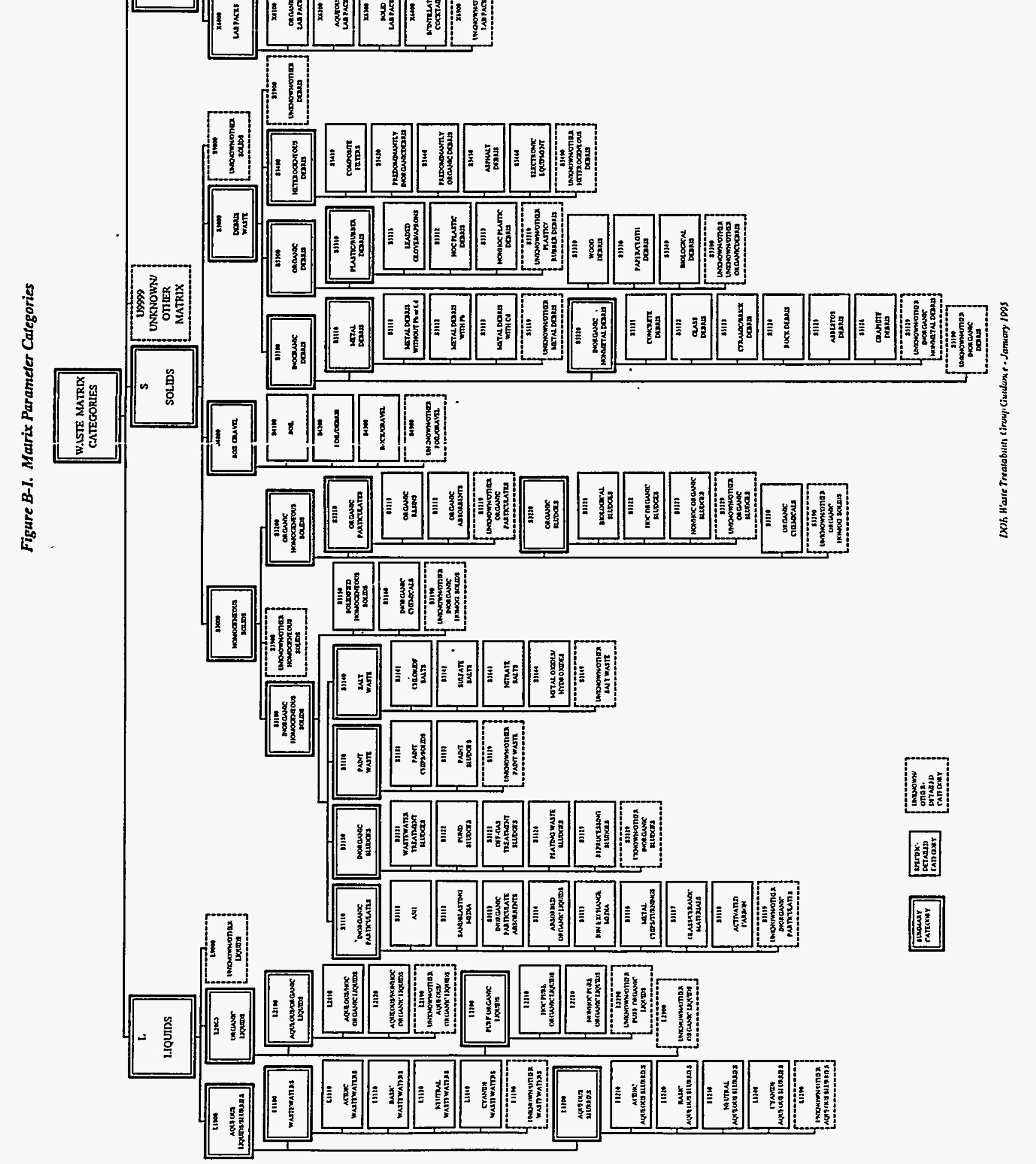




\section{APPENDIX C}

EPA CODES BY DESCRIPTIVE

COMPONENT ELEMENTS 
Table C-1. Organics (Excluding Dioxins)

\begin{tabular}{|c|c|}
\hline $\mathrm{EPACOBF}$ & 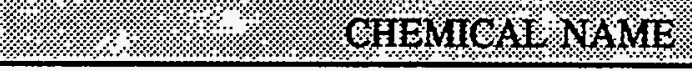 \\
\hline D012 & Endrin \\
\hline D013 & Lindane \\
\hline D014 & Methoxychlor \\
\hline D015 & Toxaphene \\
\hline D016 & $2,4-D$ \\
\hline D017 & Silvex \\
\hline D018 & Benzene \\
\hline D019 & Carbon tetrachloride \\
\hline D020 & Chlordane \\
\hline D021 & Chlorobenzene \\
\hline D022 & Chloroform \\
\hline D023 & o-cresol \\
\hline D024 & m-cresol \\
\hline D025 & p-cresol \\
\hline D026 & Cresol \\
\hline D027 & 1,4-dichlorobenzene \\
\hline D028 & 1,2-dichloroethane \\
\hline D029 & 1,1-dichloroethylene \\
\hline D030 & 2,4-dinitrotoluene \\
\hline D031 & Heptachlor \\
\hline D032 & Hexachlorobenzene \\
\hline D033 & Hexachlorobutadiene \\
\hline D034 & Hexachloroethane \\
\hline D035 & Methyl ethyl ketone \\
\hline D036 & Nitrobenzene \\
\hline D037 & Pentachlorophenol \\
\hline D038 & Pyridine \\
\hline D039 & Tetrachloroethylene \\
\hline
\end{tabular}


Table C-1. Organics (Excluding Dioxins)

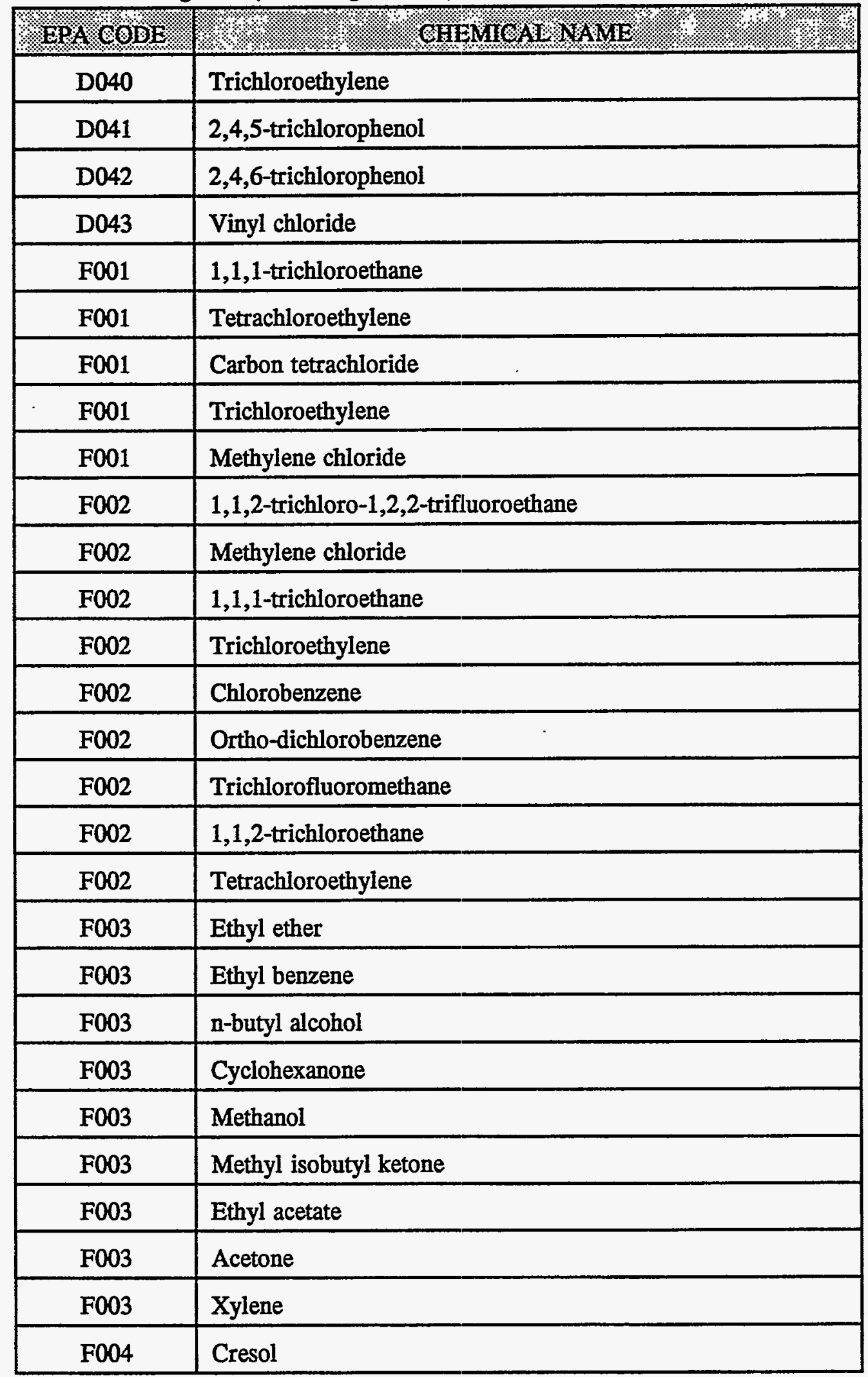


Table C-1. Organics (Excluding Dioxins)




Table C-1. Organics (Excluding Dioxins)

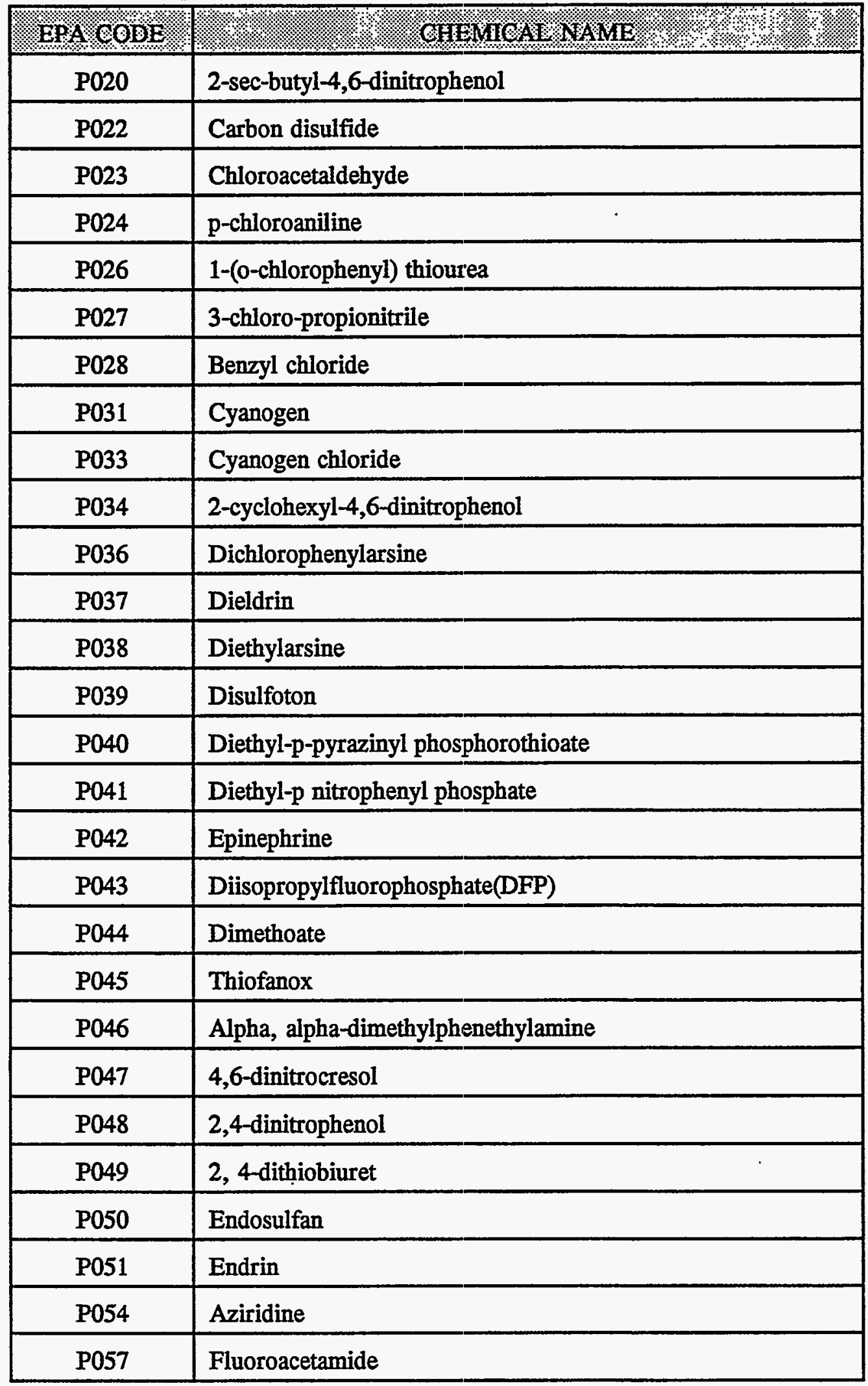


Table C-1. Organics (Excluding Dioxins)

\begin{tabular}{|c|c|}
\hline हEA & (.) \\
\hline P058 & Fluoroacetic acid, sodium salt \\
\hline P059 & Heptachlor \\
\hline $\mathrm{PO60}$ & Isodrin \\
\hline $\mathrm{P} 062$ & Hexaethyltetraphosphate \\
\hline P064 & Isocyanic acid, ethyl ester \\
\hline P066 & Methomyl \\
\hline P067 & 2-methylaziridine \\
\hline P068 & Methyl hydrazine \\
\hline P069 & Methylacetonitrile \\
\hline P070 & Aldicarb \\
\hline P071 & Methyl parathion \\
\hline $\mathrm{PO} 072$ & 1-naphthyl-2-thiourea \\
\hline $\mathrm{P} 075$ & Nicotine and salts \\
\hline $\mathrm{PO77}$ & p-nitroaniline \\
\hline P081 & Nitroglycerin (also see Table C-6) \\
\hline P082 & $\mathrm{N}$-nitrosodimethylamine \\
\hline P084 & N-nitrosomethylvinylamine \\
\hline P085 & Octamethylpyrophosphoramide \\
\hline P088 & Endothall \\
\hline P089 & Parathion \\
\hline P092 & Phenyl mercury acetate (also see Table C-4) \\
\hline P093 & N-phenylthiourea \\
\hline P094 & Phorate \\
\hline P095 & Phosgene \\
\hline P097 & Famphur \\
\hline P101 & Ethyl cyanide \\
\hline P102 & Propargyl alcholol \\
\hline P108 & Strychnine and salts \\
\hline
\end{tabular}


Table C-1. Organics (Excluding Dioxins)

\begin{tabular}{|c|c|}
\hline EPAPOPF & CHEMHCA1 NAME \\
\hline P109 & Tetraethyldithiopyrophosphate \\
\hline $\mathbf{P} 110$ & Tetraethyl lead \\
\hline P111 & Tetraethyl pyrophosphate \\
\hline P112 & Tetranitromethane (also see Table C-6) \\
\hline P116 & Thiosemicarbazide \\
\hline P118 & Trichloromethanethiol \\
\hline P123 & Toxaphene \\
\hline U001 & Acetaldehyde \\
\hline U002 & Acetone \\
\hline U003 & Acetonitrile \\
\hline U004 & Acetophenone \\
\hline U005 & 2-acetylaminofluorene \\
\hline U006 & Acetyl chloride (also see Tables C-5 and C-6) \\
\hline U007 & Acrylamide \\
\hline U008 & Acrylic acid \\
\hline U009 & Acrylonitrile \\
\hline U010 & Mitomycin C \\
\hline U011 & Amitrole \\
\hline U012 & Aniline \\
\hline U014 & Auramine \\
\hline U015 & Azaserine \\
\hline U016 & Benz(c)acridine \\
\hline U017 & Benzal chloride \\
\hline U018 & Benz(a)anthracene \\
\hline U019 & Benzene \\
\hline U020 & Benzenesulfonyl chloride (also see Tables C-5 and C-6) \\
\hline U021 & Benzidine \\
\hline U022 & Benzo(a)pyrene \\
\hline
\end{tabular}


Table C-1. Organics (Excluding Dioxins)

\begin{tabular}{|l|l|}
\hline EPA COOB & \\
\hline U023 & Benzotrichloride (also see Tables C-5 and C-6) \\
\hline U024 & bis(2-chloroethoxy) methane \\
\hline U025 & bis(2-chloroethyl) ether \\
\hline U026 & Chlornaphazin \\
\hline U027 & bis(2-chloroisopropyl) ether \\
\hline U028 & bis(2-ethylhexyl) phthalate \\
\hline U029 & Bromomethane \\
\hline U030 & 4-bromophenyl phenyl ether \\
\hline U031 & n-butyl alcohol \\
\hline U033 & Carbonyl fluoride (also see Table C-6) \\
\hline U034 & Trichloroacetaldehyde \\
\hline U035 & Chlorambucil \\
\hline U036 & Chlordane (alpha and gamma) \\
\hline U037 & Chlorobenzene \\
\hline U038 & Chlorobenzilate \\
\hline U039 & p-chloro-m-cresol \\
\hline U041 & 1-chloro-2,3-epoxypropane \\
\hline U042 & 2-chloro ethyl vinyl ether \\
\hline U043 & Vinyl chloride \\
\hline U044 & Chloroform \\
\hline U045 & Chloromethane \\
\hline U046 & Chloromethyl methyl ether \\
\hline U047 & 2-chloronaphthalene \\
\hline U048 & 2-chlorophenol \\
\hline U049 & 4-chloro-o-toluidine hydrochloride \\
\hline U050 & Chrysene \\
\hline U051 & Creosote \\
\hline U052 & Cresol (cresylic acid) \\
\hline & \\
\hline
\end{tabular}


Table C-1. Organics (Excluding Dioxins)

\begin{tabular}{|c|c|}
\hline $\mathrm{EPA} \odot \mathrm{OBE}$ & 1: \\
\hline $\mathrm{U} 053$ & Crotonaldehyde \\
\hline U055 & Cumene \\
\hline U056 & Cyclohexane \\
\hline U057 & Cyclohexanone \\
\hline U058 & Cyclophosphamide \\
\hline U059 & Daunomycin \\
\hline $\mathrm{U} 060$ & DDD \\
\hline U061 & DDT \\
\hline U062 & Diallate \\
\hline U063 & Dibenz $(a, h)$ anthracene \\
\hline $\mathrm{U} 064$ & 1,2,7,8-dibenzopyrene \\
\hline $\mathrm{U} 066$ & 1,2-dibromo-3-chloropropane \\
\hline U067 & 1,2-dibromoethane \\
\hline U068 & Dibromomethane \\
\hline U069 & Di-n-butyl phthalate \\
\hline U070 & o-dichlorobenzene \\
\hline U071 & m-dichlorobenzene \\
\hline U072 & p-dichlorobenzene \\
\hline U073 & 3,3-dichlorobenzidine \\
\hline U074 & cis-1,4-dichloro-2-butene \\
\hline U075 & Dichlorodifluoromethane \\
\hline U076 & 1,1-dichloroethane \\
\hline U077 & 1,2-dichloroethane \\
\hline U078 & 1,1-dichloroethylene \\
\hline U079 & 1,2-dichloroethylene \\
\hline U080 & Methylene chloride \\
\hline U081 & 2,4-dichlorophenol \\
\hline U082 & 2,6-dichlorophenol \\
\hline
\end{tabular}


Table C-1. Organics (Excluding Dioxins)

\begin{tabular}{|c|c|}
\hline EPA $\odot O D E: \%$ & $1 \% 1 \%$ (1) \\
\hline U083 & 1,2-dichloropropane \\
\hline U084 & 1,3-dichloropropene \\
\hline U085 & 1,2,3,4-diepoxybutane \\
\hline U086 & $\mathrm{N}, \mathrm{N}$-diethylhydrazine \\
\hline U087 & O,O-diethyl S-methyldithiophosphate \\
\hline U088 & Diethyl phthalate \\
\hline U089 & Diethyl stilbestrol \\
\hline U090 & Dihydrosafrole \\
\hline U091 & 3,3-dimethoxybenzidine \\
\hline $\mathrm{U} 092$ & Dimethylamine \\
\hline U093 & p-dimethylaminoazobenzene \\
\hline U094 & 7,12-dimethyl benz(a)anthracene \\
\hline U095 & 3,3'-dimethylbenzidine \\
\hline $\mathrm{U096}$ & a,a-dimethyl benzyl hydroperoxide (also see Table $C-6$ ) \\
\hline U097 & Dimethylcarbomyl chloride \\
\hline U098 & 1,1-dimethylhydrazine \\
\hline U099 & 1,2-dimethylhydrazine \\
\hline $\mathrm{U} 101$ & 2,4-dimethylphenol \\
\hline $\mathrm{U} 102$ & Dimethyl phthalate \\
\hline $\mathrm{U} 103$ & Dimethyl sulfate \\
\hline $\mathrm{U} 105$ & 2,4-dinitrotoluene \\
\hline $\mathrm{U} 106$ & 2,6-dinitrotoluene \\
\hline U107 & Di-n-octyl phthalate \\
\hline $\mathrm{U} 108$ & 1,4-dioxane \\
\hline $\mathrm{U} 109$ & 1,2-diphenylhydrazine \\
\hline $\mathrm{U} 110$ & Dipropylamine \\
\hline $\mathrm{U} 111$ & Di-n-propylnitrosoamine \\
\hline $\mathrm{U} 112$ & Ethyl acetate \\
\hline
\end{tabular}


Table C-1. Organics (Excluding Dioxins)

\begin{tabular}{|c|c|}
\hline EPAQPOE. & (1., \\
\hline U113 & Ethyl acrylate \\
\hline $\mathrm{U} 114$ & Ethylene bis-dithiocarbamic acid \\
\hline U115 & Ethylene oxide \\
\hline $\mathrm{U} 116$ & Ethylene thiourea \\
\hline $\mathrm{U} 117$ & Ethyl ether \\
\hline U118 & Ethyl methacrylate \\
\hline $\mathrm{U} 119$ & Ethyl methane sulfonate \\
\hline U120 & Fluoranthene \\
\hline $\mathrm{U} 121$ & Trichloromonofluoromethane \\
\hline $\mathrm{U} 122$ & Formaldehyde \\
\hline $\mathrm{U} 123$ & Formic acid (also see Table C-5) \\
\hline U124 & Furan \\
\hline $\mathrm{U} 125$ & Furfural \\
\hline $\mathrm{U} 126$ & Glycidyaldehyde \\
\hline $\mathrm{U} 127$ & Hexachlorobenzene \\
\hline $\mathrm{U} 128$ & Hexachlorobutadiene \\
\hline $\mathrm{U} 129$ & Lindane \\
\hline $\mathrm{U} 130$ & Hexachlorocyclopentadiene \\
\hline $\mathrm{U} 131$ & Hexachloroethane \\
\hline $\mathrm{U} 132$ & Hexachlorophene \\
\hline U137 & Indeno $(1,2,3-c, d)$ pyrene \\
\hline $\mathrm{U} 138$ & Iodomethane \\
\hline $\mathrm{U} 140$ & Isobutyl alcohol \\
\hline $\mathrm{U} 141$ & Isosafrole \\
\hline $\mathrm{U} 142$ & Kepone \\
\hline $\mathrm{U} 143$ & Lasiocarpine \\
\hline $\mathrm{U} 146$ & Lead subacetate \\
\hline U147 & Maleic anhydride \\
\hline
\end{tabular}


Table C-1. Organics (Excluding Dioxins)

\begin{tabular}{|c|c|}
\hline EPA & (1.8. \\
\hline U148 & Maleic hydrazide \\
\hline U149 & Malononitrile \\
\hline $\mathrm{U} 150$ & Melphalan \\
\hline $\mathrm{U} 152$ & Methacrylonitrile \\
\hline $\mathrm{U} 153$ & Methane thiol \\
\hline $\mathrm{U} 154$ & Methanol \\
\hline U155 & Methapyrilene \\
\hline $\mathrm{U} 156$ & Methyl chlorocarbonate \\
\hline $\mathrm{U} 157$ & 3-methylchloanthrene \\
\hline $\mathrm{U} 158$ & 4,4'-methylene-bis-(2-chloroaniline) \\
\hline U159 & Methyl ethyl ketone \\
\hline $\mathrm{U} 160$ & Methyl ethyl ketone peroxide (Also see Table C-6) \\
\hline $\mathrm{U} 161$ & Methyl isobutyl ketone \\
\hline $\mathrm{U} 162$ & Methyl methacrylate \\
\hline $\mathrm{U} 163$ & $\mathrm{~N}$-methyl $\mathrm{N}^{\prime}$-nitro $\mathrm{N}$-nitrosoguanidine \\
\hline U164 & Methylthiouracil \\
\hline $\mathrm{U} 165$ & Naphthalene \\
\hline $\mathrm{U} 166$ & 1,4-naphthoquinone \\
\hline $\mathrm{U} 167$ & 1-naphthlyamine \\
\hline $\mathrm{U} 168$ & 2-napthylamine \\
\hline $\mathrm{U} 169$ & Nitrobenzene \\
\hline $\mathrm{U} 170$ & 4-nitrophenol \\
\hline $\mathrm{U} 171$ & 2-nitropropane \\
\hline $\mathrm{U} 172$ & n-nitroso-di-n-butylamine \\
\hline $\mathrm{U} 173$ & N-nitroso-di-n-ethanolamine \\
\hline $\mathrm{U} 174$ & $\mathrm{~N}$-nitrosodiethylamine \\
\hline $\mathrm{U} 176$ & N-nitroso-N-ethylurea \\
\hline U177 & N-nitroso-N-methylurea \\
\hline
\end{tabular}


Table C-1. Organics (Excluding Dioxins)

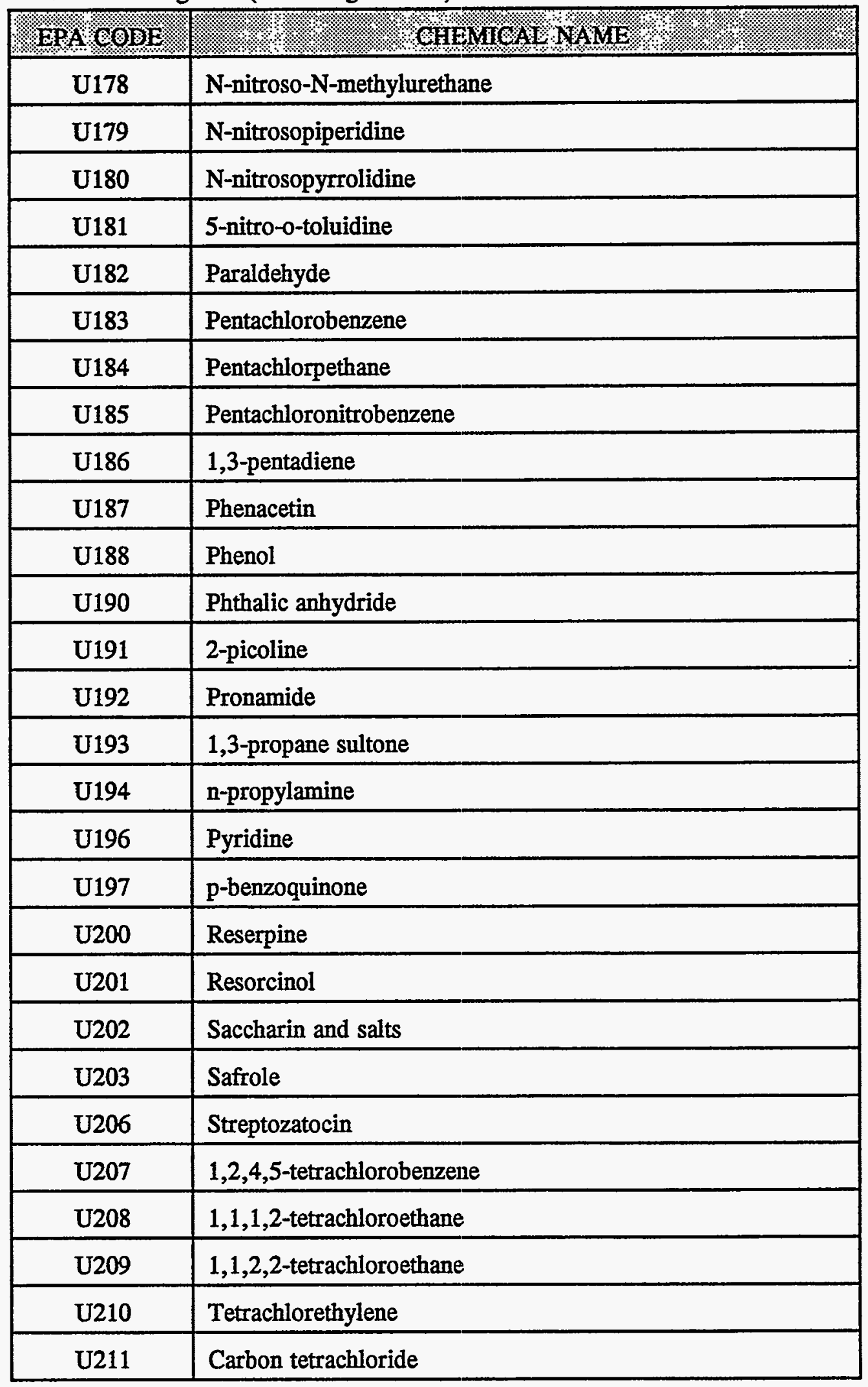


Table C-1. Organics (Excluding Dioxins)

\begin{tabular}{|c|c|}
\hline $\mathrm{EPA} \mathrm{CODE}$ & (1: \\
\hline U213 & Tetrahydrofuran \\
\hline $\mathrm{U} 218$ & Thioacetamide \\
\hline $\mathrm{U} 219$ & Thiourea \\
\hline $\mathrm{U} 220$ & Toluene \\
\hline U221 & Toluenediamine \\
\hline $\mathrm{U} 222$ & o-toluidine hydrochloride \\
\hline $\mathrm{U} 223$ & Toluene diisocyanate (also see Table $\mathrm{C}-6$ ) \\
\hline $\mathrm{U} 225$ & Tribromomethane \\
\hline $\mathrm{U} 226$ & 1,1,1-trichloroethane \\
\hline U227 & 1,1,2-trichloroethane \\
\hline $\mathrm{U} 228$ & Trichloroethylene \\
\hline $\mathrm{U} 234$ & sym-trinitrobenzene (also see Table C- 6 ) \\
\hline $\mathrm{U} 235$ & tris-(2,3-dibromopropyl)-phosphate \\
\hline $\mathrm{U} 236$ & Trypan blue \\
\hline U237 & Uracil mustard \\
\hline $\mathrm{U} 238$ & Ethyl carbamate \\
\hline U239 & Xylenes \\
\hline $\mathrm{U} 240$ & 2,4-dichlorophenoxyacetic acid \\
\hline $\mathrm{U} 243$ & Hexachloropropene \\
\hline U244 & Thiram \\
\hline $\mathrm{U} 246$ & Cyanogen bromide \\
\hline $\mathrm{U} 247$ & Methoxychlor \\
\hline $\mathrm{U} 248$ & Warfarin $(>3 \%)$ \\
\hline U328 & Benzenamine, 2-methyl \\
\hline
\end{tabular}


Table C-1. Organics (Excluding Dioxins)

\begin{tabular}{|c|l|}
\hline $\mathrm{EPA}$ COBE & \multicolumn{1}{|c|}{. } \\
\hline $\mathrm{U} 353$ & Benzenamine, 4-methyl \\
\hline $\mathrm{U} 359$ & 2-ethoxyethanol \\
\hline
\end{tabular}

1 2-chloro-1,3-butadiene, 3-chloropropene, 1,1-dichloroethane, 1,2-dichloroethane, 1,2-dichloropropane, cis-1,3-dichloropropene, trans-1,3-dichloropropene, bis(2-ethylhexyl)-phthalate, hexachloroethane.

2 Chloroform, 1,2-dichloroethane, 1,1-dichloroethylene, methylene chloride, carbon tetrachloride, 1,1,2-trichloroethane trichloroethylene, vinyl chloride, hexachlorobenzene, hexachlorobutadiene, hexachloroethane.

3 Wastewaters/residues from chlorophenolic wood preserving processes.

- Wastewaters/residues from creosote wood preserving processes.

s Acenaphtheno, anthracene, benzene, benzo(a)anthracene, benzo(a)pyrene, bis(2-ethythexyl)phthalate, chrysene, di-n-butyl phthalate, ethylbenzene, fluorene, naphthalene, phenanthrene, phenol, pyrene, toluene, xylene(s).

6 Benzene, benzo(a)pyrene, bis(2-ethylhexyl)phthalate, chrysene, di-n-butyl phthalate, ethylbenzene, fluorene, naphthalene, phenanthrene, phenol, pyreze, toluene, xylene(s).

7 Leachate from hazardous waste disposal areas. 
Table C-2. Organics - Dioxins

\begin{tabular}{|c|l|}
\hline EPAPODE & 10 \\
\hline F020 & $\begin{array}{l}\text { Tetra- and pentachlorodibenzo-p-dioxins; tetra- and pentachlorodi-benzofurans; tri- } \\
\text { and tetrachlorophenols and their chlorophenoxy derivative acids, esters, ethers, } \\
\text { amine, and other salts }\end{array}$ \\
\hline F021 & $\begin{array}{l}\text { Penta- and hexachlorodibenzo-p-dioxins; penta- and hexachlorodibenzofurans; } \\
\text { pentachlorophenol and its derivatives }\end{array}$ \\
\hline F022 & $\begin{array}{l}\text { Tetra-, penta-, and hexachlorodibenzo-p-dioxins; tetra-, penta-, and } \\
\text { hexachlorodibenzofurans }\end{array}$ \\
\hline F023 & $\begin{array}{l}\text { Tetra- and pentachlorodibenzo-p-dioxins; tetra- and pentachlorodibenzofurans; tri- } \\
\text { and tetrachlorophenols and their chlorophenoxy derivative acids, esters, ethers, } \\
\text { amine, and other salts. }\end{array}$ \\
\hline F026 & $\begin{array}{l}\text { Tetra-, penta-, and hexachlorodibenzo-p-dioxins; tetra-, penta-, and } \\
\text { hexachlorodibenzofurans }\end{array}$ \\
\hline F027 & $\begin{array}{l}\text { Tetra-, penta-, and hexachlorodibenzo-p-dioxins; tetra-, penta-, and } \\
\text { hexachlorodibenzofurans; tri-, tetra-, and pentachlorophenols and their chlorophenoxy } \\
\text { derivative acids, esters, ethers, amine, and other salts }\end{array}$ \\
\hline F028 & $\begin{array}{l}\text { Tetra-, penta-, and hexachlorodibenzo-p-dioxins; tetra-, penta-, and } \\
\text { hexachlorodibenzofurans; tri-, tetra-, and pentachlorophenols and their chlorophenoxy } \\
\text { derivative acids, esters, ethers, amine, and other salts }\end{array}$ \\
\hline $\begin{array}{l}\text { Multiple organic compounds, including tetra-, penta-, and hexachlorodibenzo-dioxins; } \\
\text { tetra-, penta-, and hexachlorodibenzo-furans (leachate from hazardous waste disposal } \\
\text { areas; also see Tables C-1, C-3, C-4, and C-7) }\end{array}$ \\
\hline
\end{tabular}


Table C-3. Metals - Excluding Mercury

\begin{tabular}{|c|c|c|}
\hline 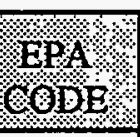 & 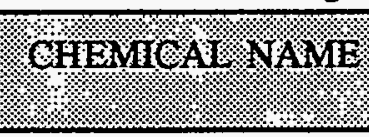 & 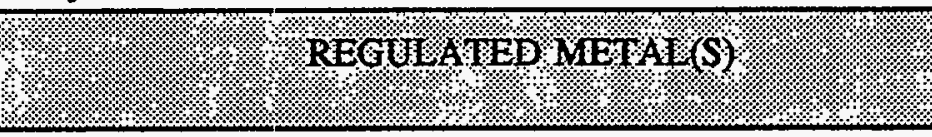 \\
\hline $\mathrm{D} 004$ & NA & Arsenic \\
\hline $\mathrm{D} 005$ & NA & Barium \\
\hline D006 & NA & Cadmium \\
\hline D007 & NA & Chromium \\
\hline D008 & NA & Lead \\
\hline D010 & NA & Selenium \\
\hline D011 & NA & Silver \\
\hline F006 & NA & Cadmium, chromium, lead, nickel, silver (also see Table C-7) \\
\hline F007 & NA & Cadmium, chromium, lead, nickel, silver (also see Table C-7) \\
\hline F008 & NA & Cadmium, chromium, lead, nickel, silver (also see Table C-7) \\
\hline F009 & NA & Cadmium, chromium, lead, nickel, silver (also see Table C-7) \\
\hline F011 & NA & Cadmium, chromium, lead, nickel, silver (also see Table C-7) \\
\hline F012 & NA & Cadmium, chromium, lead, nickel, silver (also see Table C-7) \\
\hline F019 & NA & Chromium (also see Table C-7) \\
\hline F024 & NA & Chromium, lead, nickel (also see Table C-1) \\
\hline F035 & NA & Arsenic, chromium \\
\hline F037 & NA & Chromium, lead, nickel (also see Tables C-1 and C-7) \\
\hline F038 & NA & Chromium, lead, nickel (also see Tables C-1 and C-T) \\
\hline F039 & NA & Several metals ${ }^{1}$ (also see Tables C-1, C-2, C-4, and C-7) \\
\hline P010 & Arsenic acid & Arsenic \\
\hline P011 & Arsenic pentoxide & Arsenic \\
\hline $\mathrm{P} 012$ & Arsenic trioxide & Arsenic \\
\hline $\mathrm{P} 013$ & Barium cyanide & Barium (also see Table C-7) \\
\hline P015 & Beryllium dust & Beryllium \\
\hline P036 & Dichloro-phenylarsine & Arsenic \\
\hline $\mathrm{P} 038$ & Diethylarsine & Arsenic \\
\hline $\mathrm{P} 073$ & Nickel carbonyl & Nickel \\
\hline $\mathrm{P} 074$ & Nickel cyanide & Nickel (also see Table C-7) \\
\hline P087 & Osmium tetroxide & Osmium tetroxide \\
\hline
\end{tabular}


Table C-3. Metals - Excluding Mercury

\begin{tabular}{|c|c|c|}
\hline ECODE & \%HEMVIV NAVE: & 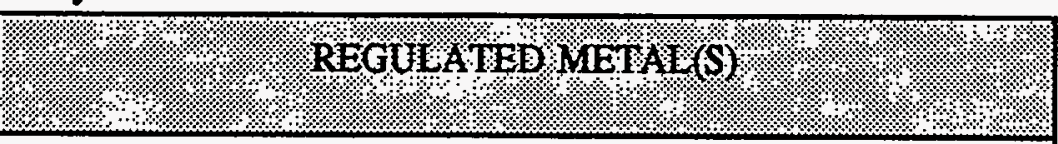 \\
\hline P099 & $\begin{array}{l}\text { Potassium silver } \\
\text { cy\&nide }\end{array}$ & Silver (also see Table C-T) \\
\hline P103 & Selenourea & Selenium \\
\hline P104 & Silver cyanide & Silver (also see Table C-7) \\
\hline P110 & Tetraethyl lead & Lead \\
\hline P113 & Thallic oxide & Thallium \\
\hline P114 & Thallium selenite & Selenium \\
\hline P115 & Thallium (I) sulfate & Thallium \\
\hline P119 & Ammonia vanadate & Vanadium \\
\hline $\mathrm{P} 120$ & Vanadium petoxide & Vanadium \\
\hline U032 & Calcium chromate & Chromium \\
\hline U136 & Cacodylic acid & Arsenic \\
\hline U144 & Lead acetate & Lead \\
\hline U145 & Lead phosphate & Lead \\
\hline U146 & Lead subacetate & Lead \\
\hline $\mathrm{U} 204$ & Selenium dioxide & Selenium \\
\hline U205 & Selenium sulfide & Selenium (also see Table C-6) \\
\hline $\mathrm{U} 214$ & Thallium (I) acetate & Thallium \\
\hline $\mathrm{U} 215$ & Thallium (I) carbonate & Thallium \\
\hline $\mathrm{U} 216$ & Thallium (I) chloride & Thallium \\
\hline U217 & Thallium (I) nitrate & Thallium \\
\hline
\end{tabular}

I Antimony, arsenic, barium, beryllium, cadmium, chromium, copper, lead, mercury, nickel, selenium, silver, thallium, vanadium, and zinc.

NA - not applicable 
Table C-4. Mercury

\begin{tabular}{|c|l|}
\hline EPA CODE & Mercury \\
\hline D009 & Me \\
\hline F039 & NA (also see Tables C-1, C-2, C-3, and C-7) \\
\hline P065 & Mercury fulminate (also see Table C-6) \\
\hline P092 & Phenyl mercury acetate \\
\hline U151 & Mercury \\
\hline
\end{tabular}

NA - not applicable

Table C-5. Corrosives

\begin{tabular}{|l|l|}
\hline EPA OODE & . \\
\hline D002 & Corrosive characteristic \\
\hline U006 & Acetyl chloride (also see Table C-1) \\
\hline U020 & Benzenesulfonyl chloride (also see Tables C-1 and C-6) \\
\hline U023 & Benzotrichloride (also see Tables C-1 and C-6) \\
\hline U123 & Formic acid (also see Table C-1) \\
\hline U134 & Hydrofluoric acid \\
\hline
\end{tabular}


Table C-6. Reactives

\begin{tabular}{|c|c|}
\hline $\mathrm{EPA} / \mathrm{OPB}$ & $1 \%$ 1.4: \\
\hline D003 & Reactive characteristic \\
\hline P006 & Aluminum phosphide \\
\hline P009 & Ammonium picrate \\
\hline P065 & Mercury fulminate (also see Table C-4) \\
\hline P081 & Nitroglycerine (also see Table C-1) \\
\hline P105 & Sodium azide \\
\hline P112 & Tetranitromethane (also see Table C-1) \\
\hline $\mathrm{P} 122$ & Zinc phosphide ( $>10 \%)$ \\
\hline U020 & Benzenesulfonyl chloride (also see Tables $\mathrm{C}-1$ and $\mathrm{C}-5$ ) \\
\hline U023 & Benzotrichloride (also see Tables C-1 and C-5) \\
\hline U033 & Carbonyl fluoride (also see Table C-1) \\
\hline $\mathrm{U} 096$ & a,a-dimethyl benzyl hydroperoxide (also see Table C-1) \\
\hline U133 & Hydrazine \\
\hline $\mathrm{U} 160$ & Methyl ethyl ketone peroxide (also see Table C-1) \\
\hline U189 & Phosphorus sulfide \\
\hline U205 & Selenium sulfide (also see Table C-3) \\
\hline U223 & Toluene diisocyanate (also see Table C-1) \\
\hline U234 & 1,3,5-trinitrobenzene (also see Table C-1) \\
\hline
\end{tabular}


Table C-7. Cyanides

\begin{tabular}{|c|c|}
\hline EPA CONE & GHEMIOA. NAVH/ \\
\hline F006 & Plating waste-if cyanides used in process (also see Table C-3) \\
\hline F007 & Plating waste (also see Table C-3) \\
\hline F008 & Plating waste (also see Table C-3) \\
\hline F009 & Plating waste (also see Table C-3) \\
\hline F010 & Note $^{1}$ \\
\hline F011 & Note $^{2}$ (also see Table C-3) \\
\hline F012 & Note $^{3}$ (also see Table C-3) \\
\hline F019 & Note $^{4}$ (also see Table C-3) \\
\hline F037 & Note $^{5}$ (also see Tables C-1 and C-3) \\
\hline F038 & Note $^{6}$ (also see Tables C-1 and C-3) \\
\hline F039 & Note $^{7}$ (also see Tables C-1, C-2, C-3, and C-4) \\
\hline P013 & Barium cyanide (also see Table C-3) \\
\hline $\mathrm{P} 021$ & Calcium Cyanide \\
\hline P029 & Copper cyanide \\
\hline P030 & Cyanides (soluble salts, complexes) \\
\hline P063 & Hydrogen cyanide \\
\hline P074 & Nickel cyanide (also see Table C-3) \\
\hline P098 & Potassium cyanide \\
\hline P099 & Potassium silver cyanide (also see Table C-3) \\
\hline P104 & Silver cyanide (also see Table C-3) \\
\hline P106 & Sodium cyanide \\
\hline P121 & Zinc cyanide \\
\hline
\end{tabular}

1 Metal heat treating operations - oil quench bath residues.

2 Metal heat treating operations - spent cyanide solutions from salt bath pot cleaning.

3 Metal heat treating operations - quenching wastewater treatment sludges.

- Wastewater treatment sludges from chemical conversion coating of aluminum.

5 Petroleum refinery primary oil/water/solids separation sludge.

- Petroleum refinery secondary emulsified oil/water/solids separation sludge.

7 Leachate from hazardous waste disposal areas (cyanides are regulated if present). 
Table C-8. Other EPA Codes

\begin{tabular}{|c|l|}
\hline EPA COBE & CHEMiCAT NAME. \\
\hline P056 & Fluorine \\
\hline P076 & Nitrogen oxide \\
\hline P078 & Nitrogen dioxide \\
\hline P096 & Phosphine \\
\hline P105 & Sodium azide \\
\hline U135 & Hydrogen sulfide \\
\hline U249 & Zinc phosphide $(<10 \%)$ \\
\hline
\end{tabular}





\section{APPENDIX D}

REGULATED CONTAMINANT PARAMETER CATEGORIES 


\begin{tabular}{|c|c|}
\hline 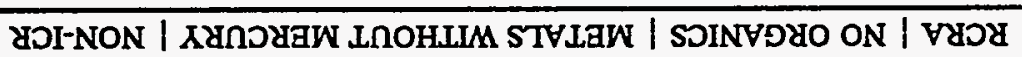 & 060 | IIN | 060 | ग8 \\
\hline 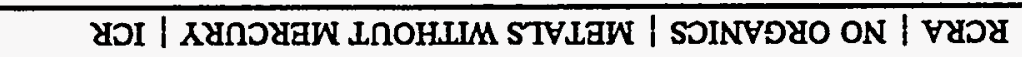 & LID | IIN | 060 | DY \\
\hline 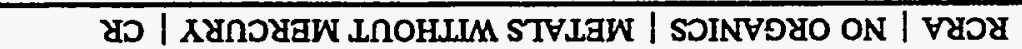 & 9IS | IIW | $060 \mid$ כ8 \\
\hline 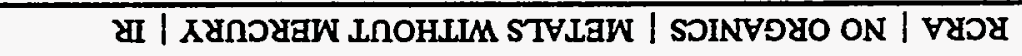 & SID | IIW | 060 | D\& \\
\hline 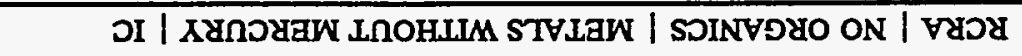 & †ID | IIN $\mid 060$ | D\& \\
\hline \& | XYחDYaW InOHLLM STVLaW I SDINYDYO ON | V\&DY & EID | IIN | 060 | Ј8 \\
\hline 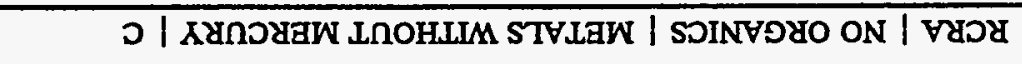 & ZTD | ITW | 060 | ว४ \\
\hline 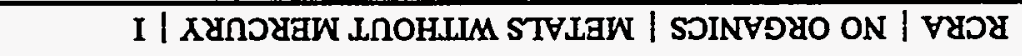 & IID | IIW $|060|$ J8 \\
\hline YOI-NON | STVIAW ON | SDINYDYO | V\&DY & 063 | 06N | ITO | د8 \\
\hline צDI | STVLAW ON | SDINYDYO | F\&DY & LIS | 06N | ITO | S\& \\
\hline \& | STVLAK ON | SSINYDYO | V\&D\& & 9ID | 06N | ITO | ว8 \\
\hline צI | STVLAW ON | SDINYDYO | F\&DY & SID | 06W | IIO | วل \\
\hline गI | STVIZW ON | SDINVDYO | V\&DY & จIS | 06N | ITO | O\& \\
\hline Y | STVLAK ON | SDINVDYO | F\&D\& & ETد | O6N | ITO | D\& \\
\hline D | STVLAW ON / SDINVDYO / V\&DY & ZID | 06N | ITO | DY \\
\hline I | STVLAW ON | SDINYDYO | F\&DY & IIJ | 06W | ITO | DY \\
\hline 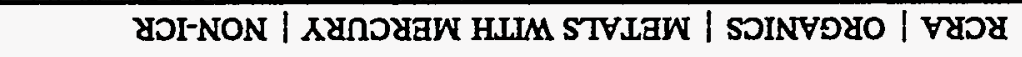 & 065 | ZTW | IIO | วष \\
\hline 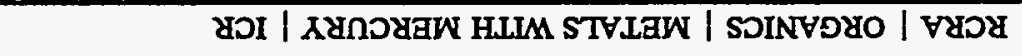 & LIS | ZIN | ITO | D\& \\
\hline 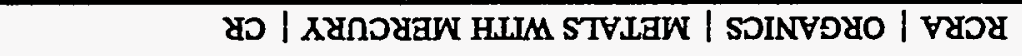 & 9โว | ZIN | IIO | วष \\
\hline 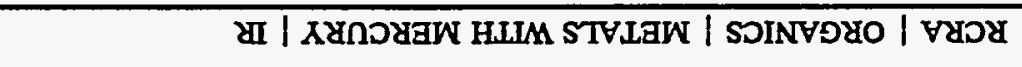 & stว | ZIW | ITO | อष \\
\hline 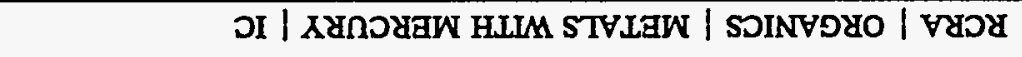 & ๑IS | ZIW | IIO | อष \\
\hline 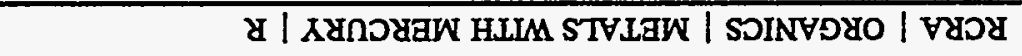 & Eโว | ZIW | โTO | วષ \\
\hline 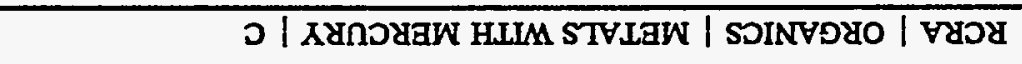 & ZIS | ZIN | โIO | จ४ \\
\hline 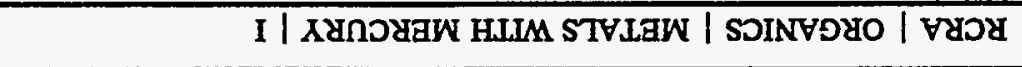 & 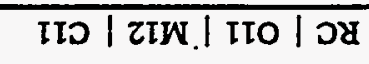 \\
\hline 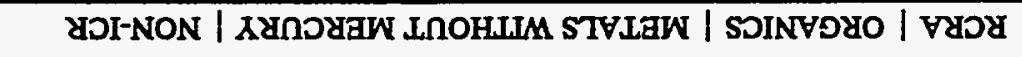 & 065 | IIW | IIO | D\& \\
\hline 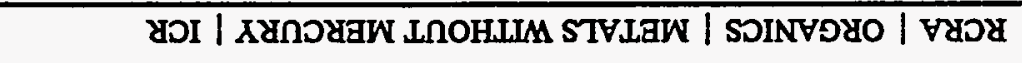 & LIS | ILW | IIO | S\& \\
\hline 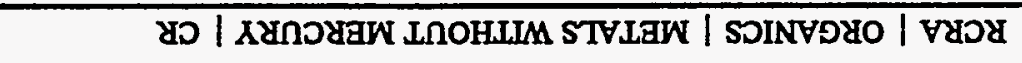 & 9IJ | IIK | โTO | ЈY \\
\hline 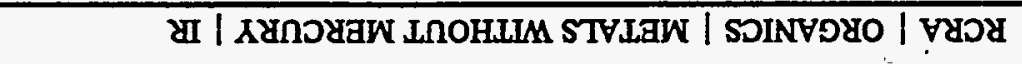 & SIS | IIK | IIO | ว४ \\
\hline 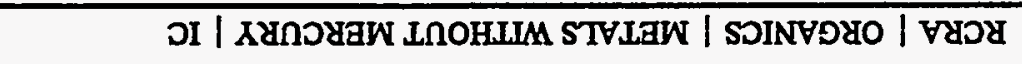 & 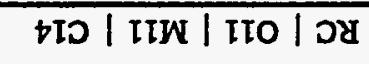 \\
\hline 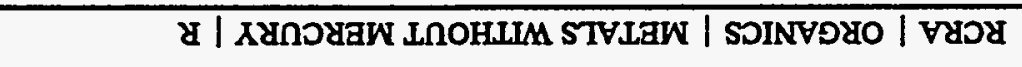 & 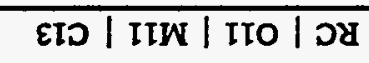 \\
\hline 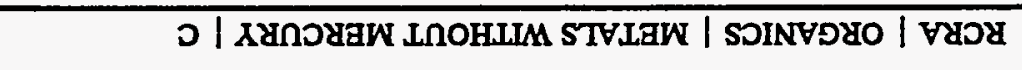 & 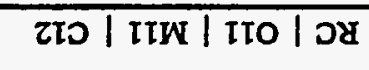 \\
\hline 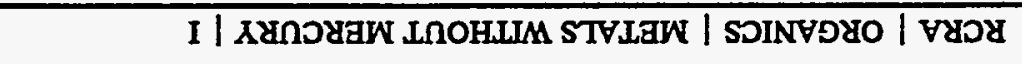 & IID | IIK | IIO | D\& \\
\hline (.). & $1,10 \%$ o \\
\hline
\end{tabular}


Table D-1. RCRA Hazardous or Mixed Waste CPCs

\begin{tabular}{|c|c|}
\hline $4.9 \mathrm{APCOONO}$ & (1.4. \\
\hline $\mathrm{RC}|090| \mathrm{M} 12 \mid \mathrm{C} 11$ & RCRA | NO ORGANICS | METALS WITH MERCURY | I \\
\hline $\mathrm{RC}|090| \mathrm{M} 12 \mid \mathrm{C} 12$ & RCRA | NO ORGANICS | METALS WTTH MERCURY | C \\
\hline $\mathrm{RC}|090| \mathrm{M} 12 \mid \mathrm{C} 13$ & RCRA | NO ORGANICS | METALS WITH MERCURY | R \\
\hline $\mathrm{RC}|090| \mathrm{M} 12 \mid \mathrm{C} 14$ & RCRA | NO ORGANICS | METALS WITH MERCURY | IC \\
\hline $\mathrm{RC}|090| \mathrm{M} 12 \mid \mathrm{C} 15$ & RCRA | NO ORGANICS | METALS WITH MERCURY | IR \\
\hline $\mathrm{RC}|090| \mathrm{M} 12 \mid \mathrm{C} 16$ & RCRA | NO ORGANICS | METALS WITH MERCURY | CR \\
\hline $\mathrm{RC}|090| \mathrm{M} 12$ | C17 & RCRA | NO ORGANICS | METALS WITH MERCURY | ICR \\
\hline $\mathrm{RC}|090| \mathrm{M} 12$ | C90 & RCRA | NO ORGANICS | METALS WITH MERCURY | NON-ICR \\
\hline $\mathrm{RC}|090| \mathrm{M} 90$ | C11 & RCRA | NO ORGANICS | NO METALS | I \\
\hline $\mathrm{RC}|\mathrm{O} 90| \mathrm{M} 90 \mid \mathrm{C} 12$ & RCRA | NO ORGANICS | NO METALS | C \\
\hline $\mathrm{RC}|090| \mathrm{M} 90$ | C13 & RCRA | NO ORGANICS | NO METALS | R \\
\hline $\mathrm{RC}|090| \mathrm{M} 90 \mid \mathrm{C} 14$ & RCRA | NO ORGANICS | NO METALS | IC \\
\hline $\mathrm{RC}|090| \mathrm{M} 90 \mid \mathrm{C} 15$ & RCRA | NO ORGANICS | NO METALS | IR \\
\hline $\mathrm{RC}|090| \mathrm{M} 90 \mid \mathrm{C} 16$ & RCRA | NO ORGANICS | NO METALS | CR \\
\hline $\mathrm{RC}|090| \mathrm{M} 90 \mid \mathrm{C} 17$ & RCRA | NO ORGANICS | NO METALS | ICR \\
\hline $\mathrm{RC}|090| \mathrm{M} 90 \mid \mathrm{C} 90$ & RCRA | NO ORGANICS | NO METALS | NON-ICR \\
\hline
\end{tabular}


Table D-2. RCRA/TSCA Hazardous or Mixed Waste CPCs

\begin{tabular}{|c|c|}
\hline \%०popopd & CPOHWH \\
\hline RT | 011 | M11 | C11 & RCRA/TSCA | ORGANICS | METALS WITHOUT MERCURY | I \\
\hline RT | $011 \mid \mathrm{M} 11$ | C12 & RCRA/TSCA | ORGANICS | METALS WTTHOUT MERCURY | c \\
\hline RT | 011 | M11 | C13 & RCRA/TSCA | ORGANICS | METALS WITHOUT MERCURY | R \\
\hline RT | $011 \mid$ M11 | C14 & RCRA/TSCA | ORGANICS | METALS WITHOUT MERCURY | IC \\
\hline RT | O11 | M11 | C15 & RCRA/TSCA | ORGANICS | METALS WITHOUT MERCURY | IR \\
\hline RT | 011 | M11 | C16 & RCRA/TSCA | ORGANICS | METALS WTTHOUT MERCURY | CR \\
\hline RT | $011 \mid$ M11 | C17 & RCRA/TSCA | ORGANICS | METALS WITHOUT MERCURY | ICR \\
\hline RT | 011 | M11 | C90 & RCRATTSCA | ORGANICS | METALS WITHOUT MERCURY | NON-ICR \\
\hline RT | 011 | M12 | C11 & RCRA/TSCA | ORGANICS | METALS WITH MERCURY | I \\
\hline $\mathrm{RT}|\mathrm{O} 11| \mathrm{M} 12$ | $\mathrm{C} 12$ & RCRA/TSCA | ORGANICS | METALS WTH MERCURY | C \\
\hline $\mathrm{RT}|\mathrm{O} 11| \mathrm{M} 12$ | C13 & RCRATTSCA | ORGANICS | METALS WITH MERCURY | R \\
\hline $\mathrm{RT}|\mathrm{O} 11| \mathrm{M} 12$ | C14 & RCRA/TSCA | ORGANICS | METALS WITH MERCURY | IC \\
\hline $\mathrm{RT}|\mathrm{O} 11| \mathrm{M} 12$ | C15 & RCRA/TSCA | ORGANICS | METALS WITH MERCURY | IR \\
\hline RT | O11 | M12 | C16 & RCRA/TSCA | ORGANICS | METALS WITH MERCURY | CR \\
\hline RT | 011 | M12 | C17 & RCRATTSCA | ORGANICS | METALS WITH MERCURY | ICR \\
\hline $\mathrm{RT}|\mathrm{O} 11| \mathrm{M} 12$ | C90 & RCRA/TSCA | ORGANICS | METALS WITH MERCURY | NON-ICR \\
\hline RT | 011 | M90 | C11 & RCRA/TSCA | ORGANICS | NO METALS | I \\
\hline RT | 011 | M90 | C12 & RCRA/TSCA | ORGANICS | NO METALS | C \\
\hline RT | 011 | M90 | C13 & RCRA/TSCA | ORGANICS | NO METALS | $R$ \\
\hline $\mathrm{RT}$ | 011 | M90 | C14 & RCRA/TSCA | ORGANICS | NO METALS | IC \\
\hline $\mathrm{RT}|\mathrm{O} 11| \mathrm{M} 90$ | C15 & RCRA/TSCA | ORGANICS | NO METAIS | IR \\
\hline RT | $011|\mathrm{M} 90| \mathrm{C} 16$ & RCRA/TSCA | ORGANICS | NO METALS | CR \\
\hline $\mathrm{RT} \mid \mathrm{O} 11$ | M90 | C17 & RCRA/TSCA | ORGANICS | NO METALS | ICR \\
\hline $\mathrm{RT} \mid \mathrm{O} 11$ | M90 | C90 & RCRA/TSCA | ORGANICS | NO METALS | NON-ICR \\
\hline RT | 090 | M11 | C11 & RCRA/TSCA | NO ORGANICS | METALS WITHOUT MERCURY | I \\
\hline $\mathrm{RT}|090| \mathrm{M} 11 \mid \mathrm{C} 12$ & RCRA/TSCA | NO ORGANICS | METALS WITHOUT MERCURY | C \\
\hline $\mathrm{RT} \mid 090$ | M11 | C13 & RCRAITSCA | NO ORGANICS | METALS WITHOUT MERCURY | R \\
\hline $\mathrm{RT} \mid 090$ | M11 | C14 & RCRA/TSCA | NO ORGANICS | METALS WITHOUT MERCURY | IC \\
\hline $\mathrm{RT} \mid \mathrm{O} 90$ | M11 | C15 & RCRA/TSCA | NO ORGANICS | METALS WTTHOUT MERCURY | IR \\
\hline $\mathrm{RT} \mid 090$ | M11 | C16 & RCRA/TSCA | NO ORGANICS | METALS WTTHOUT MERCURY | CR \\
\hline $\mathrm{RT} \mid \mathrm{O} 90$ | M11 | C17 & RCRATTSCA | NO ORGANICS | METALS WITHOUT MERCURY | ICR \\
\hline $\mathrm{RT} \mid 090$ | M11 | C90 & RCRA/TSCA | NO ORGANICS | METALS WITHOUT MERCURY | NON-ICR \\
\hline
\end{tabular}


Table D-2. RCRA/TSCA Hazardous or Mixed Waste CPCs

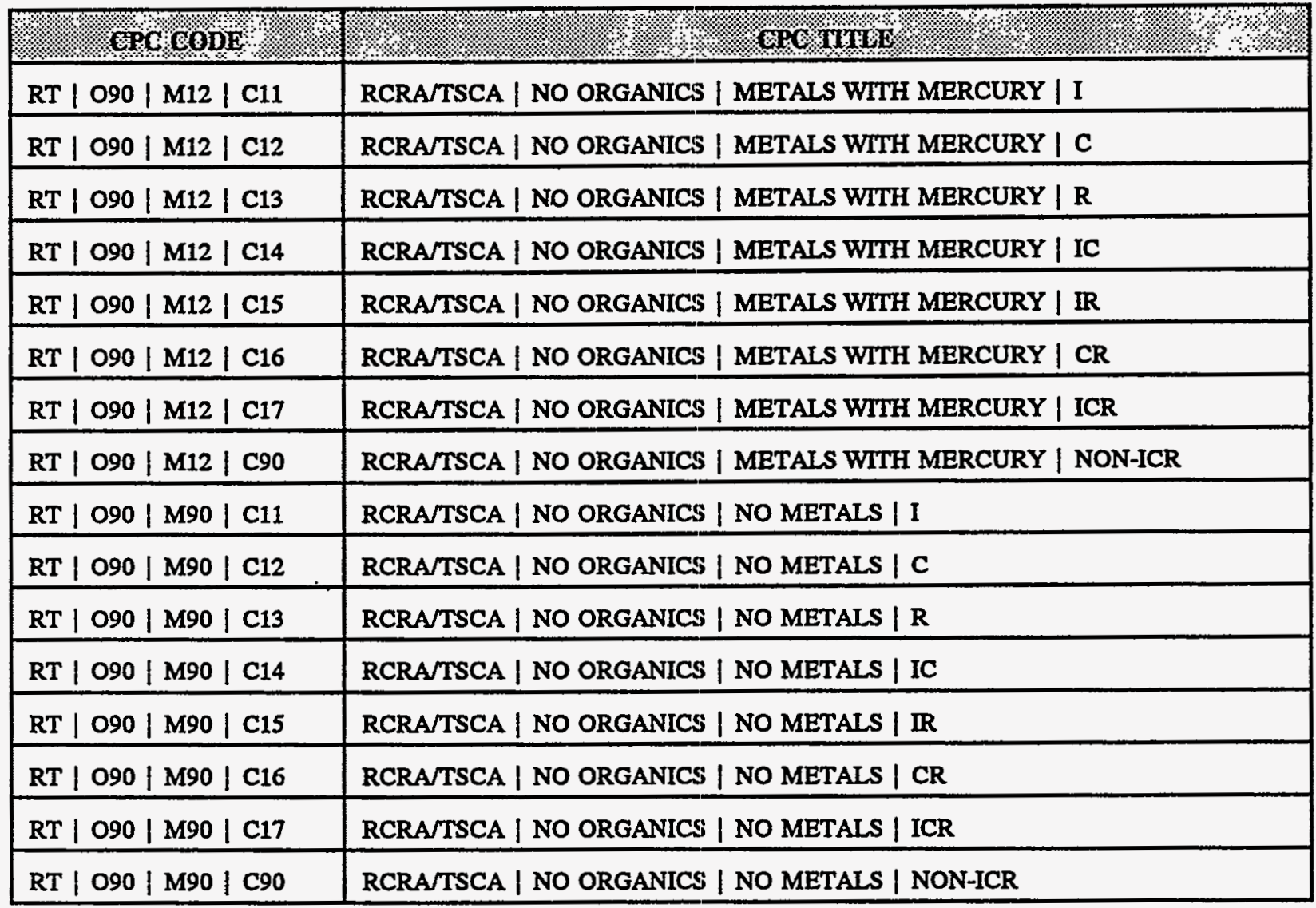




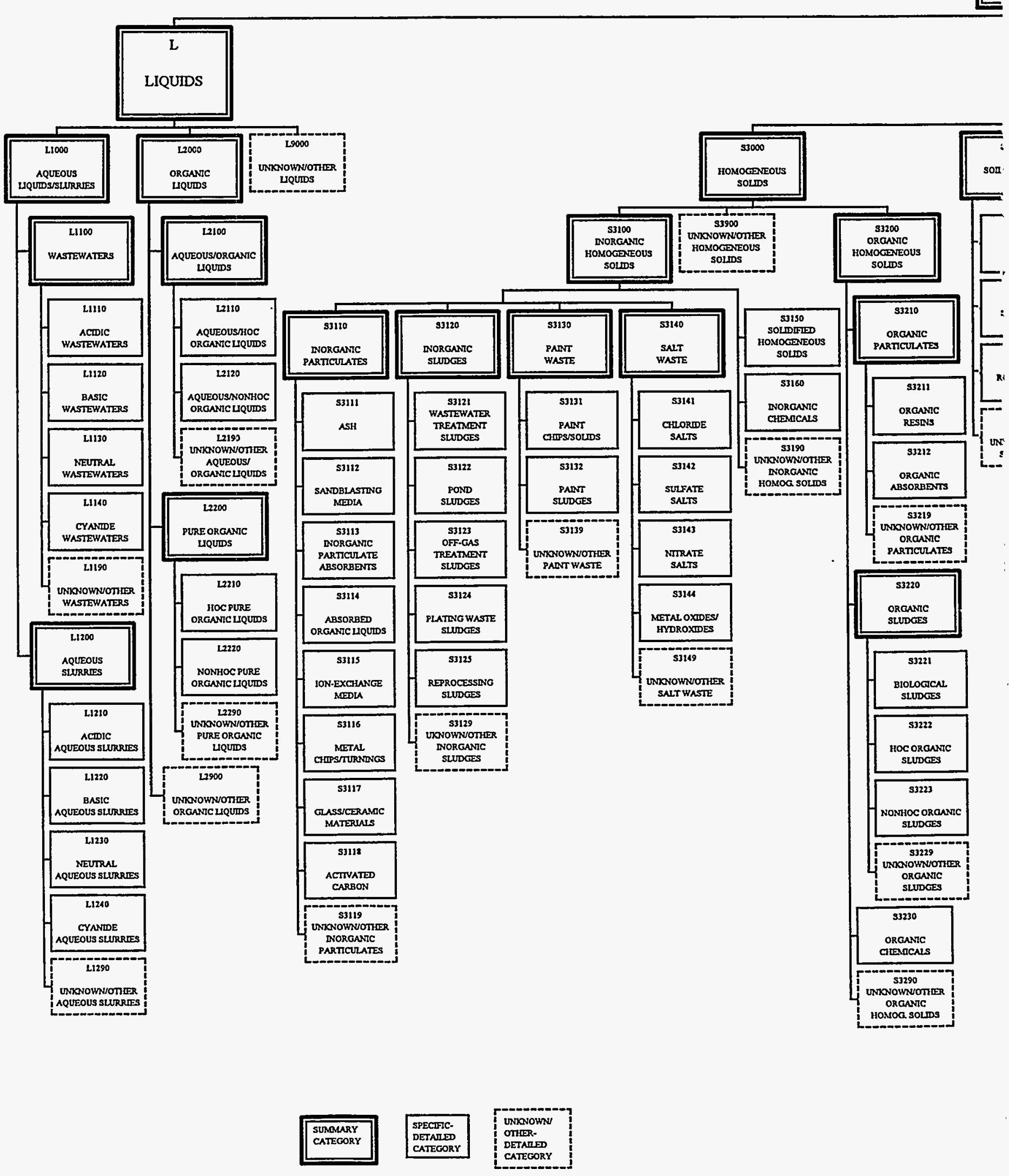




\section{x Parameter Categories}

IE MATRDX IEGORIES

SOLIDS
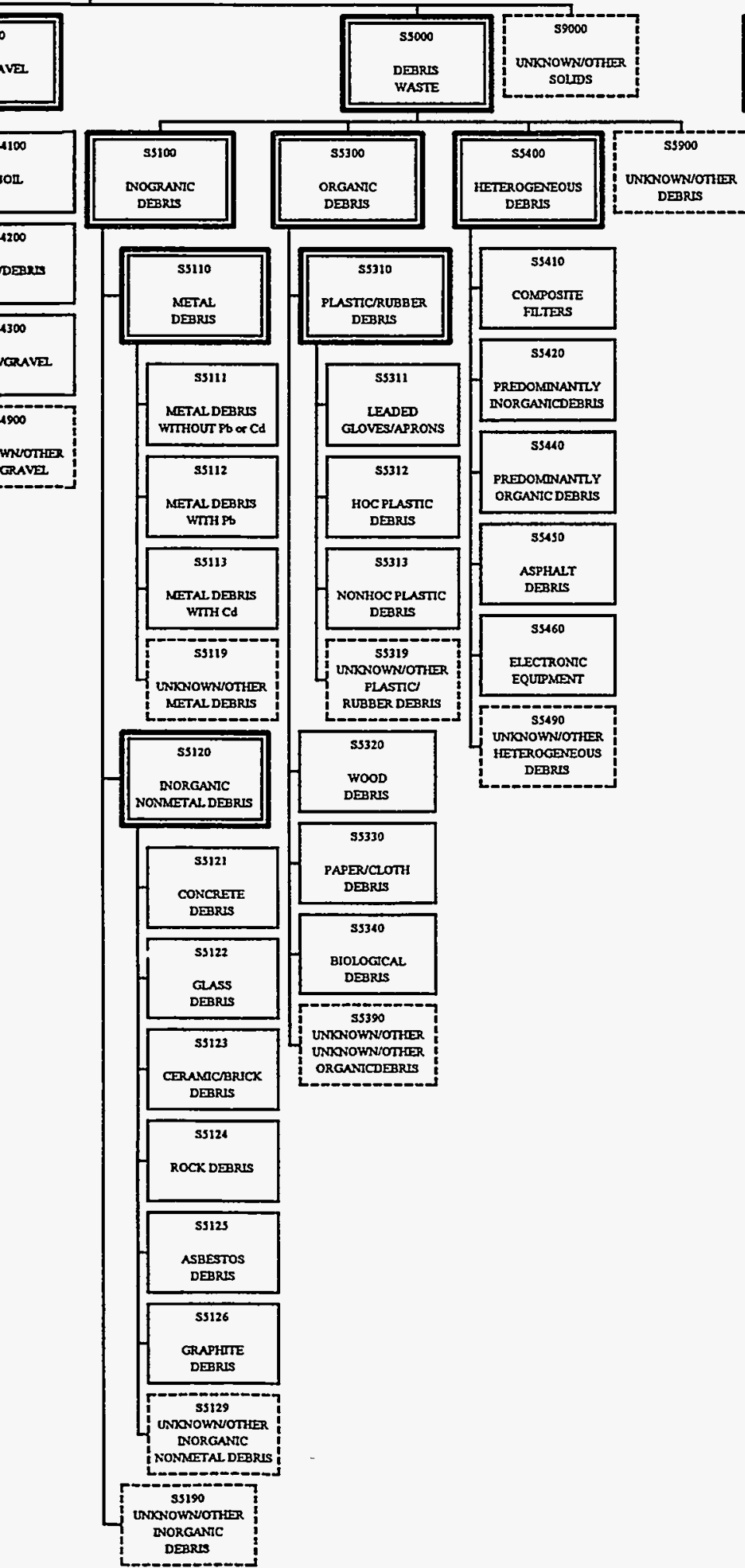
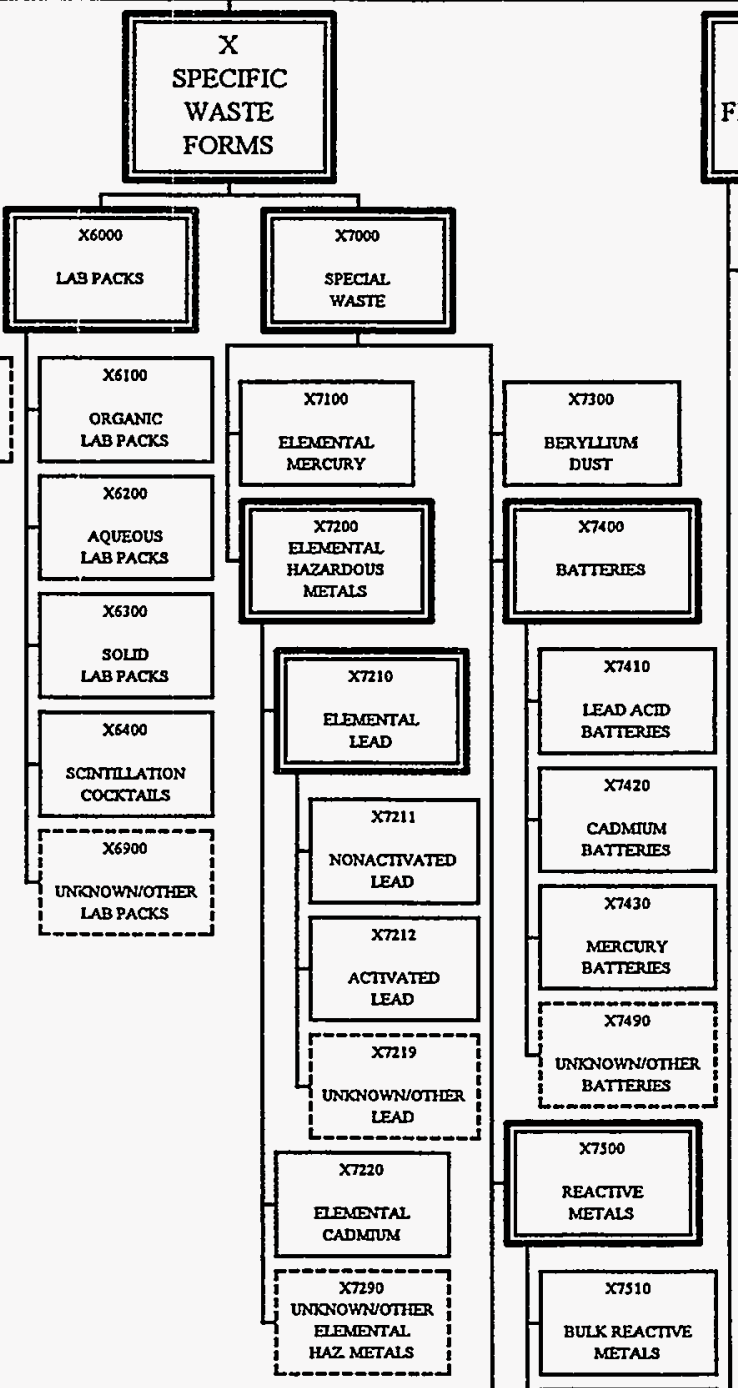

$x 7420$ BATTERIES

$\times 7430$

MERCURY

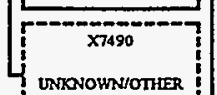
BATTERTES
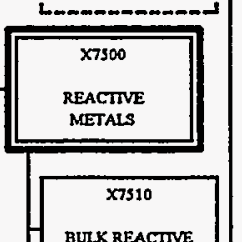

FINAL WASTE FORMS
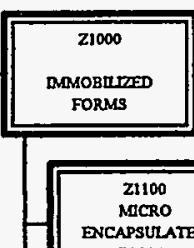

FORMS


Group Gutdance - Jamuary 1995 